Promoting Mental Health in Older Adults

by

Chloe Uyen Hoang, M.A.

A Dissertation

In

\title{
COUNSELING PSYCHOLOGY
}

Submitted to the Graduate Faculty of Texas Tech University in

Partial Fulfillment of

the Requirements for the Degree of

DOCTOR OF PHILOSOPHY

\section{Approved}

Erin Hardin, Ph.D.

Chairperson of the Committee

Christine Robitschek, Ph.D.

Susan Hendrick, Ph.D.

Steven Richards, Ph.D.

Fred Hartmeister

Dean of the Graduate School

August, 2009 
(C) 2009, Chloe Uyen Hoang 


\section{ACKNOWLEDGEMENTS}

First, I would like to express my deepest gratitude to Dr. Erin Hardin, my academic and research advisor, for her unwavering support and guidance throughout my graduate training. Thank you for giving me a chance to explore the world of impossibilities (yet possible to achieve), challenging me so I can cultivate my personal and professional development, and believing in my growth potentials when I lost faith in myself. Thank you Dr. Christine Robitschek for giving me the opportunities to participate in research and be a part of the Personal Growth Initiative Lab. I appreciate the time you took to share with me your knowledge of statistics and the qualities of being an excellent researcher. Knowing that you took time to teach me the rights from the wrongs when I make mistakes means a great deal to me. To Dr. Susan Hendrick, I greatly appreciate for allowing me to be creative, challenge my own boundary, and make the most of my experiences at the Southwest Cancer Treatment and Research Center. Your wisdom and personal conviction to live in the present and plan for the future, and balance professional and personal lives inspire me and give me perspectives when I needed them the most. To Dr. Steven Richards, thank you for being there in times of need. Your zealous and helpful advices, suggestions, and offers pave the steps to my journey as a graduate student.

Second, I would like to thank Peter Laverty (the Director for the Seniors are Special), Larry Sava (the Wellness Director at UMC Activities Center), Julie Dominiguez, Reverend James O’Connor at St. Elizabeth Catholic Church, Pastor Mike Stallsworth at Calvary Baptist Church, Pastor Jerry Wilson at Southcrest Baptist Church, Anna Thomas, and many others whose names I may have forgotten to mention for offering their resources to collect data for this study. Most of all, I would like to thank the 
seniors who participated in the study. Without their participation, this research would not be possible.

Finally, I would like to dedicate this work to God for working miracles and bestowing upon me many blessings, to my grandparents and parents for instilling in me the values of higher education and encouraging me to persevere in the face of challenges, to my husband Thai for making many sacrifices so I can achieve my dreams, and to my baby Elyse for teaching me the value of time and to be balanced in life. 


\section{TABLE OF CONTENTS}

ACKNOWLEDGEMENT

ABSTRACT

vii

LIST OF TABLES

ix

LIST OF FIGURES

$\mathrm{X}$

CHAPTER

I. INTRODUCTION

Historical and Evolving Conceptions of Mental Health

Keyes's Structure of Mental Health

3

Mental Health in Older Adults in the Context of Successful Aging

The Selection, Optimization, and Compensation (SOC) Model

Erikson's Ego-Integrity versus Despair Concept

9

Predictors of Ego-Integrity and Mental Health

12

Self-Discrepancy Predicting Ego-Integrity and Mental Health

Personal Growth Initiative Predicting Ego-Integrity and Mental Health

The Proposed Model in the Current Study

II. METHOD

Participants

Measures 
Texas Tech University, Chloe Uyen Hoang, August, 2009

Personal Growth Initiative

Self-Discrepancy 32

Ego-Integrity 34

Mental Health 35

Procedure 41

III. RESULTS

Preliminary Analyses

Analysis of the Measurement Model 45

Analysis of the Structural Model 48

Test of the Mediated Effects 55

Tests of Secondary Hypotheses 57

IV. DISCUSSION 74

\section{REFERENCES}

\section{APPENDIX}

A. Extended Literature Review 98

B. Participant Recruitment Flyer 144

C. Prize Drawing Form 145

D. Demographic Questionnaire 146

E. Physical Health Status 148

F. Functional Limitation 149

G. Personal Growth Initiative Scale 150

H. Marker Placement Task 151

I. Self-Discrepancy Scale 153 
Texas Tech University, Chloe Uyen Hoang, August, 2009

$\begin{array}{ll}\text { J. Ego-Integrity Scale } & 154\end{array}$

K. Scales of Emotional Well-Being 156

L. Scale of Psychological Well-Being 157

M. Scale of Social Well-Being 159

$\begin{array}{lll}\text { N. Information Form } & 160\end{array}$

O. Contact Information Form 161

P. Debriefing Letter 162 


\begin{abstract}
The percentage of older Americans over age 65 is estimated to grow from $12 \%$ to at least $21 \%$ by 2050 (Federal Interagency Forum on Aging-Related Statistics, 2006). Given the projected growth rate, it is important for mental health professionals to understand factors and mechanisms that are involved in the process of optimal and successful aging in order to help older adults protect against the state of languishing and enhance the state of flourishing in later life. The current study employed two life-span perspectives, Erikson's $(1959,1980)$ theory of ego-integrity versus despair and the Selection, Optimization, and Compensation (SOC) model (Baltes \& Baltes, 1990; Baltes, Lindenberger, \& Staudinger, 1998), to examine the relations among personal growth initiative (PGI; Robitschek, 1998), self-discrepancy (Higgins, 1987), and ego-integrity (Erikson, 1959, 1980) have on Keyes' (2002, 2003, 2005a, 2005b) multidimensional theoretical and operational definition of mental health.

The current study hypothesized that PGI and self-discrepancy predicted egointegrity, which in turn predicted multidimensional mental health. The following predictions also were hypothesized: (1) PGI negatively predicts self-discrepancy, (2) physical health status negatively predicts self-discrepancy, and (3) age negatively predicts physical health status. Structural equation modeling analyses and model modifications were conducted on both the total sample and the women only group. Results revealed that self-discrepancy predicted mental health for both the total sample and the women only group. Partial mediation occurred between PGI and mental health for the total sample only and did so through the indirect effects of physical health status and self-discrepancy rather than through ego-integrity as the study had predicted. As for
\end{abstract}


the women only group, PGI exerted a total effect on mental health. The final overall model accounted for a large amount of variance in mental health $(75.1 \%$ for the total sample and $87 \%$ for the women only). The findings of this study found support for the SOC model and the ego-integrity versus despair theory. In sum, PGI appeared to be a desirable personality trait that is likely to promote physical and mental health in old age, and low self-discrepancy is predictive of greater mental health. Implications for geropsychology research and practice are discussed. 


\section{LIST OF TABLES}

1. Means, standard deviations, and z-statistics of skewness and kurtosis for the measured variables for the total sample and women only

2. Correlations among the measured variables for the total sample and women only

3. Goodness of fit indices for the measurement model and the structural model for the total sample and women only

4. Standardized factor loadings for the total sample and women only

5. The statistical significance checklist of the direct, indirect, and total effects of the final structural model for the total sample and women only

6. Total mediated effects in the final structural model for the total sample and women only

7. Specific mediated effects in the structural model for the total sample 


\section{LIST OF FIGURES}

1. Keyes's model of mental health 24

2. Hypothesized model 25

3. Hypothesized structural model 69

4. Final structural model for the total sample $\quad 70$

5. Final structural model for women only 71

6. The final direct effects model with path loadings for the total sample 72

7. The final direct effects model with path loadings for women only 73 


\section{CHAPTER I}

\section{INTRODUCTION}

Aging, a universal biological phenomenon, is an imminent part of life. Currently, there are approximately 35 million adults who are at the age of 65 and older, which is about $12 \%$ of the total U.S. population (Federal Interagency Forum on Aging-Related Statistics, 2006). This number is estimated to reach 40.2 million by $2010,71.5$ million in 2030, and 86.7 million in 2050 (Federal Interagency Forum on Aging-Related Statistics, 2006). Looking at the statistics, there is no doubt that the number of older individuals will continue to rise gradually into the next century as more people continue to live past their 80 s due to medical and technological advances, setting the projected population of older adults to be at least $21 \%$ of the total U.S. population by 2050 (Federal Interagency Forum on Aging-Related Statistics, 2006).

In spite of the upward trend, research concerning the needs of this population is either lacking or falling short compared to other social science areas (NIMH, 2006), which poses a challenge for geriatric mental health professionals in terms of ways to improve and maintain mental health in this population and to facilitate the process of optimal and successful aging. Numerous past and current mental health literatures have documented the beneficial effects of mental health in old age, ranging from protecting older adults from physical and cognitive impairment to sustaining the viability of federal health care programs to enhancing flourishing in later life overall (Frazer, Leicht, \& Baker, 1996; Heidrich \& D’Amico, 1993; Keyes, 2002, 2003, 2004; Sambamoorthi, Olfson, Wei, \& Crystal, 2006; Saxena, van Ommeren, Tang, \& Armstrong, 2005; Vandervoort \& Skorikov, 2002; Van der Kooy, Van Hout, Van Marwijk, De Haan, 
Stehouwer, \& Beekman, 2006). Given the pressing needs to advance mental health research and the benefits of having mental health in old age, it is the overall objective of the present study to explore factors that contribute to mental health and optimal aging in late adulthood.

\section{Historical and Evolving Conceptions of Mental Health}

Much has been written about the concept of mental health such as how mental health should be defined or measured and indicators to infer mental health. For example, Rogers (1961) and Jahoda (1958) described mental health using terms like personal growth or actualizing tendency, attitude toward self, adaptation, and integration of personality, whereas Freud (1961) described mental health as the absence of mental illness. As seen, many challenges exist in defining mental health since it is an evaluative term that differs across cultures and time (Smith, 1959). Despite the theoretical difficulties, there is one popular definition of mental health that several theoretical frameworks articulated, and that is "...it is not merely the absence of disease or infirmity,... [but] a state of well-being in which the individual realizes his or her own abilities, can cope with the normal stresses of life, can work productively and fruitfully, and is able to make a contribution to his or her community" (World Health Organization, 2001a, 2001b, p. 1). This definition of mental health implies that (a) mental health is multidimensional, and (b) mental health is based on the absence of mental illness/disease as well as the presence of positive emotions and psychosocial functioning. This definition of mental health is also reiterated in various theoretical viewpoints in the mental health literature (Jahoda, 1958; Keyes, 2002; Rowe \& Kahn, 1997; Ryff \& Singer, 1998; Smith, 1959; U.S. Department of Health and Human Services, 1999). For example, the hedonic 
viewpoint defines emotional well-being as the presence of positive emotions and the eudaimonic viewpoint defines psychosocial well-being as the presence of psychosocial functioning (Keyes, 2002, 2003, 2005a, 2005b; Waterman, 1993).

Keyes's Structure of Mental Health

Although the definition of mental health is multidimensional, mental health is often measured using a single indicator, such as a measure of life satisfaction (Heidrich \& Powwattana, 2004), positive and negative affects (Petrocelli \& Smith, 2005; Phillips \& Silvia, 2005), general level of happiness in life (Heidrich \& Powwattana, 2004), and anxiety and/or depression (Bruch, Rivet, Laurenti, 2000; Heidrich, Forsthoff, \& Ward, 1994; Heidrich \& Ryff, 1993a, 1993b). Rarely, mental health indicators are assessed multidimensionally or integratively. Yet, in recent years, using the most popular theoretical view of mental health from the literature, Keyes (1998, 2002, 2003, 2005a; Keyes \& Waterman, 2003) was able to propose clearly defined criteria and procedures to measure mental health. He has compiled a list of $14^{\mathrm{a}}$ important indicators or diagnostic symptoms that enable researchers to consistently define and quantify individuals' level of mental health.

The Hedonic Perspective. The $14^{\mathrm{a}}$ important diagnostic symptoms of mental health that Keyes proposed derive from the hedonic and eudaimonic philosophical views and these two philosophical perspectives are concerned with individuals' perception and evaluation of their level of affective state (i.e., emotional well-being) and their level of psychosocial functioning (i.e., psychological and social well-being; Keyes, 1998, 2002, 2003; Keyes, Shmotkin, \& Ryff, 2002; Keyes \& Waterman, 2003; Ryan \& Deci, 2001; Waterman, 1993) (see Figure 1). The hedonic perspective stresses that well-being 
consists of experiencing happiness and pleasure, which reflects the domain of emotional well-being. Indicators or diagnostic symptoms that comprise the emotional/hedonic wellbeing domain of mental health are: (1) happiness (i.e., the extent to which individuals generally feel content or happy about life), (2) satisfaction with life (i.e., the extent to which individuals are satisfied with life overall or in specific areas), and (3) the balance of positive and negative affects (i.e., the extent to which individuals experience more positive feelings and fewer negative feelings; Keyes, 2003; Keyes \& Waterman, 2003).

The Eudaimonic Perspective. The eudaimonic perspective highlights that wellbeing consists of realizing and fulfilling potentials individuals have set for themselves, which reflects the domain of functional well-being (i.e., the psychological and social well-being domains; Keyes, 1998, 2002, 2003; Waterman, 1993). Indicators that define the functional/eudaimonic well-being domain of mental health consist of two separate categories: indicators that describe strictly the psychological domain of well-being and indicators that describe only the social domain of well-being (see Figure 1). The psychological well-being domain, described as how well one is functioning, adjusting, and adapting to personal life, includes: (1) autonomy (i.e., the degree to which individuals have the ability to be self-determined and make autonomous decisions in life free from the pressure or influence of others); (2) self-acceptance (i.e., the extent to which individuals have a positive evaluation of self); (3) environmental mastery (i.e., the extent to which individuals can handle their daily life demands and handle their unpredictable complex environments); (4) purpose in life (i.e., the extent to which individuals have meaning, direction, and goals in life); (5) personal growth (i.e., the extent to which individuals are feeling and sensing that they are developing and growing 
as a person); and (6) positive relations with others (i.e., the extent to which individuals have intimate, trusting, and satisfying relationships with others; Keyes \& Ryff, 1999; Ryff, 1989; Ryff \& Keyes, 1995). In contrast, the social well-being domain, described as the degree to which one is functioning, adjusting, and adapting to the social aspects of life, consists of five diagnostic symptoms: (1) social actualization (i.e., the extent to which individuals find society has the potential to evolve in a positive direction); (2) social acceptance (i.e., the extent to which individuals have a positive appraisal of or positive attitude toward others); (3) social coherence (i.e., the extent to which individuals find society has meaning or is predictable); (4) social integration (i.e., the extent to which individuals sense that they are a part of society or their community); and (5) social contribution (i.e., the extent to which individuals feel they have something important or of value to contribute to society; Keyes, 1998).

Levels of Mental Health. Based on these $14^{\mathrm{a}}$ indicators, individuals' level of mental health can be measured on three levels ranging from languishing to moderately mentally healthy to flourishing in life by using empirically well-established psychometric scales as suggested in Keyes’s (1998, 2002, 2003; Keyes \& Ryff, 1999; Ryff, 1989; Ryff \& Keyes, 1995) writing. Languishing in life is defined as a state in which individuals feel jaded with life in general, and there are feelings of ennui, emptiness, loss, and a lack of purpose or meaning. Individuals who are languishing in life can be viewed as lacking the feeling of positive emotions and not functioning well in personal and social life. In contrast, flourishing in life is defined as a state in which individuals have a drive or an enthusiasm for life in general, and there is the presence of determination, motivation, energy, and ambition to live life to the fullest. The life of flourishing 
individuals is filled with positive emotions and they function psychologically and socially well.

In Keyes’s (1998, 2002, 2003; Keyes \& Ryff, 1999; Ryff, 1989; Ryff \& Keyes, 1995) writings, the specific levels of mental health (i.e., languishing to moderately mentally healthy to flourishing) are specific diagnostic labels that indicate a higher or lower level of mental health. In fact, certain criteria must be met using one of the two approaches (i.e., the categorical and continuous approaches) when assigning the three levels of mental health (Keyes, 2003, 2005b). Both the categorical and continuous methods of diagnosing individuals' level of mental health can be summarized by assessing how high or low individuals score on the $14^{\mathrm{a}}$ symptoms of the emotional, psychological, and social scales. Specifically, the categorical method yields a diagnosis whether individuals are languishing, moderately mentally healthy, or flourishing based on how many of the $14^{\mathrm{a}}$ indices of emotional and functional well-being an individual scores high or low. If individuals score low on at least 1 out of 3 symptoms of emotional wellbeing and at least 6 out of 11 functional well-being symptoms, then individuals can be diagnosed as languishing in life. On the other hand, if individuals score high on at least 1 out of 3 symptoms of emotional well-being and 6 out of 11 functional well-being symptoms, then individuals can be diagnosed as flourishing in life. Individuals for whom scores that are in the middle range, not too extreme to be diagnosed as either languishing or flourishing, can be considered to be moderately mentally healthy.

In contrast to the categorical approach, the continuous approach simply sums all scores of the emotional, psychological, and social well-being scales together. Low overall mental health scores using the continuous approach indicate the state of languishing in 
life, whereas high overall mental health scores indicate the state of flourishing in life (Keyes, 2002, 2003, 2005a). This method was used in the current study because (a) scores on an interval measurement scale are more useful in and fit with the statistical criteria of structural equation modeling and (b) it fits with the study's objective, which is to understand the extent to which factors contribute to the overall level rather than to the specific indicators of mental health.

Keyes' (2002, 2003, 2005a, 2005b) multidimensional description of mental health not only describes the domains of well-being that advance the understanding of optimal human experience and functioning, it has provided an operational definition that explains how the construct can be measured as well. Since Keyes' theoretical and operational formulation of mental health is newly constructed, there is very little known about whether or how mental health is related to successful aging; specifically, whether or how successful aging is related to the mental state of flourishing and languishing in the life of older adults.

\section{Mental Health in Older Adults in the Context of Successful Aging}

In the aging literature, mental health in older adults is often conceptualized from the life-span perspective as being the same as or an outcome of successful or optimal aging (Baltes \& Baltes, 1990; Erikson, 1959, 1980; Rowe \& Kahn, 1997). According to the life-span perspective, successful aging contains three components: the absence of disease, the presence of high psychosocial functioning, and active engagement with life (Baltes \& Baltes, 1990; Gatz \& Zarit, 1999; Rowe \& Kahn, 1997; Valliant, 2002). The first two of the basic components of successful aging are consistent with the theoretical and operational definition of mental health as previously mentioned (Jahoda, 1958; 
Keyes, 2002; Rowe \& Kahn, 1997; Ryff \& Singer, 1998; Smith, 1959; U.S. Department of Health and Human Services, 1999; WHO, 2001a, 2001b). Further, the final component of successful aging, which is active engagement with life, alludes to one of the indicators / components that other theorists (e.g., Jahoda, 1958; Rogers, 1961) have used to define mental health. As seen, the three components of successful aging share a high degree of convergent validity with the multidimensional definition and characteristics of mental health described above. Given the high degree of convergent validity between successful aging and mental health, two assumptions can be made: (1) the presence of mental health in old age reflects the sign of successful aging and (2) successful aging indicates the presence of mental health.

\section{The Selection, Optimization, and Compensation (SOC) Model}

There are two well-accepted theoretical perspectives on life-span development that clearly articulate the importance of the absence of disease, the presence of high psychosocial functioning, and active engagement with life as keys to successful aging. These two theoretical perspectives are the Selection, Optimization, and Compensation (SOC) model (Baltes \& Baltes, 1990; Baltes, Lindenberger, \& Staudinger, 1998) and Erikson's $(1959,1980)$ concept of ego-integrity versus despair. According to Baltes and Baltes (1990; Baltes et al., 1998), because age-related losses and declines are imminent as older adults age, older adults must continue to engage in the pursuit of personally fulfilling goals and be flexible and adaptable when pursuing these goals in order to maintain or enhance mental health in late adulthood. From this perspective, mental health in old age suggests the interaction between inner psychological and outer social influences of knowing when and how to engage in personal growth. Further, the SOC 
model reinforces the view that the likelihood of successful aging depends on older adults' ability to engage and be flexible in growth opportunities in order to maintain a healthy emotional, psychological, and social lifestyle (Baltes \& Baltes, 1990; Baltes et al., 1998). As discussed, the core foundation of the SOC model not only describes the process of continued personal growth in old age as the strategy needed to maintain multidimensional mental health, it also resonates with one of the three important components of successful aging, which is active engagement with life (Baltes \& Baltes, 1990; Rowe \& Kahn, 1997).

\section{Erikson's Ego-Integrity versus Despair Concept}

In addition to Baltes and Baltes's (1990; Baltes et al., 1998) Selection, Optimization, and Compensation (SOC) model of successful aging, Erikson $(1959,1980)$ also defined successful aging from the life-span perspective in the last stage called egointegrity versus despair. As a life-span theorist, Erikson $(1959,1980)$ argued that successful aging is a developmental process that consists of the interplay between the individual and society. Erikson believed that individuals proceed through a series of eight different stages of the life cycle from childhood to old age and must overcome a crisis or a conflict at each stage in their social environment. In Erikson's writing, he stated that if individuals are able to resolve the struggles of that particular stage successfully, then they experience the psychosocial strength of that stage, which suggests the presence of wellbeing (i.e., mental health).

Research Findings and Hypotheses Regarding Ego-Integrity. According to Erikson, in late adulthood, older adults proceed through the eighth stage of ego-integrity versus despair (Erikson, 1959, 1980). In this stage, older adults are confronted with end- 
of-life issues and they begin to evaluate and reflect on their past life experiences. If older adults are successful at getting their inner life in order, then ego-integrity is experienced and wisdom is achieved. If not, then despair is experienced and wisdom is less likely to be achieved. In other words, successful aging / mental health is inferred when older adults experience these features of ego-integrity: having self-acceptance, lacking death anxiety, accepting the past without regrets, having an integrated self-concept, feeling content about the past, developing positive relations with others, and feeling satisfied with current life (Erikson, 1959, 1980; Hamachek, 1990; Hogstel \& Curry, 1995; Santor \& Zuroff, 1994). In contrast, less successful aging or a low level of mental health is inferred when older adults experience these features of ego-despair: experiencing death anxiety, feeling regrets about the past, not having an integrated self-concept, finding life dissatisfying, and not having positive relationships with others (Erikson, 1959, 1980; Hamachek, 1990; Hogstel \& Curry, 1995; Santor \& Zuroff, 1994).

Critical to the experience of ego-integrity and an antecedent of mental health, according to Erikson $(1959,1980)$, is the integration of conflicting self-concepts. This idea of the integrated self-concept as a component of mental health was also articulated in Rogers's (1961) and Jahoda's (1958) writings as previously discussed. In Erikson's writings, he defined successful aging as the absence or low levels of despair and death anxiety in addition to the presence of contentment and satisfaction with life, selfacceptance, and positive relations with others. As seen, Erikson's idea of successful aging is clearly consistent with the popular previously mentioned theoretical definitions of mental health (Jahoda, 1958; Keyes, 2002; Rogers, 1961; Ryff \& Singer, 1998; Smith, 
1959; U.S. Department of Health and Human Services, 1999; World Health

Organization, 1948, 2001a, 2001b).

From a theoretical perspective, Erikson's $(1959,1980)$ idea of ego-integrity should predict mental health, a sign of successful aging, as defined above. Previous research does demonstrate that ego-integrity is predictive of general concepts of subjective psychological well-being. Generally, evidence from ego-integrity literature indicates that experiencing ego-integrity in old age was positively associated with higher psychological well-being, higher positive emotions, and lower levels of depression and negative affectivity (Boylin, Gordon, \& Nehrke, 1976; Hogstel \& Curry, 1995; James \& Zarrett, 2005; Ranzijn \& Luszcz, 1999; Rylands \& Rickwood, 2001; Santor \& Zuroff, 1994; Torges, Stewart, \& Miner-Rubino, 2005). However, in past literature, measures of death anxiety, life satisfaction, self-acceptance, reminiscence, locus of control, or acceptance of the past are usually employed to define and measure subsets of ego integrity features (see Boylin, Gordon, \& Nehrke, 1976; Domino \& Hanna, 1989; Nehrke, Bellucci, \& Gabriel, 1978; Nehrke, Hulicka, \& Morganti, 1980; Ranzijn \& Luszcz, 1999; Ryff \& Heincke, 1983; Torges, Stewart, \& Miner-Rubino, 2005; Taft \& Nehrke, 1990; Whitbourne, Zuschlag, Elliot, \& Waterman, 1992). Hence, ego-integrity was defined and measured in a limited way, possessing only certain core features of egointegrity, as measured by the instruments the researchers selected. If ego-integrity is defined as encompassing a broad array of behavioral, emotional, and cognitive characteristics, using only certain measures to define and measure a subset of egointegrity features may insufficiently capture, perhaps even obscure, Erikson's conception of ego-integrity, which in turn may lead to the problem of construct underrepresentation. 
Because previous literature has not examined ego-integrity broadly and the extent to which ego-integrity influences the multidimensional definition of mental health, the current study attempted to fill in this gap by employing a psychometrically established measure of ego-integrity (Ryff \& Heincke, 1983) that globally assesses all salient behavioral, emotional, and cognitive features of ego-integrity to predict multidimensional mental health in older adults.

\section{Predictors of Ego-Integrity and Mental Health}

Ego-integrity undoubtedly predicts mental health as suggested by its theoretical propositions (Erikson, 1959, 1980) and previous research (Boylin, Gordon, \& Nehrke, 1976; Hogstel \& Curry, 1995; James \& Zarrett, 2005; Ranzijn \& Luszcz, 1999; Rylands \& Rickwood, 2001; Santor \& Zuroff, 1994; Torges, Stewart, \& Miner-Rubino, 2005). If experiencing ego-integrity is conducive to or synonymous with mental health or successful aging in late adulthood, what influences ego-integrity then? Given that egointegrity is a personality construct and mental health is inherently an evaluative concept influenced by individuals' perceptions and intrapersonal characteristics (Smith, 1959), intrapersonal rather than interpersonal factors may have the explanatory and predictive power explaining this inquiry. In particular, the internal processes of self-discrepancy (Higgins, 1987) and personal growth initiative (Robitschek, 1998, 1999, 2003) are of particular interest since they may be consistent with the meaning of successful aging and the presence of mental health from the life-span perspectives of Erikson's $(1959,1980)$ ego-integrity and the SOC model (Baltes \& Baltes, 1990; Baltes et al., 1998) as discussed next. 
In Erikson's $(1959,1980)$ description of ego-integrity as a mechanism that influences successful adaptation in old age, he highlighted an integrated sense of self as important to the experience of ego-integrity. This integrated self-concept consisted of bridging the gap among the different aspects of the self and of accepting experiences that cannot be changed in the past. As conceptualized, a consistent self-concept is important in maintaining or enhancing mental health in old age and a crucial prerequisite for egointegrity. From this rationale, representation of the self-concept, specifically selfdiscrepancy (Higgins, 1987), appears to predict ego-integrity, which in turn predicts mental health in old age.

The second mechanism that explains successful aging and mental health in old age is the SOC model (Baltes and Baltes, 1990; Baltes et al., 1998). The main premise in the SOC model is that successful aging requires intentional and active engagement in the pursuit of personally meaningful goals as older adults age. This idea of continued personal growth suggests that personal growth initiative (PGI; Robitschek, 1998) may be an intrapersonal variable that explains the experiences of ego-integrity and mental health in old age. Specifically, as older adults intentionally seek out growth opportunities to improve the self and understand their life, they are more likely to experience egointegrity, which in turn would likely predict mental health. From this rationale, PGI appears to predict ego-integrity, which in turn predicts mental health in old age. Based on Erikson's (1959, 1980) ego-integrity concept and Baltes and Baltes's (1990, Baltes et al., 1998) SOC model, self-discrepancy and personal growth initiative may function as predictors of ego-integrity and mental health in late adulthood; hence, these intrapersonal factors were examined in the study. 


\section{Self-Discrepancy Predicting Ego-Integrity and Mental Health}

Historical and current literature pertaining to the self generally has illustrated that conflicting and unintegrated self views can lead to psychological conflicts and emotional distress (Freud, 1961; Higgins, 1987; Rogers, 1961), whereas an organized, coherent and integrated pattern of the self is related to emotional and psychological health (Freud, 1961; Higgins, 1987; Rogers, 1961). From the life-span perspective, Labouvie-Vief (2003, 2004; Labouvie-Vief, Chiodo, \& Goguen, 1995) also discussed the importance of an integrated and coherent self-representation to successful aging. Although literature on conflicting self-representation has stated the psychological benefits of a consistent selfconcept and the psychological harms of an inconsistent self-concept, most selfrepresentation theories have done so in general terms. Thus far, only self-discrepancy theory (Higgins, 1987) specifically classifies the particular negative consequences of different types of inconsistent self-representation. According to the theory, discrepancy of the actual self (i.e., representation of who one is currently) from the ideal self (i.e., representation of the type of person one wishes to be), also known as the ideal selfdiscrepancy, is linked to the absence of positive outcomes and to dejection-related affects such as depression; discrepancy of the actual self from the ought self (i.e., representation of the type of person one has the moral obligation to fulfill), also known as the ought selfdiscrepancy, is linked to the presence of negative outcomes and agitation-related affects such as anxiety.

Research Findings Regarding Self-Discrepancy

Although self-discrepancy theory was originally formulated to explain negative affective outcomes, specifically depression and anxiety (Higgins, 1987), a relevant 
prediction is that a lack of self-discrepancy or a match of self-beliefs should also be related to positive affective outcomes that result in better psychological well-being (Heidrich \& Ryff, 1993a, 1993b). Several studies have found that the level of selfdiscrepancy is predictive of positive emotional states. For example, ideal self-discrepancy was found to be negatively related to psychological well-being such as purpose in life, positive relations with others, life satisfaction, and happiness in college adults and geriatric samples (Heidrich, 1999; Heidrich, Forsthoff, \& Ward, 1994; Heidrich \& Ryff, 1993a, 1993b; Heidrich \& Ward, 1992; Ryff, 1991). Further, Higgins (1987) has found that the absence of ideal self-discrepancy is related to feelings of happiness and satisfaction, whereas the absence of ought discrepancy is related to feelings of calmness and security. In addition, self-discrepancies were found to be negatively associated with optimism (Hardin \& Leong, 2005), associated with decreased positive affects of cheerfulness and tranquility (Hardin \& Lakin, 2007), and negatively related to general positive affects such as excited, enthusiastic, and proud (Hardin, Weigold, Robitschek, \& Nixon, 2007).

Research Findings Regarding Self-Discrepancy in Old Age. In addition to research linking the ideal and ought self-discrepancies to well-being and distress, there is evidence from the life-span developmental perspective that ideal self-discrepancies are more salient to and more predictive of optimal mental health in old age than ought selfdiscrepancies (Birren \& Renner, 1980). Findings suggest that because older adults experience age-related losses (e.g., physical health decline, cognitive impairment, and motor functioning deterioration) as part of the process of aging and because fulfilling the ought self may be dependent on physical health status, older adults compensate for losses 
by focusing on their ideal self, rather than the ought self, as a goal standard to strive for in an attempt to reduce psychological distress and maintain mental health (Baltes \& Baltes, 1990; Dixon \& Baltes, 1986; Heidrich, Forsthoff, \& Ward, 1994; Heidrich \& Ward, 1992). In light of the above findings, the current study only examined ideal selfdiscrepancy in the elderly.

Research has also looked at the relationships among self-discrepancy, age, physical health status, and mental health from a developmental trajectory. In cross-sectional studies comparing younger, middle-aged, and older adults, ideal self-discrepancy was found to decrease across age groups and not within an age group, and ideal self-discrepancy was also found to be negatively related to psychological well-being in all three age groups (Heidrich, 1999; Heidrich, Forsthoff, \& Ward, 1994; Heidrich \& Ryff, 1993a, 1993b; Heidrich \& Ward, 1992; Ryff, 1991). One explanation for the decrease in ideal self-discrepancy was because of the lowered ideal self assessments as individuals age; hence, the ideal self becomes more attainable. Perhaps another reason for the decrease in the ideal self toward late life is better explained by the Selection, Optimization, and Compensation (SOC) model (Baltes \& Baltes, 1990) of adjusting to old age. To compensate for physical and social losses, older adults selectively may optimize aspects of themselves or goals that are attainable, resulting in decreased ideal self-discrepancy.

Although ideal self-discrepancy decreases with age, it increases as physical health problems increase. Specifically, findings reveal that for those with poorer physical health such as those with cancer, levels of ideal self-discrepancy were greater than compared to those with better physical health (Heidrich \& Ward, 1992). In longitudinal studies, poorer 
physical health status was also found to be associated with greater ideal self-discrepancy (Heidrich \& Powwattana, 2004).

Several key points can be drawn from the aforementioned findings in selfdiscrepancy literature. One, ideal self-discrepancy is predictive of negative emotional distress as well as positive psychological outcomes. Two, ideal self-discrepancy decreases with age, but increases with poorer physical health status, which in turn is linked to lower well-being. Three, a low level of self-discrepancy indicates an integrated and consistent sense of self, and thus should predict the presence of ego-integrity, which in turn is predictive of higher mental health.

\section{Hypotheses Regarding Self-Discrepancy in the Current Study}

Although these three key findings indicate (1) the antecedents of self-discrepancy and (2) the role of self-discrepancy in maintaining and enhancing mental health directly and indirectly, one major limitation of this previous research is that only certain aspects of mental health were measured. If mental health is defined as encompassing several symptoms of positive feelings and functioning (Keyes, 2002, 2003, 2005a), not measuring mental health multidimensionally may misrepresent the theoretical definition of mental health in late adulthood. Hence, the current study sought to address this limitation by replicating the three previous key points in the elderly using multidimensional assessments of mental health. More specifically, the current study examined these research questions: (1) the extent to which multidimensional mental health is influenced by the level of the ideal self-discrepancy, (2) whether the role of physical health status in maintaining or impairing mental health is largely due to the 
effects of self-discrepancy, and (3) whether having an integrated, consistent selfrepresentation is linked to ego-integrity, which in turn is predictive of mental health.

\section{Personal Growth Initiative Predicting Ego-Integrity and Mental Health}

Central to the life-span developmental perspective of Erikson's theory (1959, 1980) and Baltes' and Baltes' (1990; Baltes et al., 1998) SOC model is the core assumption that development is a process that lasts a life time and growth / change does not stop when individuals reach late adulthood. Baltes and Baltes (1990; Baltes et al., 1998), in particular, stated in the SOC model that continued growth and development despite age-related decline / loss is essential to successful aging. Based on this argument, the inner strength of personal growth initiative (PGI; Robitschek, 1998) emerges as a potential personality variable that plays a role in older adults' ability to function, adjust, and adapt to emotional, psychological, and social demands. This idea of the continuous active engagement in growth opportunities also reflects one of the core components of successful aging mentioned in Rowe and Kahn's (1997) writing as well as in Roger's (1961) writing, in which he refers to the concept of the general propensity for growing, changing, and optimizing some aspects of the self as the actualizing tendency.

Definition of PGI. As a construct, PGI is defined as the process of actively and intentionally engaging in growth opportunities to develop and change as a person (Robitschek, 1998, 1999). In order for PGI to be present, cognitive and behavioral components are required (Robitschek, 1998, 1999). The cognitive component refers to the individuals' thought processes of valuing and having the awareness and the knowledge of the change process. The behavioral component describes the process of 
seizing growth opportunities and executing the actions necessary to implement self change and development.

Important to the definition of PGI is the concept that personal growth is a purposeful and intentional process rather than an outcome that results from unintentional behaviors (Robitschek, 1998, 1999). This makes Robitschek's (1998, 1999) conception of PGI theoretically distinct from Ryff's (1989; Ryff \& Keyes, 1995) conception of personal growth. In Ryff's theory of personal growth (1989; Ryff \& Keyes, 1995), individuals are aware of the process of ongoing self growth and development; however, they are not necessarily intentionally engaging in the process. Even though both Robitschek's PGI (1998, 1999) and Ryff's personal growth (1989; Ryff \& Keyes, 1995) theories describe individuals' orientation toward personal growth (Robitschek \& Kashubeck, 1999), each theory portrays the process of personal growth dissimilarly, which in turn provides different implications for research and practice. More specifically, when personal growth changes are intentional as a result of therapy, this process is called PGI (Robitschek, 1998, 1999) and not Ryff's (1989) personal growth. Thus, this study focuses on PGI as it represents the type of personal growth orientation most likely to be affected by therapy and other interventions.

Research Findings and Hypotheses Regarding PGI. There are several benefits to having a high level of PGI. One of the core benefits of PGI is that continued growth allows individuals to capitalize on growth opportunities to constantly improve the self and to accomplish goals that are important and meaningful to the individual (Robitschek, 1998, 1999, 2003). From this conceptualization, there seems to be a link between PGI and ego-integrity in that if older adults are high in PGI, then they are more likely to 
experience features of ego-integrity since the intentional and active engagement in growth opportunities allows them to successfully resolve psychosocial struggles in late life (Erikson, 1959, 1980). However, the relationship between PGI and ego-integrity has not been empirically tested in the literature. Therefore, the current study sought to fill-in the gap by examining whether PGI is a significant predictor of ego-integrity.

Another benefit of a high level of PGI is that it is linked to greater mental health directly and indirectly. Thus far, prior empirical research studies have found that a higher level of PGI is related directly to (1) greater positive affect or well-being (Hardin et al., 2007; Robitschek, 1998, 1999; 2003; Robitschek \& Keyes, 2006) and (2) lower levels of distress or poor functioning (Hardin et al., 2007; Robitschek \& Kashubeck, 1999). Indirectly, PGI predicts mental health through its relations with self-discrepancy (Hardin et al., 2007). Specifically, Hardin and colleagues found that higher levels of PGI predict fewer negative affects, higher positive affects, and lower self-discrepancies. Further, individuals with higher levels of PGI were more likely to experience lower levels of social anxiety because they had lower self-discrepancies than individuals who are low in PGI (i.e., self-discrepancy is a mediator between PGI and social anxiety). Although this evidence indicates that PGI has a direct and indirect relationship to distress and wellbeing through self-discrepancy, these findings exist predominantly in college student samples and are limited in other populations such as older adults (Spering, 2008). Therefore, the present study sought to address this limitation by empirically testing the specific direct and indirect influence of PGI on overall mental health in the aging population. 
The Proposed Model in the Current Study (see Figure 2)

The current study attempts to provide an integrated picture of mental health in older adults from the life-span perspective using structural equation modeling (SEM). The overarching goal of the study was to extend and confirm previous findings to test a model in which PGI and self-discrepancy directly and indirectly predict multidimensional mental health. Since there are gender differences in the average longevity of older adults (Cavanaugh \& Blanchard-Fields, 2006) and previous research has found gender differences between PGI and other constructs such as assertiveness and expressiveness (see Robitschek \& Cook, 1999; Spering, 2008), the current study also attempted to examine gender differences in the proposed model.

From the life-span perspectives of Erikson's $(1959,1980)$ ego-integrity and Baltes and Baltes's (1990, Baltes et al., 1998) Selective Optimization with Compensation (SOC) model, successful aging is a life-long process involving the continued engagement in growth opportunities and understanding one's inner life to experience a healthy emotional, psychological, and social life. More specifically, Erikson's (1959, 1980) concept of ego-integrity outlined that an integrated sense of self (i.e., low levels of selfdiscrepancy) (a) is crucial to the development of healthy emotional and psychosocial well-being (Boylin, Gordon, \& Nehrke, 1976; Hogstel \& Curry, 1995; James \& Zarrett, 2005; Ranzijn \& Luszcz, 1999; Rylands \& Rickwood, 2001; Santor \& Zuroff, 1994; Torges, Stewart, \& Miner-Rubino, 2005) and (b) may be a key requirement that is predictive of ego-integrity. In this sense, ego-integrity may serve as a mediator that explains how and why a relationship exists between self-discrepancy and mental health in older adults. 
In addition to Erikson's $(1959,1980)$ theory of ego-integrity, Baltes and Baltes (1990, Baltes et al., 1998) argued in the SOC model that the process of intentional continued growth despite age-related losses is also essential to the likelihood of successful aging or the presence of mental health. This concept of intentional and active engagement in growth opportunities implies that PGI (Robitschek, 1998) predicts mental health and possibly ego-integrity. If older adults are active in their pursuit of personally fulfilling goals, then they are more likely to experience the fruits of old age (i.e., high levels of ego-integrity). Experiencing features of ego-integrity, in turn, would likely lead to higher mental health. From this rationale, ego-integrity may also serve as a mediating variable between PGI and mental health in older adults. In sum, the current study sought to fulfill the following objectives:

1. The primary objective of the present study was to test the hypothesis that PGI positively predicts mental health and self-discrepancy negatively predicts mental health through the mediated effect of ego-integrity.

a. Specifically, PGI was hypothesized to relate positively to egointegrity, whereas self-discrepancy was hypothesized to relate negatively to ego-integrity. In other words, older adults would be more likely to experience core features of ego-integrity if they have high levels of PGI and low levels of self-discrepancy.

b. Ego-integrity was hypothesized to correlate positively with the overall level of mental health. In other words, older adults who successfully have formulated or experienced positive features of ego-integrity would be more likely to experience higher levels of the state of 
flourishing in life and less likely to experience the state of languishing in life.

2. Secondary objectives of the present study were to replicate the following previous research findings:

a. Consistent with previous literature (Hardin et al., 2007), PGI was hypothesized to negatively predict self-discrepancy, which in turn negatively predicts mental health.

b. Since previous findings indicate that self-discrepancy mediates the relation between physical health status and mental health (Heidrich \& Powwattana, 2004; Heidrich \& Ward, 1992), the current study also hypothesized that physical health status negatively predicts selfdiscrepancy, which in turn negatively predicts mental health.

c. Given that physical health status is dependent on age (Birren \& Renner, 1980; Federal Interagency Forum on Aging-Related Statistics, 2006; Frazer, Leicht, \& Baker, 1996; Heidrich \& D’Amico, 1993; Saxena, van Ommeren, Tang, \& Armstrong, 2005; Vandervoort \& Skorikov, 2002), the present study predicted that there would be a negative relationship between age and physical health status, in that as older adults age, their physical health status would decline. 


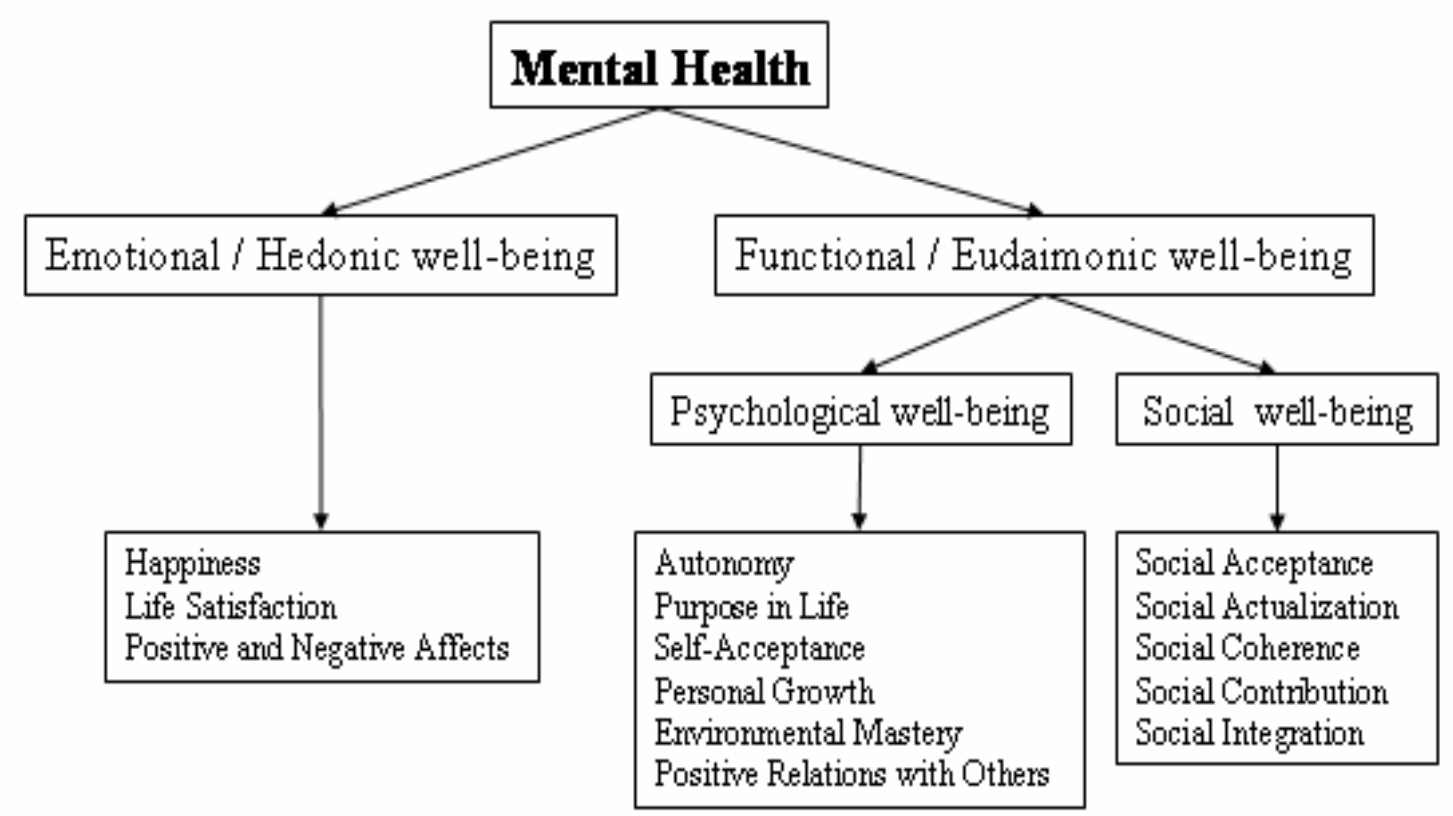

Figure 1. Keyes's (2002, 2003, 2005a) model of mental health. 


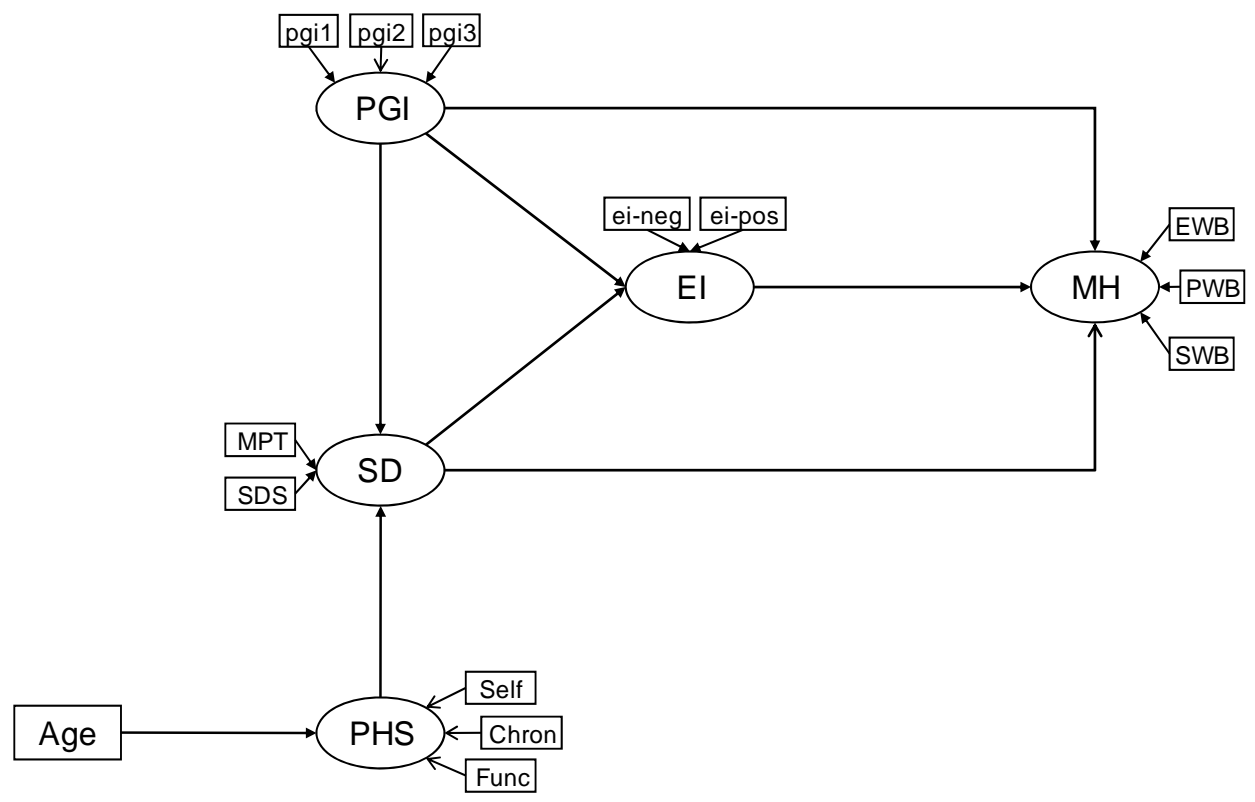

Note. $\mathrm{PGI}=$ personal growth initiative (pgi1 - pgi3 $=$ item parcels for PGI); $\mathrm{SD}=$ selfdiscrepancy $(\mathrm{MPT}=$ Marker Placement Task; $\mathrm{SDS}=$ Self-Discrepancy Scale); PHS = physical health status $($ Self $=$ self-rated health; Chron $=$ number of chronic medical problems; Func $=$ functional limitation $) ; \mathrm{EI}=$ ego-integrity $(\mathrm{ei}-\mathrm{neg}=$ negative-item parcel \& ei-pos = positive-item parcel); $\mathrm{MH}=$ overall mental health $(\mathrm{EWB}=$ Emotional Well-Being; PWB = Psychological Well-Being; SWB = Social Well-Being).

Figure 2. Hypothesized model. 


\begin{abstract}
Author Notes
${ }^{a}$ In Keyes (2007), there were 13 indicators of mental health categorized into the psychological, social, and emotional domains. The indicators of psychological and social well-being domains remained the same (i.e., the psychological well-being domain consisted of 6 indicators and the social well-being domain consisted of 5 indicators). The emotional well-being domain was changed from consisting of 3 to 2 indicators. Specifically, the indicators (a) Happiness and (b) Negative Affect from the Balance of Positive and Negative Affects Scale were dropped, and only the indicators (a) Satisfaction with Life and (b) Positive Affect from the Balance of Positive and Negative Affects Scale were retained.
\end{abstract}




\section{CHAPTER II}

\section{METHOD}

\section{Participants}

Seniors who were at the age of 65 and older were eligible to participate in the study. Age 65 was used to define old age because it is the normal age of retirement and this age has been used in the past to determine eligibility for various governmental services available to older adults (Butler, Lewis, Sunderland, 1998).

Potential participants in the present study were recruited from the community through social, church, and civic organizations such as senior centers, bible study groups, senior luncheons, senior housing centers, and other such places where there was a significant number of older adults. Older adults who have chronic physical and mental illness were not recruited since they were part of the vulnerable population and were not the population of interest in the current study. To ensure that vulnerable older adults were excluded from the study, participants who live in nursing homes were not recruited and data from participants who stated that they were currently taking a cognitive enhancement medication on the demographic information page (see Appendix D) were not used in analyses.

After receiving permission from administrators at the various sites, flyers outlining a brief description of the study along with participation information were posted at the places of interest to recruit potential participants (see Appendix B for flyer). To enhance participation rate and compensate seniors for their time, participants received a chance to win one of several prizes when they took part in the study. The range of prizes 
included a $\$ 30$ gift card, a dinner gift certificates to a local restaurant, and various memory training workbooks by different authors (see Appendix $\mathrm{C}$ for drawing form). A priori power analysis using a program called NIESEM (Dudgeon, 2003) was conducted to obtain an estimate of sample size needed in the current study. The analysis suggested that a sample size of 114 would provide the desired power of .95 with an alpha level of .05, RMSEA null value of .05, RMSEA alternate value of .10, and with 70 degrees of freedom. Of the 322 distributed surveys, 266 surveys were returned, yielding $80.12 \%$ response rate. Note that the $80.12 \%$ returned rate accounts for both methods of recruitment (take-home and on-site). Of the 266 returned surveys, 70 surveys were excluded from final analyses due to more than $1 \%$ missing items per case / measure and / or meeting the exclusionary criterion of taking Alzheimer's medication, leaving a final sample of 196 participants.

These 196 participants were between 69 and 93 years old with the mean age of 75 , and the modal age was 70 . The majority of participants self-identified as female (68.4\%) and Caucasian (96.4\%). Most participants self-identified as married or partnered (51.5\%), with $35.7 \%$ widowed, $9.2 \%$ divorced, $2 \%$ single or never married, $1 \%$ separated; .5\% indicated having a significant other with whom they do not live. The most frequently endorsed class was middle class (59.7\%); 1.5\% were upper class, $16.3 \%$ were upper middle class, $10.2 \%$ were lower middle class, and $12.2 \%$ were working class. More than one-third of the sample had a college degree $(2.6 \%$ have a doctoral degree, $13.3 \%$ have a Master's degree, 5.6\% have some graduate school training, 10.7\% have a Bachelor's degree; and 4.1\% had an Associate's degree); nearly one-third of the sample 
(26.5\%) had completed some college education; and more than a third of the sample (37.2\%) had a high school education or a high school diploma or the equivalent.

\section{Measures}

Demographics. Participants filled out a brief demographic questionnaire that included questions about their age, gender, racial/ethnic identification, highest level of education completed, socioeconomic status, relationship status, living arrangements, physical health status, and group / church organization involvement (see Appendix D).

Physical health status. Physical health status was assessed multidimensionally to reflect three components (i.e., psychological, medical, and social; Liang, Bennett, Whitelaw, \& Maeda, 1991). The psychological component of physical health assessed how individuals perceive their own physical health, both in general and in relation to others. This was assessed by two items, a global subjective and a social comparative health appraisal rating (see Appendix E). Participants rated the global subjective health item "In general, would you say your physical health is" and the social comparative health item "In general, compared with other people your age, would you say that your physical health is" on a 5 -point Likert scale $(1=$ poor to $5=$ excellent $)$. The sum of these two items may range from 2 to 10 , with higher scores indicating better self-rated health. The internal consistency for this scale is .89 in the current sample. Self-rated health has been shown to correlate with mortality (Mossey \& Shapiro, 1982; Siegel, Bradley, \& Kasl, 2003).

The medical definition of physical health assesses the number of chronic health problems most frequently reported by older adults (Federal Interagency Forum on AgingRelated Statistics, 2006). The list of chronic health problems contained 14 items 
including hypertension, arthritis of the hip or knee, arthritis of the hand or wrist, diabetes, heart problems, cancer, emphysema, osteoporosis, stroke, sciatica, bowel disease, heart attack, congestive heart failure, and coronary artery disease (see Appendix E). These commonly occurring health problems also appeared in the Medicare Health Outcomes Survey (Centers for Medicare \& Medicaid Services, 2004) that Medicare managed care uses annually to gather information about the health status of adults who are 65 years old or older. Participants indicated the presence or absence of each of the commonly occurring chronic illnesses on the list. Total scores were calculated by summing the affirmative answers. Possible total scores range from 0 to 14, with higher scores indicating more chronic health problems.

The social definition of physical health assesses the degree of functional limitation older adults may be experiencing due to their physical illnesses. Specifically, the basic Activities of Daily Living Index (ADL; Katz, 1983) and the Instrumental Activities of Daily Living Index (IADL; Lawton \& Brody, 1969) were used to measure functional disability (see Appendix F). ADL (Katz, 1983) assesses six personal care activities required of living independently: bathing, dressing, eating, getting in / out of bed / chairs, walking, and using the toilet. IADL (Lawton \& Brody, 1969) assesses the level of help needed in performing eight instrumental activities necessary in daily living such as using the telephone, getting to places beyond walking distance, shopping for food / clothes, preparing meals, doing housework or "handyman" work, doing laundry, taking medications, and managing money. Participants rated the ADL and IADL on a 3-point scale $(0=$ unable to do at all; $1=$ need some help; $2=$ need no help $)$. All items were summed together to yield the total score (possible range $0-48$ ), with a higher score 
indicating more independence and lesser difficulty in performing basic and instrumental activities of daily living. In previous research, the correlation between ADL and IADL measures was .90 , reflecting the one-dimensional nature of both scales combined (Liang et al., 2003). By itself, the internal reliability of ADL ranges between $.90-.91$ and of IADL ranges between .79 - .85 (Liang, Bennett, Whitelaw, \& Maeda, 1991). Further, functional limitation (i.e., ADL and IADL) was related to age, marital status, and education in both U.S. and Japanese older adults samples (Liang, Bennett, Whitelaw, \& Maeda, 1991). In the current sample, the internal reliability of the combined scales is .90 .

Personal growth initiative. Personal growth initiative, defined as the process of taking the initiative to actively and intentionally engage in growth opportunities as a way to develop as a person, was assessed using the nine-item Personal Growth Initiative Scale (PGIS; Robitschek, 1998, 1999; see Appendix G). Sample items of the PGIS include "If I want to change something in my life, I initiate the transition process" and "I take charge of my life." The PGIS is a unidimensional scale based on a 6-point Likert response format ranging from 0 (definitely disagree) to 5 (definitely agree). All items in the PGIS are positively worded, which makes reverse coding not necessary. To obtain the total score, all items were summed together. Total scores may range from 0 to 45 , with higher scores signifying higher levels of PGI.

The internal consistency of the scale in the current study is .94. Previous studies reported the reliabilities of the scale range from .78 to .90 in samples of EuropeanAmerican and Mexican-American college students, and test-retest reliability estimated from 1 to 8 weeks were between .78 and .84 (Robitschek, 1998, 1999, 2003). Evidence of convergent validity revealed that PGIS is positively correlated with assertiveness $(r=.41$ 
$-.48)$, internal locus of control $(r=.51-.56)$, and instrumentality $(r=.45-.62)$, and negatively correlated with chance locus of control $(r=-.09--.24)$ (Robitschek, 1998, 2003). Evidence of discriminant validity was supported by PGIS scores nonsignificantly correlating with social desirability $(r=.00)$, SAT scores $(r=.15)$, and age $(r=.02)$ (Robitschek, 1998).

Self-Discrepancy. In the current study, self-discrepancy was assessed globally by the Marker Placement Task (MPT; Heppen \& Ogilvie, 2003, see Appendix H) and in specific domains by the Self-Discrepancy Scale (SDS; Heidrich, 1999; Heidrich, Forshoff, \& Ward, 1994, see Appendix I). Before participants filled out the selfdiscrepancy measures, they were provided with full instructions and the definition of the actual and ideal self-discrepancy concept. The ideal self was represented by a circle (approximately $2.8 \mathrm{~cm}$ in diameter) in the upper right corner of the page, and the actual self was represented by a one centimeter sticker labeled with the word "ACTUAL." To perform the self-discrepancy judgment task, participants were asked to place the one $\mathrm{cm}$ "ACTUAL" sticker anywhere on the ideal self page to best represent their subjective judgment of the distance between their actual self and their ideal self (i.e., the discrepancy or congruency between their actual and ideal selves). The MPT operationalizes self discrepancies as the linear distance between the marker and the circle. As a spatial task, the technique used in the MPT elicits a relatively large range of self-discrepancy magnitudes and eliminates the possible problem of restriction in range inherent in trait-listing methods (see Boldero \& Francis, 2000). Further, because the MPT elicits a relatively immediate and global self-discrepancy judgment, it is a more efficient measure of self-discrepancy compared with the other existing lengthy self-discrepancy 
measures. In the current study, to control for unnecessary metric errors, two independent raters measured the distance between ideal self and actual self. The average of the two ratings was used as the final MPT score in all analyses. Overall, the average discrepancy between raters was $.06 \mathrm{~mm}$ and the discrepancy was $0 \mathrm{~mm}$ for $56.1 \%$ of cases (i.e., 110 cases of 196 total sample).

The second measure that was used to assess self-discrepancy is the SelfDiscrepancy Scale (SDS; Heidrich, 1999; Heidrich, Forshoff, \& Ward, 1994, see Appendix I). The Self-Discrepancy Scale (SDS; Heidrich, 1999; Heidrich, Forshoff, \& Ward, 1994) is a 20-item self-report inventory that asks participants to indicate the extent of their agreement from 1 (strongly disagree) to 6 (strongly agree) with the statement, "My actual self and ideal self are a very close match," in each of 20 life domains. Examples of domains include, "my physical health," "coping with changes," "taking care of health," and "pursuing my leisure interests and hobbies." The total scores were computed by averaging the ratings across the 20 domains; higher self-discrepancy scale scores indicate lower levels of self-discrepancy (i.e., a closer match or congruency between actual and ideal self). In previous studies, the average inter-item correlation was .37 and internal consistency (Cronbach's alpha) ranged from .87 to .92 (Heidrich, 1999; Heidrich et al., 1994; Heidrich \& Powwattana, 2004). The Cronbach's alpha level for the present study is .93 . Construct validity was supported by significant correlations with other self-discrepancy measures, self-esteem, psychological well-being, depression, and physical health variables (Heidrich, 1999; Heidrich et al., 1994; Heidrich \& Powwattana, 2004). Content and convergent validity were supported in that high levels of selfdiscrepancy were significantly related to lower levels of self-esteem and psychological 
well-being and higher depression scores (Heidrich, 1999; Heidrich et al., 1994; Heidrich \& Powwattana, 2004).

Ego Integrity. Ryff and Heincke's (1983) Ego Integrity Scale was used to assess Erikson's last psychosocial stage of development - ego integrity (see Appendix J). The scale has 16 items based on a 6-point Likert scale, ranging from 1 (strongly disagree) to 6 (strongly agree), and it operationalizes key features of ego integrity as the acceptance of the past without regret, the adaptation to disappointments and / or failures, the lack of death anxiety, the feeling of contentment with self and others, and the continuation of living the present life meaningfully without worrying about the unknowable future. Examples of items from the scale are "My life has been fulfilling, and I am not frightened by the thought of death," "If I had to do it all over again, there are a few things about my life that I would change," and "I feel generally contented with what I have accomplished in my life." Items from the scale are phrased in positive and negative directions to reduce the opportunity for response bias. The scoring procedure for the scale consists of reversing the negatively scored items first and then summing them together with other positively worded items, which creates a possible range of composite scores from 16 to 96, with higher scores indicating higher levels of ego integrity.

The internal consistency of the scale was reported to be between .80 and .82 , and test-retest coefficient for the scale over a 6-week period in a college student sample was .85 (Ryff \& Heincke, 1983). Consistent with previous studies, the internal consistency in the present data is .81 . Evidence for discriminant and convergent validity revealed that ego integrity is negatively correlated with deferent and impulsive personality traits, and significantly and positively correlated to personality traits of complexity (i.e., the extent 
to which individuals have command of the complex environment) and generativity (i.e., the extent to which individuals are concerned about providing guidance to the next generation) (Ryff \& Heincke, 1983).

\section{Mental Health}

Mental health was measured using three indices (emotional, psychological, and social well-being) that are based on Keyes's works (2002, 2003, 2005a, 2005b; Keyes \& Waterman, 2003) and have well-established psychometric properties.

Emotional well-being. Three indicators were used to measure emotional wellbeing: life satisfaction, happiness, and the balance of positive and negative affects. Life satisfaction and happiness were assessed using a single item adapted from Cantril's (1967; as cited in Keyes, 2005a; Keyes \& Waterman, 2003) Self-Anchoring Scale (see Appendix K). This single-item measure of global satisfaction with life asked participants to rate how satisfied they are with their life overall these days on a scale from 0 (terrible) to 10 (delighted). Participants were also asked to rate a single-item measure of happiness (“overall these days, how happy are you with your life") on a scale from 0 (worst possible situation) to 10 (best possible situation). Supporting the validity of Cantril's measure, scores have been found to predict other measures of life satisfaction and happiness (see Andrews \& Robinson's (1991) study; as cited in Keyes, 2005a; Keyes \& Waterman, 2003).

A measure of positive and negative affect based on Bradburn's (1969; as cited in Keyes, 2005a; Keyes \& Waterman, 2003) affect balance scale was also used. Respondents were asked to indicate how frequently during the past 30 days they have experienced six negative affects ("so sad nothing could cheer you up," "nervous," 
"restless or fidgety," "hopeless," "that everything was an effort," and "worthless") and six positive affects ("cheerful," "in good spirits," "extremely happy," "calm and peaceful," "satisfied," and "full of life") (Keyes, 2005a; Keyes, Shmotkin, \& Ryff, 2002) (see Appendix K) on a five-point rating scale, ranging from 0 (none of the time) to 4 (all the time). To find the positive and negative affect total score, indicators of the negative affect were first reverse coded. Then, the score of the negative affect was summed together with the indicators of the positive affect score to yield the overall affect score. The possible total score could range from 0 to 48 , with higher composite scores indicating the experience of higher levels of positive affect and lower levels of negative affect. The internal consistency reliability of the positive and negative affect scale was reported to be above .80 (Mroczek \& Kolarz, 1998 as cited in Keyes, 2005a; Keyes, Shmotkin, \& Ryff, 2002). The Cronbach's alpha for the current study is .87 , which is consistent with previous findings.

To obtain the total score of emotional well-being, the two single items of life satisfaction and happiness were summed together with the average of the positive and negative affect scale, as suggested by Keyes (2005a), with higher total scores representing higher levels of emotional well-being and positive feelings in life.

Psychological well-being. Ryff's (1989; Ryff \& Keyes, 1995) Scales of Psychological Well-Being was used as the indicator of psychological well-being (see Appendix L). The scale defines psychological well-being as possessing six dimensions: autonomy, environmental mastery, personal growth, self-acceptance, positive relations with others, and purpose in life. Autonomy is defined as the extent to which individuals are not influenced by social pressures / norms when making decisions and can be self- 
determined ("I have confidence in my opinions, even if they are contrary to the general consensus"). Environmental mastery is characterized as the extent to which individuals have control over managing their complex environments ("I am quite good at managing the many responsibilities of my daily life"). Personal growth is described as the extent to which individuals value the process of changing, growing, and striving as a person ("For me, life has been a continuous process of learning, changing, and growth"). Selfacceptance is defined as the extent to which individuals accept multiple aspects of who they are, their qualities and past actions ("I like most aspects of my personality"). Positive relations with others is defined as the extent to which individuals can develop and maintain positive, intimate, and trusting interpersonal relationships with others ("I have not experienced many warm and trusting relationships with others" (reversed scored)). Purpose in life is defined as the extent to which individuals find life has meaning, purpose, and direction ("Some people wander aimlessly through life, but I am not one of them").

The original scale consists of 120 items, which has 20 items per dimension, and uses a 6-point Likert-type rating ranging from 1 (strongly disagree) to 6 (strongly agree). The internal consistency of the 120 -item scale is usually reported based on its subscales ranging from .86 to .91 (Ryff, 1989). The internal reliability for the overall 120-item scale was not found in the literature. Six-week test-retest reliability coefficients for the 20 -item subscales range from .81 to .88 , suggesting that the six domains of psychological wellbeing are stable over time (Ryff, 1989). Evidence of convergent validity reveals that all six indicators of psychological well-being were positively related to life satisfaction, selfesteem, and morale and negatively associated with chance and powerful locus of control 
and depression (Ryff, 1989). Ryff (1989) also provided evidence for discriminant validity. Specifically, results show that there were no age differences for SelfAcceptance; as age increases, there were higher self-ratings for environmental mastery and autonomy and lower self-ratings for purpose in life and personal growth.

Because 120 items may have been a burden on older participants, the current study utilized a shorter form of the scale that has three items per dimension, for a total of 18 items. Although the low reliabilities found in early studies led Ryff (Ryff \& Keyes, 1995 ) to caution against using the 18 -item scale, they were used in this study due to several reality-based constraints. First, because the present study used older adults from the community, asking them to fill out the long form of the psychological well-being scale is a cognitive burden on them. It may have deterred them from participating in the study in the first place. Second, because the study also included other measures, having another long measure in the study would have increased the time it took to complete the questionnaires, which may have posed the problem of participants skipping questions or quitting early in the process, which would have resulted in excessive missing or unusable data. The decision to use the short form of the scale was the best option in this situation and it reiterates the inherent nature of research as explained by the Bubble Hypothesis (i.e., every research study will have strengths and limitations; no single research study will have only strengths) (Gelso, 1979).

Consistent with the long 120-item scale, the short 18 -item scale has excellent content validity but modest internal consistency estimated to be around .50 (see Ryff \& Keyes, 1995). Further, the short 18-item scale was reported to have a correlation ranging from .70 to .89 with the 120-item scale (Ryff \& Keyes, 1995). Although reliabilities on 
the 18-item scale were previously reported to be around .50 (see Ryff \& Keyes, 1995), the Cronbach's alpha level for the overall 18-item scale in this study is .82 .

Like the long 120-item form, the 18-item scale has negatively and positively phrased items. The scoring procedure involved first reverse-coding the negatively worded items, then averaging the items together for each subscale (with higher scores on a subscale indicating a higher level of that type of psychological well-being). The composite score for psychological well-being was obtained by summing together the scores on the six subscales, which brings the possible range of scores from 18 to 108 (higher score indicates higher level of psychological well-being).

Social well-being. Keyes' (1998) 15-item Scale of Social Well-Being, defined as individuals' appraisal of their social life in society, was used to measure symptoms of social well-being (see Appendix M). According to Keyes (1998), social well-being comprises five characteristics: social acceptance, social actualization, social coherence, social contribution, and social integration. Social acceptance is defined as the extent to which individuals have a positive perception of people in society ("I believe that people are kind"). Social actualization is defined as the extent to which individuals believe that society has the possibility to evolve positively in their lifetime ("The world is becoming a better place for everyone"). Social coherence is defined as the extent to which individuals find the society comprehensible, manageable, and predictable ("I cannot make sense of what's going on in the world" (reverse-coded item)). Social contribution is defined as the extent to which individuals have something important to contribute or share with their community or society ("I have something valuable to give to the world"). Social 
integration is defined as the extent to which individuals assess they are part of the society or their community ("My community is a source of comfort").

In the short-form, 15-item scale, each subscale consists of three items worded both positively and negatively to prevent response bias. The response rating of the scale is based on a Likert format ranging from 1 (strongly disagree) to 6 (strongly agree). The total score was obtained by first reverse-scoring the negatively worded items, then computing the sum of all items, bringing the possible range of the total score to between 15 and 90 (higher scores representing higher levels of social well-being).

Supporting internal consistency of the scale, Cronbach's alpha for the 3-item social well-being scale was .81 for all items combined; estimate of the test-retest reliability for the complete scale was not reported (Keyes, 1998). The internal reliability for the current study is .79. Evidence of convergent and discriminant validity indicated that the scale is moderately related to generativity, perceived neighborhood health, perceived life constraints, happiness, and life satisfaction, and negatively correlated with anomie (defined as the absence of social norms and values) ( $r$ 's $=-.28$ to -.55 ) (Keyes, 1998).

To obtain the total score for mental health, the composite scores of emotional, psychological, and social well-being dimensions were added together, a method that was recommended and used previously by Keyes (2002). Higher scores indicated the presence of and/or higher levels of mental health (i.e., the state of flourishing in life), and lower scores represented the absence of and/or lower levels of mental health (i.e., the state of languishing in life). 


\section{Procedure}

Participants first read the information form (see Appendix N) and then filled out a study packet containing the nine questionnaires and a demographic information page. The demographic information was always administered first, which included measures of physical health status. Since the purpose of the present study is to test for mediation, measures of the predictor variables (PGI and self-discrepancy) were presented next in counterbalanced sequence. Measures of self-discrepancy were always presented together; given that the MPT is a global measure of self-discrepancy and the SDS is a domain specific measure of self-discrepancy, the Marker Placement Task (MPT; Heppen \& Ogilvie, 2003) was always presented first followed by the Self-Discrepancy Scale (SDS; Heidrich, 1999). Also, because the MPT provides the full instructions and the definition of the actual and ideal self-discrepancy concepts, presenting the MPT prior to the SDS makes more sense logically. After measures of the predictors (PGI and self-discrepancy) were presented, a measure of the mediator (ego integrity) was presented, followed finally by measures of the outcome variable (mental health), which also were in counterbalanced sequence. Participants were informed that their responses would be kept confidential. After participants completed the questionnaire packets, they were asked to fill out a prize drawing form for a chance to win a prize as discussed above.

Participants were given a chance either to complete the questionnaires at their own convenience and mail them back using a provided pre-paid postage envelope, or to complete the questionnaires in small groups. If participants preferred to complete the questionnaires at their own time and mail them back, they were asked to fill out a contact information form (see Appendix O). The purpose of the contact information form was for 
the researcher to send participants a reminder if the questionnaires hadn't been returned after two weeks and to send them a debriefing letter (see Appendix P) along with a thank you note for their participation. 


\section{CHAPTER III}

\section{RESULTS}

Data analyses were conducted in three stages: preliminary data analyses, analysis of the measurement model, and analysis of the structural model and the mediated effects. In stage one, data were screened for (1) the amount and pattern of missing data and (2) univariate and multivariate normality. In the second stage, the measurement model was constructed and tested. In the final stage, analysis of the structural model including model modifications and tests of the mediated effects were performed. Structural equation modeling (SEM) using maximum likelihood method in EQS for Windows Version 6.1 (Bentler, 2005) was used as the primary data analytic strategy for both stages two and three of analyses. Preliminary Analyses

The 266 returned surveys were screened for exclusionary criteria and the amount and pattern of missing data. Analyses revealed that 70 cases had to be excluded from final analyses for the following reasons: 8 cases due to participants reporting they are currently or were previously taking Alzheimer's medication and 62 cases due to missing more than $1 \%$ of items per measure. The criterion of less than $1 \%$ of the cases with missing values was used because Tabachnick and Fidell (2007) recommended using a conservative number (e.g., less than 5\%) when there is a small to moderate sample size (i.e., $N=100-200)$. After 266 data were screened and unusable data were deleted, 196 surveys (i.e., $73.68 \%$ of the 266 surveys) were included in the final analyses. Note that 196 usable surveys (134 for women and 62 for men) exceeded the minimum sample size of 114 needed to obtain the desired power of .95 with an alpha level of .05 with 70 
degrees of freedom according to NIESEM (Dudgeon, 2003). Further, the number of surveys collected from each gender yielded enough power to analyze the results for the women only but not for the men.

Of 196 usable surveys, 159 surveys (i.e., 81.12\%) contained completed data and 37 surveys (i.e., 18.88\%) contained only one missing item from the entire questionnaire packet. These 37 surveys were further screened for missing data and the patterns of missing data were tested using SPSS Missing Value Analysis. The Little's MCAR test $\left[\chi^{2}\right.$ $(3321)=3414.10, p=.13]$ indicated that the pattern of missing data was completely at random (MCAR). Since data from the 37 cases were missing completely at random (MCAR), case mean substitution was used to impute the missing value because it provides a conservative estimate of the missing value and it doesn't reduce variability of the variable with the missing value (Kline, 2005; Tabachnick \& Fidell, 2007).

Means, standard deviations, z-statistics for skewness and kurtosis (found in Table 1) revealed that most, if not all, observed variables are skewed and kurtotic for the total sample and for the women only group, suggesting univariate non-normality is present. Further, all of the scores fell within the possible ranges and the mean scores were comparable to the normative college student samples. Specifically, the mean scores for PGIS in the college student samples ranged between 30.41 to 33.18 (Robitschek, 1998, 1999, 2003), which were comparable to the means in the current sample of older adults (the mean for the total sample was 34.74 and the mean for women only group was 35.10 ).

Correlations among the 11 observed variables can be found in Table 2. As shown, the correlations among the three indices of physical health status are statistically related to each other and are as follows for the total sample and the women only group, 
respectively: self-rated health and chronic conditions, $r=-.52$ and $-.51, p<.01$; self-rated health and functional limitation, $r=.39$ and $.41, p<.01$; chronic conditions and functional limitation, $r=-.23$ and $-.23, p<.01$. Further, the two measures of selfdiscrepancy (Marker Placement Task and Self-Discrepancy Scale) are positively related to each other for the total sample and women only group $(r=.30$ and $.34, p<.01)$. Finally, the three measures of mental health (i.e., emotional, psychological, and social well-being) are also positively related to each other, ranging from $r=.52$ to $.58, p<.01$ for the total sample and for the women only group.

Analysis of the Measurement Model

The measurement model was constructed and tested to assess for the relationship between the measured variables and the latent constructs and the degree of fit of the present data to the model. For the physical health status latent construct, three indicators were used: self-rated health, number of chronic health problems, and functional limitation. The self-discrepancy construct was defined by two measured variables, the Marker Placement Task (Heppen \& Ogilvie, 2003) and the Self-Discrepancy Scale (Heidrich, 1999; Heidrich et al., 1994). For the mental health construct, the scales of emotional, psychological, and social well-being were used as indicators. The Ego Integrity Scale (EIS; Ryff \& Heincke, 1983) and the Personal Growth Initiative Scale (PGIS; Robitschek, 1998, 1999) were used to define ego-integrity and PGI constructs, respectively. Exploratory and confirmatory factor analyses revealed that the EIS (Ryff \& Heincke, 1983) is a two-factor measure. Specifically, negatively worded items loaded together on one factor, whereas positively worded items loaded together on another factor. Due to this two-dimensional factor, two parcels were formed yielding 9 negatively 
worded items in one parcel and 7 positively worded items in another parcel. As for the PGIS (Robitschek, 1998, 1999), exploratory and confirmatory factor analyses revealed that the PGIS is a single unidimensional scale. Therefore, the adjacent items parceling method was used since previous research indicated no statistical differences between this method and the nonnormally distributed item parceling method (Bandalos, 2002). The adjacent items parceling method for the PGIS resulted in three three-item parcels (i.e., items 1-3, 4-6, and 7-9).

To help with model identification, the following indicators were fixed to 1.0: selfrated health for the physical health status construct, PGI packet 1 for the PGI construct, Marker Placement Task for the self-discrepancy construct, ego-integrity negatively worded packet for the ego-integrity construct, and the psychological well-being scale for the mental health construct. When testing the measurement model, all factors were allowed to correlate since previous research indicated that these constructs were related (see the Extended Literature Review in Appendix A). Further, the measurement models for the total sample and for the women only group were interpreted using use the Robust Maximum Likelihood Estimation (RMLE), the Satorra-Bentler $\chi^{2}$ statistics, and the robust standard errors since the Mardia's coefficient was $>5.00$ and its Z-statistic was $\geq$ 1.96, indicating the presence of multivariate non-normality (Byrne, 2006). Specifically, the Mardia's coefficient was 94.92 and its z-score was 33.64 for the total sample, whereas the Mardia's coefficient was 79.35 and its z-score was 23.26 for the women only group.

To assess the fit of the measurement and structural models to the data, SEM literature recommends using several fit indices (Hu \& Bentler, 1999; Kline, 2005; 
McDonald \& Ho, 2002; Satorra \& Benter, 2001). The following fit indices were used in the current study: the Satorra-Bentler $\chi^{2} / \mathrm{df}$ ratio, the Comparative Fit Index (CFI), the incremental fit index (IFI), the Root Mean Square Error of Approximation (RMSEA), and the nonrobust standardized root-mean-square residual (nonrobust SRMR). Because the current study utilizes the robust statistics results, the Satorra-Bentler chi-square rather than the independent chi-square value was used (Satorra \& Benter, 2001). In general, a $\mathrm{SB} \chi^{2} / \mathrm{df}$ ratio $\leq 3$ indicates a good fit of the model to the data (Satorra $\&$ Benter, 2001). Further, values $\geq .90$ (Kline, 2005; McDonald \& Ho, 2002) or $\geq .95$ (Hu \& Bentler, 1999) for the CFI and IFI indices are considered evidence of good fit. The RMSEA index indicates unacceptable fit at values close to .10 , a reasonable fit at $.06-.08$, and a close fit at .05 or less (Hu \& Bentler, 1999). Finally, a cutoff value $\leq .08$ is desired for the nonrobust SRMR fit index (Hu \& Bentler, 1999). Joint criteria were also used to determine goodness of fit in the structural model in that if CFI is $\geq .95$ and the nonrobust $\mathrm{SRMR}$ is $\leq .08$, or the RMSEA is $\leq .05$ and nonrobust $\mathrm{SRMR}$ is $\leq .08$, this suggests that the data are a good fit to the model (Hu \& Bentler, 1999).

Confirmatory factor analysis revealed that the measurement model is a good fit to the data for the total sample: Satorra-Bentler $\chi^{2}(55, N=196)=75.91, p<.05 ; \mathrm{SB} \chi^{2} / \mathrm{df}=$ 1.38; CFI $=.98 ; \mathrm{IFI}=.98 ; \mathrm{RMSEA}=.04(90 \% \mathrm{CI}: .01-.07)$; and nonrobust SRMR $=$ .04 ; as well as for women only: Satorra-Bentler $\chi^{2}(55, N=134)=77.69, p<.05$; SB $\chi^{2} / \mathrm{df}=1.41 ; \mathrm{CFI}=.96 ; \mathrm{IFI}=.97 ; \mathrm{RMSEA}=.06(90 \% \mathrm{CI}: .02-.08) ;$ and nonrobust $\mathrm{SRMR}=.05$ (see Table 3 ). The standardized factor loadings for the measured variables on their latent construct for the total sample and women only can be found in Table 4. As shown, all measured variables loaded significantly on their latent variable, $p<.05$. Since 
the measurement models for the total sample and women only fit the data well, the structural model was tested next.

\section{Analysis of the Structural Model}

There are three major approaches for testing models that include mediating variables: the causal steps, the difference in coefficients, and the products of coefficients (MacKinnon, Lockwood, Hoffman, West, \& Sheets, 2002). The causal steps approach, the most commonly employed approach in the psychological literature, requires testing for mediation through a series of steps as outlined in Baron and Kenny's (1986) writing. The difference in coefficients approach involves comparing two regression or correlation coefficients before and after accounting for the mediating variable (MacKinnon et al., 2002). The product of coefficients approach involves computing the mediated effect by multiplying the path coefficient for the predictor-mediator path by the mediator-outcome path (MacKinnon et al., 2002).

In the current study, the products of coefficients approach, also known as the method of effects decomposition, was used to test for mediation in the proposed structural model (Bollen, 1987; MacKinnon, 2000). The method of effects decomposition tests for the significance of the direct, indirect, and total effects for all variables in a single SEM analysis. The product of coefficients method (MacKinnon, 2000) has several advantages compared to the other tests of mediation. First, the product of coefficients method has more power compared to other approaches of testing mediation. Second, the product of coefficients method allows for the testing of multiple mediators simultaneously; whereas the causal steps method does not (MacKinnon, 2000). Third, the estimate of the mediated effect cannot be obtained using the causal steps method without 
combining it with other approaches (MacKinnon, 2000). Finally, the causal steps approach does not provide confidence limits of multiple mediated effects and cannot test for statistical significance of multiple mediated effects (MacKinnon, 2000). Since the current study had multiple mediators and was interested in testing the statistical significance of the mediated effects, the product of coefficients method was employed. Fit indices were evaluated using the same standards as previously mentioned.

For the total sample, the hypothesized structural model (see Figure 3) provided an adequate fit to the data: Satorra-Bentler $\chi^{2}(70, N=196)=135.46, p<.001 ; \mathrm{SB} \chi^{2} / \mathrm{df}=$ 1.94; $\mathrm{CFI}=.93 ; \mathrm{IFI}=.93 ; \mathrm{RMSEA}=.07(90 \% \mathrm{CI}: .05-.09) ;$ and nonrobust SRMR $=$ .12 (see Table 3 ). Similarly, when the men were removed and only women were analyzed, the hypothesized structural model provided an adequate fit to the data: SatorraBentler $\chi^{2}(70, N=134)=126.65, p<.001 ; \mathrm{SB} \chi^{2} / \mathrm{df}=1.81 ; \mathrm{CFI}=.91 ; \mathrm{IFI}=.91$; RMSEA $=.08(90 \% \mathrm{CI}: .06-.10) ;$ and nonrobust SRMR $=.14$

To improve the fit of the structural model, the Lagrange Multiplier (LM) test and the Wald test were consulted. The LM test suggested adding a path from PGI to physical health status for the total sample and women only. Given that current research by Robitschek and colleagues (Spering, Robitschek, \& Hoang, 2008) found that PGI was related to healthy behaviors in college students, this path was added (see path $\mathrm{i}$ in the final structural model, Figure 4).

The LM test also suggested allowing the measurement error between emotional and psychological well-being (EWB-PWB) to correlate in both the total and women only samples. Note that the suggestion to correlate emotional and psychological domains of well-being appear to be different from Keyes' structure of mental health, which 
organized psychological and social domains of well-being to be related under the category of functioning / eudaimonic well-being. Even though correlating measurement errors between emotional and psychological well-being may improve the goodness of fit of the model, SEM literature regards correlating error terms, in general, to be conceptually and theoretically tricky (see Gerbing \& Anderson, 1984; Green \& Hershberger, 2000; Reddy, 1992; Tabachnick \& Fidell, 2007). Therefore, substantive theoretical and methodological justification and interpretability of the model were considered before allowing the measurement errors between emotional and psychological well-being to correlate.

Based on theoretical ground, Keyes's (Keyes \& Waterman, 2003) regarded all 3 domains of well-being as mutually distinct, yet related. Specifically, indicators of emotional and psychological well-being are more related to each other than indicators of psychological and social well-being. The specific indicators that emotional and psychological well-being share together are personal growth, purpose in life, positive relations with others, autonomy, life satisfaction, happiness, and positive affect (McGregor \& Little, 1998). These indicators of emotional and psychological well-being are related to each other because they define well-being from the private, inner, \& personal dimension, which consisted of positive emotions and functioning.

Traditionally, functioning was defined from the private dimension as the ability to fully function and strive in one's private life (Ryff, 1989; Ryff \& Keyes, 1995). Recently, functioning was defined from the eudaimonic perspective as the ability to realize one's full potentials in the psychological and social domains (Keyes, 2006). Keyes (2006) believed that individuals' level of functioning is more than their ability to strive and 
adjust to their personal life, but to their social life as well since individuals coexist in society, community, and neighborhood. Social well-being did not exist within the eudaimonic (functioning) tradition originally since mental health literature did not acknowledge the social aspect to influence one's well-being / mental health. Because mental health literature failed to recognize the importance of social aspect in one's mental health, Keyes (1998) reorganized the functioning domain of mental health to include social well-being as well. Since the restructuring of the functioning domain of mental health, very little research has been done to assess the extent to which emotional, psychological, and social domains of well-being are related to or different from each other. Therefore, before allowing the errors for emotional and psychological well-being to correlate, conceptual rationales and empirical evidence providing support that emotional and psychological domains of well-being (a) are related to each other and (b) are different from social well-being must be established first.

There are four reasons in which emotional and psychological domains of wellbeing (a) are related to each other and (b) are different from social well-being. First, previous research indicated that individuals who are high in life satisfaction and happiness (i.e., high in emotional well-being) reported having high levels of psychological well-being as well (see Keyes, 2002, 2005a; Keyes \& Waterman, 2003; Ryff, 1989; Ryff \& Keyes, 1995). Second, when subjective well-being is operationalized, scales of emotional well-being and psychological well-being are usually employed since they reflect the affective and cognitive components of subjective well-being (Keyes, Shmotkin, \& Ryff, 2002). Third, research has indicated that emotional and psychological domains of well-being reflect the inner, private, and personal criteria for evaluating one's 
life; whereas social well-being reflects the outer, public, and social criteria for evaluating one's life (Keyes, 1998). Finally, happiness and meaningfulness are connected to personal evaluation rather than to social tasks (McGregor \& Little, 1998).

To ensure that the mental health measurement model when the error terms between emotional and psychological well-being are correlated remains highly similar to the mental health measurement model when the error terms are not correlated, confirmation factor analyses for both the total sample and the women only group were conducted. Afterward, a bivariate correlation using the standardized factor loadings and error terms shared between these two measurement models were calculated. Results revealed that for the total sample, the correlation was $r(6)=.90, p<.05$. Similarly, for the women only group, the correlation was $r(6)=.87, p<.05$. Since the correlation between the two mental health measurement models for both the total sample and the women only group was highly correlated, this indicates that allowing the error terms between emotional and psychological well-being did not change the mental health construct in any way. Therefore, the correlation between emotional and psychological well-being error terms was added to the model in both the total and women only samples. After the two paths were added (PGI predicting physical health status and correlating measurement errors for emotional and psychological well-being), the fit of the model was significantly improved between the hypothesized model A (Figure 3) and LM test modified model B for both the total sample and women only: Satorra-Bentler $\chi_{\text {difference }}^{2}(2, N=196)=32.86, p<.001$ and Satorra-Bentler $\chi_{\text {difference }}^{2}(2, N=134)=$ 23.22, $p<.001$, respectively (see Table 3 ). 
The Wald test (which is a test of dropping parameters) was explored next. The Wald test suggested deleting the path from age to physical health status (i.e., deleting path $\mathrm{h}$ in Figure 3) from the model to further improve model fit for the total sample and women only. When the correlation between age and the three indicators of physical health status was examined for the total sample and women only, results indicated that age negatively related only to functional limitation and did not relate to self-rated health or the number of health problems (see Table 2). These results seem to suggest that chronological age appears to be tied only to the social definition of physical health status and not to the psychological or medical definitions of physical health status in the current sample. Hence, this may explain why the direct path from age to overall physical health status contributed less than $1 \%$ of the variance for the total sample and less than $2 \%$ of the variance for women only in the model. Therefore, it seems reasonable to drop the path from age to physical health status (path h) from the model.

Further improvement in fit of the model to the data did emerge with the deletion of the path from age to physical health status (i.e., path $\mathrm{h}$ ) for only the total sample and not for women. The difference in chi-square between the LM test modified model B and the Wald test modified model C was significant for the total sample, Satorra-Bentler $\chi_{\text {difference }}^{2}(12, N=196)=22.89, p<.05$, but not for the women only group, SatorraBentler $\chi_{\text {difference }}^{2}(12, N=134)=14.17, p>.05$ (see Table 3$)$. Because model $\mathrm{C}$ was the most parsimonious model and the best fitting model relative to models $\mathrm{A}$ and $\mathrm{B}$, model $\mathrm{C}$ (depicted in Figure 4) was used as the final model to test for the mediating effects for the total sample. However, because model $\mathrm{C}$ did not result in significant improvement in fit, as indicated by the Satorra-Bentler chi-square difference test, model B (see Figure 5) was 
used as the final model to test for mediating effects for the women only group. The direct effects for the final model for the total sample can be found in Figure 6 and for the women only group can be found in Figure 7.

Since modifications were made to the model and paths were added and deleted that were not hypothesized for the total sample and women only group, Tabachnick and Fidell (2007) recommended calculating a bivariate correlation between the hypothesized and final model to assess for the degree of change in the parameter estimates when crossvalidation on a new set of data is not available. The bivariate correlation between the initial and final parameter estimates, the standardized factor loadings, path coefficients, and error terms shared between the hypothesized and final models were calculated. For the total sample, the correlation between the hypothesized and the final model $\mathrm{C}$ was $r$ $(32)=.99, p<.01$. Similarly, for the women only group, the correlation between the hypothesized and the final model B was $r(33)=.97, p<.01$. Since the correlation for both the total sample and women only group was higher than .90 and was statistically significant, this suggests the parameter estimates between the hypothesized and the final models are highly related despite the post-hoc model modifications.

Amount of variance in the outcome variables that was accounted for by the predictors and mediators was assessed next. Results revealed that for the total sample, $75.1 \%$ of the variance in mental health was accounted for by PGI, self-discrepancy, and ego-integrity. More specifically, PGI and self-discrepancy accounted for $31.1 \%$ of the variance in ego-integrity; $75.5 \%$ of the variance in self-discrepancy was accounted for by PGI and physical health status; finally, PGI accounted for $21.1 \%$ of the variance in physical health status. As for the women only group, $87 \%$ of the variance in mental 
health was accounted for by PGI, self-discrepancy, and ego-integrity. In addition, PGI and self-discrepancy accounted for $65.2 \%$ of the variance in ego-integrity; $70.5 \%$ of the variance in self-discrepancy was accounted for by PGI and physical health status; finally, PGI and age accounted for $29.3 \%$ of the variance in physical health status.

\section{Test of the Mediated Effects}

Since the overall objective of the present study was to identify and assess for the direct and indirect effects of the predictors and mediators on mental health, the direct, indirect, and total effects for the variables in the final structural model were examined to determine whether partial, full, or no mediation is present. The presence of partial mediation is supported when the direct and indirect effects are statistically significant; the presence of full mediation is supported when the indirect effects are statistically significant and the direct effect is not; and mediation did not occur when the direct effect is statistically significant and the indirect effects are not.

As shown in Table 5, mediation occurred only for the total sample and not for the women only group. Specifically, for the total sample, the effect of PGI on mental health was partially mediated. In other words, PGI predicted mental health directly and indirectly. As shown in Figure 4, the indirect effect of PGI on mental health may occur through physical health status, self-discrepancies, or ego integrity. As shown in Figure 6 and Tables 5 and 6, however, PGI had neither a direct nor an indirect effect on ego integrity. Thus, through the indirect route, PGI passed through physical health status and self-discrepancy to predict mental health (see Figure 4; Tables 5 \& 6). Having a high level of PGI was (1) linked directly to higher mental health and (2) linked to a higher 
level of physical health status that was predictive of a lower level of self-discrepancy, which in turn is linked to higher levels of mental health.

In addition to PGI directly and indirectly predicting mental health, PGI also directly and indirectly predicted self-discrepancy for the total sample only (see Figure 6; Tables $5 \& 6$ ). In other words, physical health status partially mediated the effect of PGI on self-discrepancy. Having a high level of PGI was (1) linked directly to lower selfdiscrepancy and (2) linked to greater physical health status that was predictive of lower levels of self-discrepancy. The specific indirect effect of PGI to self-discrepancy through physical health status was tested for its statistical significance by using the unstandardized indirect path coefficients and standard errors to compute the $95 \%$ confidence interval. As shown in Table 7, the 95\% confidence interval for this specific mediated effect did not include zero, suggesting that the mediated effect of physical health status on PGI and self-discrepancy was not likely due to chance.

For the women only group, PGI did not have an individual direct or indirect effect on mental health. Rather, it is through the total effect (the combined direct and indirect effects of physical health status and self-discrepancy) that PGI exerted an influence on mental health (see Tables 5 and 6). In other words, a high level of PGI was linked to (1) greater mental health directly and (2) greater physical health status that was predictive of a lower level of self-discrepancy, which was predictive of higher levels of mental health only when the direct and indirect effects of physical health status and self-discrepancy were combined. Further, PGI directly predicted self-discrepancy and the indirect effect of PGI to self-discrepancy via physical health status was not present (see Tables $5 \& 6$ ). The 
significant direct effect of PGI to self-self-discrepancy indicated a negative relationship, suggesting a high level of PGI was linked directly to a lower level of self-discrepancy.

Contrary to the study hypothesis, self-discrepancy did not have either a direct or indirect effect on mental health individually for the total sample or the women only group (see Table 5 and 6). Even though the individual direct and indirect effects of selfdiscrepancy on mental health were not statistically significant, self-discrepancy still predicted mental health through combining the direct effect and indirect effect of egointegrity for the total sample and women only group (see Tables 5 and 6). In other words, the mediated effect of ego-integrity was not present in the traditional sense described in SEM literature; however, the effect of self-discrepancy on mental health is there when the direct and indirect effects are combined. More specifically, a high level of selfdiscrepancy was linked to (1) lower mental health directly and (2) a lower level of egointegrity that was predictive of lower levels of mental health only when the direct and indirect effects of ego-integrity were combined for both the total sample and women only group.

\section{Tests of Secondary Hypotheses}

The secondary objectives of the study were to replicate the following previous findings: that PGI negatively predicted self-discrepancy (Hardin et al., 2007), that physical health status negatively predicted self-discrepancy (Heidrich \& Powwattana, 2004; Heidrich \& Ward, 1992), and that age negatively predicted physical health status (Birren \& Renner, 1980; Federal Interagency Forum on Aging-Related Statistics, 2006; Frazer, Leicht, \& Baker, 1996; Heidrich \& D'Amico, 1993; Saxena, van Ommeren, Tang, \& Armstrong, 2005; Vandervoort \& Skorikov, 2002). As predicted, results show 
that PGI and physical health status negatively predicted self-discrepancy for both the total sample and the women only group (see Figure 6 and 7, paths $\mathrm{f}$ and g). Interestingly, for the total sample only, PGI not only negatively predicted self-discrepancy directly (see Figure 6, path f) but also indirectly through physical health status in that high levels of PGI indicated high levels of physical health status (see Figure 6, path i), which in turn, were indicative of lower levels of self-discrepancy (see Figure 6, path g). As for the women only group, PGI had a direct effect but not an indirect effect on self-discrepancy (see Table 5). Finally, contrary to expectation, age did not significantly predict physical health status for the total sample; hence, this relationship (path h) was deleted from the final model (see Figure 6). Similarly, age did not significantly predict physical health status for the women only group (see Figure 7). 
Table 1

Means, standard deviations, and z-statistics of skewness and kurtosis for the measured variables for the total sample $(N=196)$ and women only $(n=134)$

\begin{tabular}{l|rrrr|rrrc}
\hline \multirow{4}{*}{ Variable } & \multicolumn{4}{|c|}{ Total sample } & \multicolumn{4}{c}{ Women only } \\
\cline { 2 - 9 } & M & SD & Skewness & Kurtosis & M & SD & Skewness & Kurtosis \\
\hline Age & 74.47 & 6.71 & 2.91 & -1.39 & 75.37 & 6.64 & 2.18 & -1.20 \\
Self Health & 6.76 & 1.74 & -1.86 & -.42 & 6.77 & 1.75 & -1.46 & -.35 \\
Health Prob & 2.58 & 1.74 & 4.35 & 1.66 & 2.71 & 1.77 & 3.57 & 1.34 \\
Func Limit & 26.84 & 2.83 & -28.64 & 106.06 & 26.78 & 3.12 & -24.12 & 85.43 \\
PGI & 34.74 & 8.37 & -6.78 & 5.79 & 35.10 & 8.19 & -5.77 & 4.58 \\
MPT & 5.71 & 4.29 & 7.04 & 5.49 & 6.15 & 4.53 & 6.05 & 4.38 \\
SDS & 32.76 & 12.85 & 7.57 & 6.12 & 32.65 & 13.19 & 7.54 & 6.42 \\
EI & 73.89 & 11.68 & -1.83 & -1.34 & 73.90 & 12.08 & -1.45 & -1.06
\end{tabular}


Table 1 Continued

\begin{tabular}{c|rccc|cccc}
\hline \multirow{2}{*}{ Variable } & \multicolumn{3}{|c|}{ Total sample } & \multicolumn{4}{c}{ Women only } \\
\cline { 2 - 9 } & $\mathbf{M}$ & SD & Skewness & Kurtosis & M & SD & Skewness & Kurtosis \\
\hline EWB & 54.48 & 8.38 & -5.99 & 2.83 & 54.09 & 8.74 & -5.13 & 2.35 \\
Life Sat & 8.11 & 1.55 & -5.07 & .77 & 8.04 & 1.64 & -4.14 & .16 \\
Happiness & 8.15 & 1.72 & -6.48 & 2.18 & 8.10 & 1.80 & -5.27 & 1.35 \\
PANA & 38.21 & 5.94 & -6.53 & 4.11 & 37.94 & 5.98 & -5.44 & 3.67 \\
PWB & 86.34 & 11.72 & -3.17 & -.87 & 86.98 & 11.77 & -3.15 & -.35 \\
SWB & 62.83 & 10.58 & -.31 & -1.68 & 62.45 & 10.67 & -.23 & -1.41 \\
\hline
\end{tabular}

Note. Self Health = self-rated health; Health Prob = number of chronic health problems; Func Limit = functional limitation; $\mathrm{PGI}=$ personal growth initiative; $\mathrm{MPT}=$ marker placement task; SDS = self-discrepancy scale; EI = ego-integrity; EWB = emotional well-being (Life Sat = life satisfaction, PANA = positive affects and negative affects); PWB = psychological wellbeing; SWB = social well-being. 
Table 2

Correlations among the measured variables for the total sample $(N=196)$ and women only $(n=134)$

\begin{tabular}{|c|c|c|c|c|c|c|c|c|c|c|c|}
\hline Variables & 1 & 2 & 3 & 4 & 5 & 6 & 7 & 8 & 9 & 10 & 11 \\
\hline 1. Age & - & -.07 & .14 & $-.18 *$ & -.07 & .02 & -.02 & -.08 & -.01 & -.17 & -.13 \\
\hline 2. Self Health & .02 & .89 & $-.51 * *$ & $.41 * *$ & $.45^{* *}$ & $-.26 * *$ & $-.49 * *$ & $.21 * *$ & $.50 * *$ & $.28 * *$ & $.29 * *$ \\
\hline 3. Health Prob & .06 & $-.52 * *$ & .43 & $-.23 * *$ & $-.26 * *$ & $.23 * *$ & $.31 * *$ & $-.24 * *$ & $-.34 * *$ & $-.27 * *$ & $-.34 * *$ \\
\hline 4. Func Limit & $-.21 * *$ & $.39 * *$ & $-.23 * *$ & .90 & $.25 * *$ & $-.21 * *$ & $-.30 * *$ & .10 & $.28 * *$ & $.18^{*}$ & $.20 *$ \\
\hline 5. PGI & -.04 & $.41 * *$ & $-.18 *$ & $.23 * *$ & .94 & $-.40 * *$ & $-.59 * *$ & $.45^{* *}$ & $.62 * *$ & $.68 * *$ & $.50 * *$ \\
\hline 6. MPT & -.003 & $-.22 * *$ & $.20 * *$ & $-.23 * *$ & $-.36 * *$ & - & $.34 * *$ & $-.36 * *$ & $-.43 * *$ & $-.39 * *$ & $-.32 * *$ \\
\hline 7. SDS & -.05 & $-.50 * *$ & $.30 * *$ & $-.28 * *$ & $-.61 * *$ & $.30 * *$ & .93 & $-.46 * *$ & $-.62 * *$ & $-.53 * *$ & $-.32 * *$ \\
\hline 8. EI & -.04 & $.20 * *$ & $-.18^{*}$ & .07 & $.45^{* *}$ & $-.32 * *$ & $-.44 * *$ & .81 & $.53 * *$ & $.62 * *$ & $.40 * *$ \\
\hline 9. EWB & .04 & $.45 * *$ & $-.27 * *$ & $.21 * *$ & $.61 * *$ & $-.36 * *$ & $-.56 * *$ & $.54 * *$ & .87 & $.52 * *$ & $.54 * *$ \\
\hline 10. PWB & -.12 & $.28 * *$ & $-.18 *$ & $.17^{*}$ & $.68 * *$ & $-.32 * *$ & $-.52 * *$ & $.63 * *$ & $.58 * *$ & .82 & $.58 * *$ \\
\hline 11. SWB & -.13 & $.26 * *$ & $-.27 * *$ & $.16^{*}$ & $.47 * *$ & $-.25 * *$ & $-.42 * *$ & $.41 * *$ & $.53 * *$ & $.56 * *$ & .79 \\
\hline
\end{tabular}

$* p<.05 ; * * p<.01$ 
Table 2 Continued

Note. Cronbach's alpha coefficients for the total sample are in bold typeface on diagonal. Correlations for the total sample are below the diagonal and correlations for women only are above the diagonal. Self Health = self-rated health; Health Prob $=$ number of chronic health problems; Func Limit = functional limitation; PGI = personal growth initiative; MPT $=$ marker placement task; SDS = self-discrepancy scale; EI = ego-integrity; EWB = emotional well-being; PWB = psychological wellbeing; SWB = social well-being. 
Table 3

Goodness of fit indices for the measurement model and the structural model for the total sample and women only

\begin{tabular}{|c|c|c|c|c|c|c|c|c|c|c|}
\hline Model & SB $\chi^{2}$ & df & SB $\chi^{2} / \mathbf{d f}$ & $\chi^{2}$ & CFI & IFI & RMSEA & $\begin{array}{c}90 \% \text { CI } \\
\text { for } \\
\text { RMSEA }\end{array}$ & $\begin{array}{c}\text { Nonrobust } \\
\text { SRMR }\end{array}$ & $\Delta \mathrm{SB} \chi^{2}(\mathrm{df})$ \\
\hline \multicolumn{11}{|c|}{ Measurement model } \\
\hline Total sample & 75.91 & 55 & 1.38 & 81.83 & .98 & .98 & .04 & $.01-.07$ & .04 & - \\
\hline Women only & 77.69 & 55 & 1.41 & 77.34 & .96 & .97 & .06 & $.02-.08$ & .05 & - \\
\hline
\end{tabular}

๙

Tests of mediation using effects decomposition

Total sample $(N=196)$

\begin{tabular}{|c|c|c|c|c|c|c|c|c|c|c|}
\hline Model A & 135.46 & 70 & 1.94 & 148.69 & .93 & .93 & .07 & $.05-.09$ & .12 & - \\
\hline Model B & 94.88 & 68 & 1.40 & 103.36 & .97 & .97 & .05 & $.02-.07$ & .05 & $32.86(2), p<.001$ \\
\hline Model C & 71.46 & 56 & 1.28 & 76.67 & .98 & .98 & .04 & $.00-.06$ & .04 & 22.89 (12), $p<.05$ \\
\hline \multicolumn{11}{|c|}{ Women only $(n=134)$} \\
\hline Model A & 126.65 & 70 & 1.81 & 136.61 & .91 & .91 & .08 & $.06-.10$ & .14 & - \\
\hline Model B & 82.89 & 68 & 1.22 & 86.81 & .98 & .98 & .04 & $.00-.07$ & .05 & $23.22(2), p<.001$ \\
\hline Model C & 68.73 & 56 & 1.23 & 71.84 & .98 & .98 & .04 & $.00-.07$ & .05 & $14.17(12), p>.05$ \\
\hline
\end{tabular}


Table 2 Continued

Note. Diagram for Model A (hypothesized model) can be found in Figure 3. Model B is the Lagrange Multiplier test in which PGI to physical health status latent variable was added and the measurement error term between emotional and psychological well-being was allowed to correlate. Model $\mathrm{C}$ is the Wald test in which the variance age and its path were removed. Bold typeface indicates the best fitting model for the particular group. 
Table 4

Standardized factor loadings for total sample $(N=196)$ and women only $(n=134)$ in the measurement model

\section{Factors / variables}

\section{Total sample Women only}

Physical health status

Self-rated health

.89

.88

Chronic conditions

$-.57-.57$

Functional limitation

.45

.47

Personal growth initiative

PGI-1

.88

.88

PGI-2

.92

.94

PGI-3

.89

.90

Self-discrepancy

MPT

.42

.49

SDS

.72

.70

Ego-integrity

EI-neg

.71

.72

EI-pos

.83

.84

Mental health

EWB

PWB

.82

.78

SWB

.63

.62

$* p<.05$

Note. $\mathrm{MPT}=$ marker placement task; $\mathrm{SDS}=$ self-discrepancy scale; $\mathrm{EWB}=$ emotional well-being; PWB = psychological well-being; $\mathrm{SWB}=$ social well-being. 
Table 5

The statistical significance checklist of the direct, indirect, and total effects of the final structural model for total sample and women only

\begin{tabular}{lcccc}
\hline Path & Direct effect & Indirect effect & Total effect & $\begin{array}{c}\text { Type of } \\
\text { mediated effect }\end{array}$ \\
\hline PGI $\rightarrow$ MH & Yes & Total sample & Partial \\
PGI $\rightarrow$ EI & No & Yes & Yes & None \\
PGI $\rightarrow$ SD & Yes & No & No & Partial \\
SD $\rightarrow$ MH & No & No & Yes & None \\
PHS $\rightarrow$ MH & - & Yes & Yes & - \\
PHS $\rightarrow$ EI & - & No & No & - \\
\hline & & Women only & & None \\
PGI $\rightarrow$ MH & No & No & Yes & None \\
PGI $\rightarrow$ EI & No & No & No & None \\
PGI $\rightarrow$ SD & Yes & No & Yes & None \\
SD $\rightarrow$ MH & No & No & Yes & - \\
PHS $\rightarrow$ MH & - & Yes & Yes & - \\
PHS $\rightarrow$ EI & - & No & No & \\
\hline
\end{tabular}

Note PHS $=$ physical health status $; \mathrm{PGI}=$ personal growth initiative; $\mathrm{SD}=$ selfdiscrepancy, $\mathrm{EI}=$ ego-integrity; $\mathrm{MH}=$ mental health . 
Table 6

Total mediated effects in the final structural model for the total sample $(N=196)$ and women only $(n=134)$

\begin{tabular}{cccc} 
Total mediated effect & $\begin{array}{c}\text { Total effect } \\
\text { (SE) }\end{array}$ & $\begin{array}{c}\text { Direct effect } \\
\text { (SE) }\end{array}$ & $\begin{array}{c}\text { Total Indirect effect } \\
\text { (SE) }\end{array}$ \\
\hline
\end{tabular}

\begin{tabular}{lccc}
\hline & \multicolumn{2}{c}{ Total sample } & \\
$\mathrm{PGI} \rightarrow \mathrm{MH}$ & $3.24(1.15)^{*}$ & $1.62(.44)^{*}$ & $1.62(.75)^{*}$ \\
$\mathrm{PGI} \rightarrow \mathrm{EI}$ & $.56(.36)$ & $.21(.20)$ & $.32(.19)$ \\
$\mathrm{PGI} \rightarrow \mathrm{SD}$ & $-.59(.11)^{*}$ & $-.46(.10)^{*}$ & $-.13(.05)^{*}$ \\
$\mathrm{SD} \rightarrow \mathrm{MH}$ & $-2.30(.93)^{*}$ & $-1.58(.84)$ & $-.72(.46)$ \\
$\mathrm{PHS} \rightarrow \mathrm{MH}$ & $1.06(.48)^{*}$ & - & $1.06(.48)^{*}$ \\
$\mathrm{PHS} \rightarrow \mathrm{EI}$ & $.25(.15)$ & - & $.25(.15)$ \\
\hline & \multicolumn{1}{c}{ Women } & & \\
$\mathrm{PGI} \rightarrow \mathrm{MH}$ & $3.38(1.57)^{*}$ & $.89(.70)$ & $2.49(1.50)$ \\
$\mathrm{PGI} \rightarrow \mathrm{EI}$ & $1.27(1.18)$ & $.26(.62)$ & $1.01(.63)$ \\
$\mathrm{PGI} \rightarrow \mathrm{SD}$ & $-.77(.21)^{*}$ & $-.60(.16)^{*}$ & $-.17(.09)$ \\
$\mathrm{SD} \rightarrow \mathrm{MH}$ & $-2.76(1.10)^{*}$ & $-.93(1.12)$ & $-1.83(1.18)$ \\
$\mathrm{PHS} \rightarrow \mathrm{MH}$ & $1.37(.65)^{*}$ & - & $1.37(.65)^{*}$ \\
$\mathrm{PHS} \rightarrow \mathrm{EI}$ & $.65(.43)$ & - & $.65(.43)$ \\
\hline
\end{tabular}

$* p<.05$

Note . PHS $=$ physical health status; $\mathrm{PGI}=$ personal growth initiative; $\mathrm{SD}=$ selfdiscrepancy, $\mathrm{EI}=$ ego-integrity; $\mathrm{MH}=$ mental health. 
Table 7

Specific mediated effects in the structural model for the total sample $(N=196)$

\begin{tabular}{lccc}
\hline Specific Mediated Effect & $\begin{array}{c}\text { Unstandardized } \\
\text { specific indirect effect }\end{array}$ & SE & $\begin{array}{c}\text { 95\% CI* } \\
\text { (lower, upper) }\end{array}$ \\
\hline $\mathrm{PGI} \rightarrow \mathrm{EI} \rightarrow \mathrm{MH}$ & .28 & .75 & $-1.19-1.75$ \\
$\mathrm{PGI} \rightarrow \mathrm{SD} \rightarrow \mathrm{EI}$ & .25 & .19 & $-.12-.62$ \\
$\mathrm{PGI} \rightarrow \mathrm{PHS} \rightarrow \mathrm{SD}$ & .13 & .05 & $.03-.23^{*}$ \\
$\mathrm{SD} \rightarrow \mathrm{EI} \rightarrow \mathrm{MH}$ & .72 & .46 & $-.18-1.62$ \\
\hline
\end{tabular}

$* p<.05$

Note. The standard error and 95\% confidence interval of the mediated effect are based on the multivariate delta method. PHS = physical health status; PGI = personal growth initiative; $\mathrm{SD}=$ self-discrepancy, $\mathrm{EI}=$ ego-integrity; $\mathrm{MH}=$ mental health. 


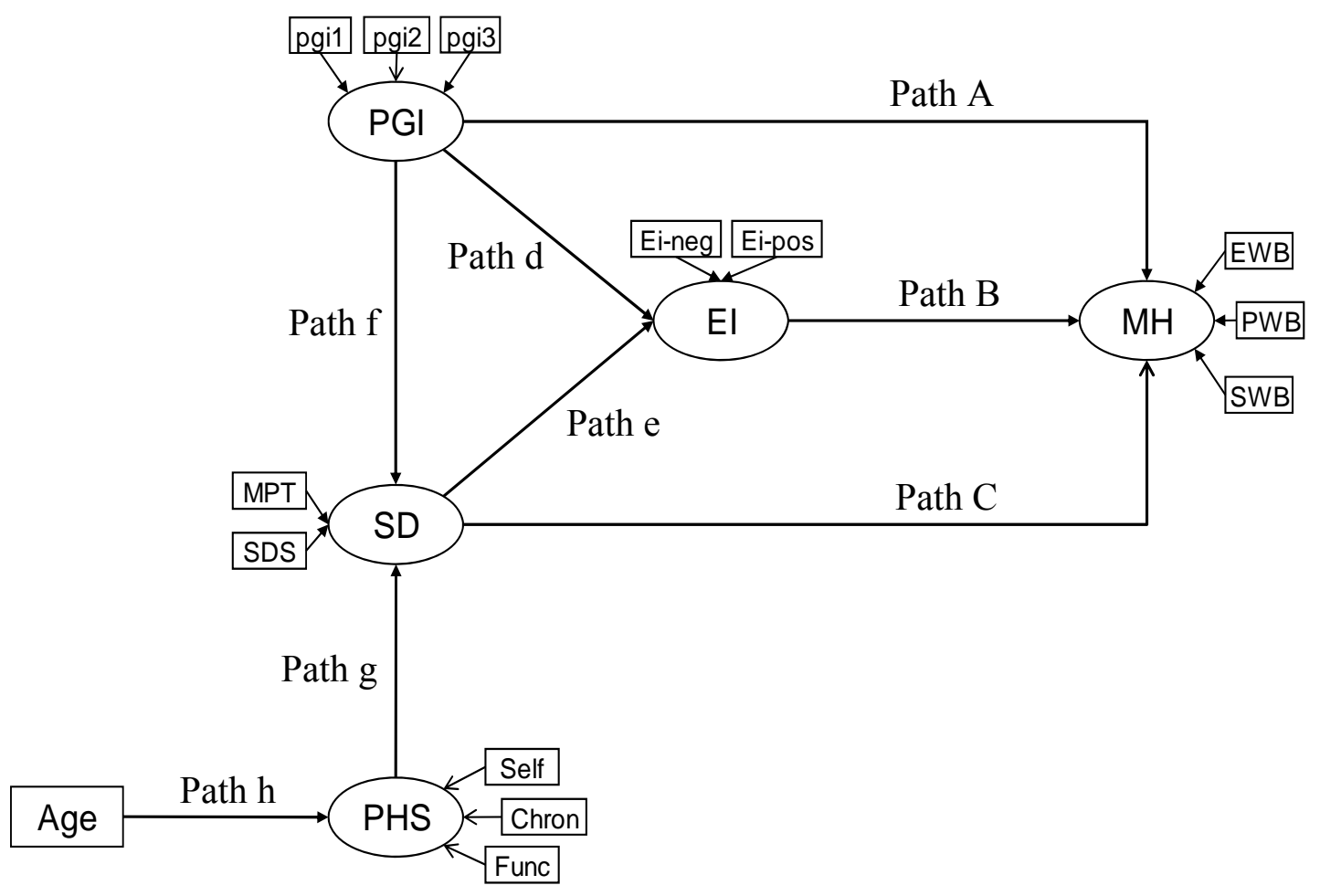

Figure 3. Hypothesized structural model. 


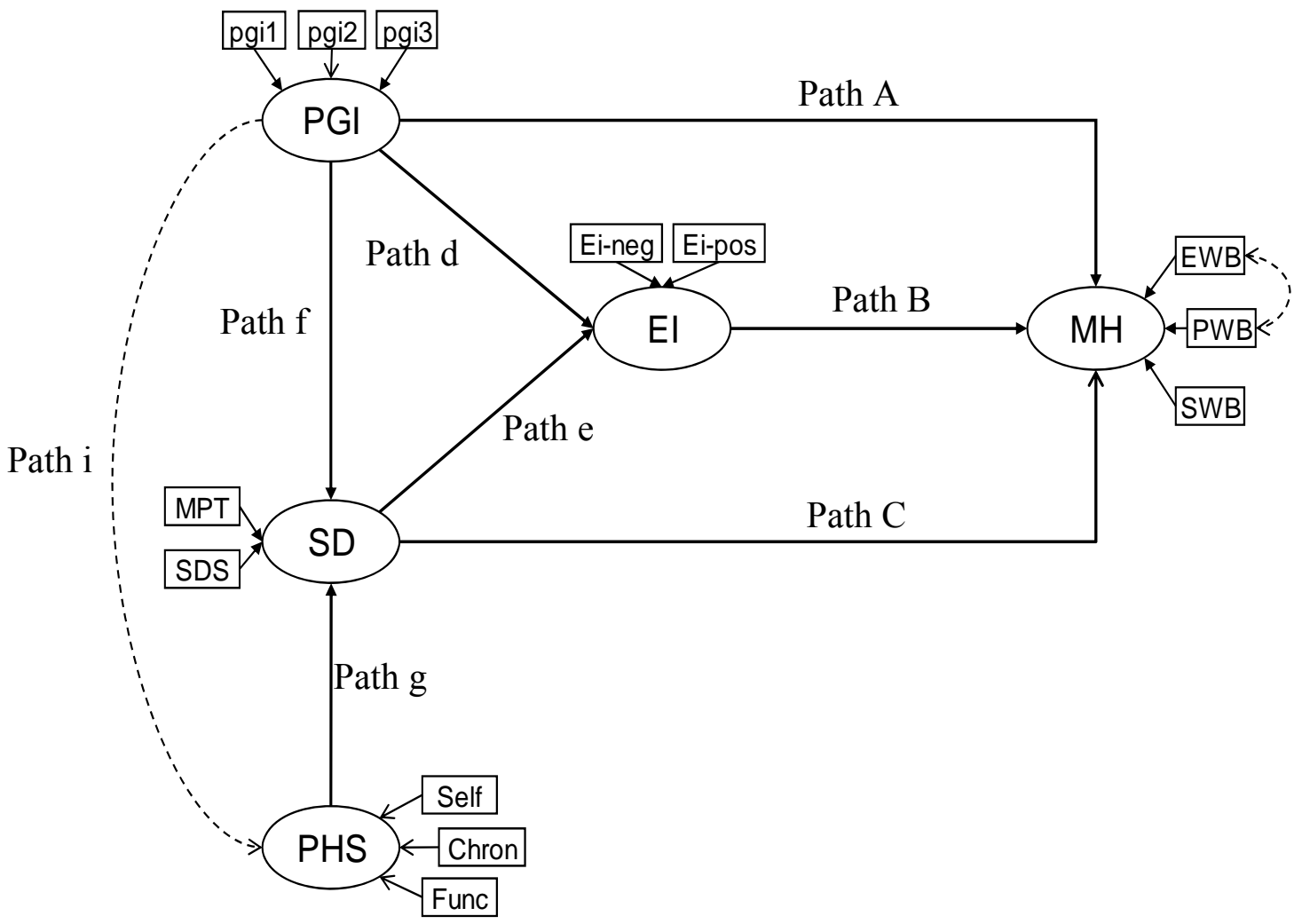

Note. Dotted lines indicate paths were added post-hoc.

Figure 4. Final structural model for the total sample. 


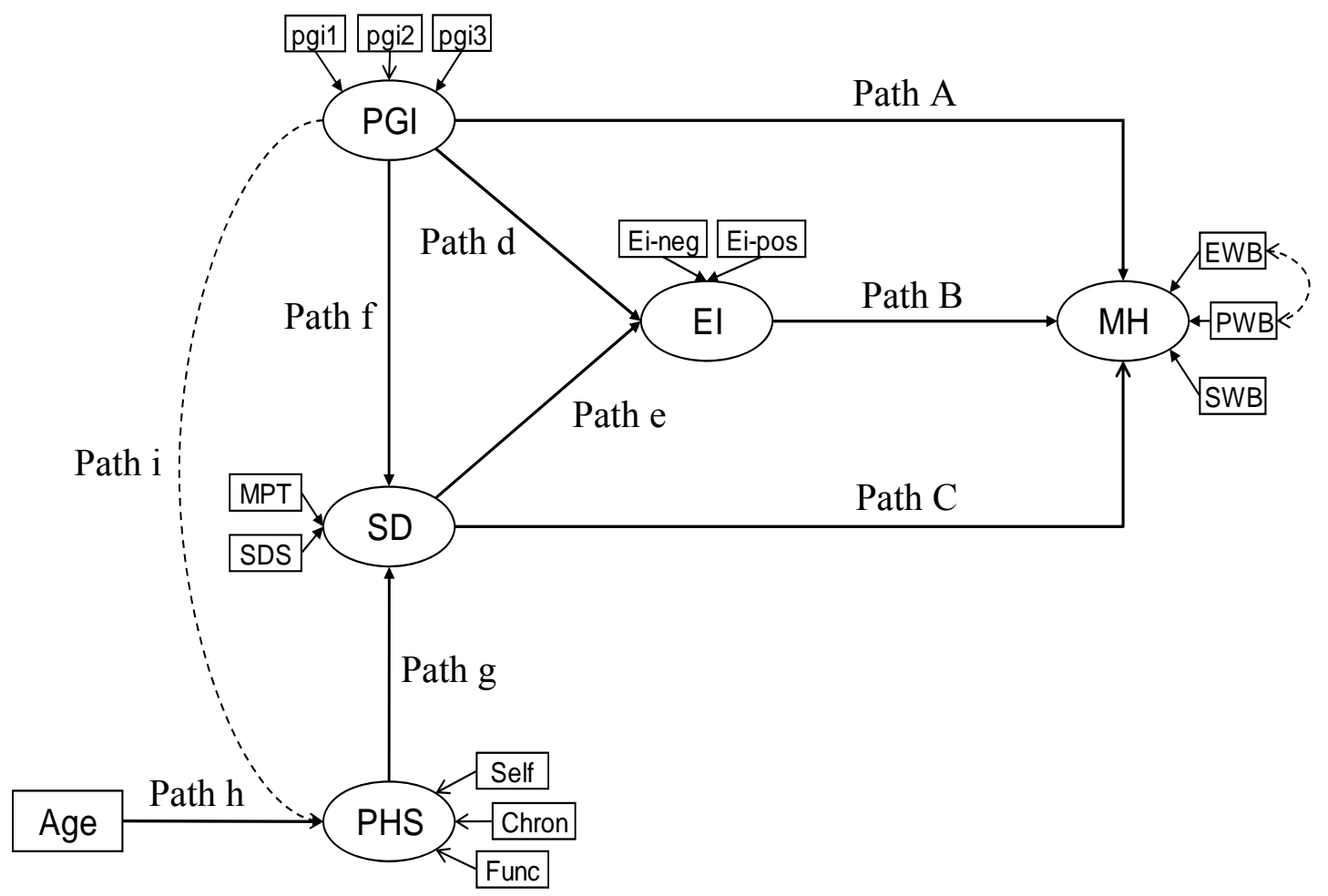

Note. Dotted lines indicate paths were added post-hoc.

Figure 5. Final structural model for women only. 


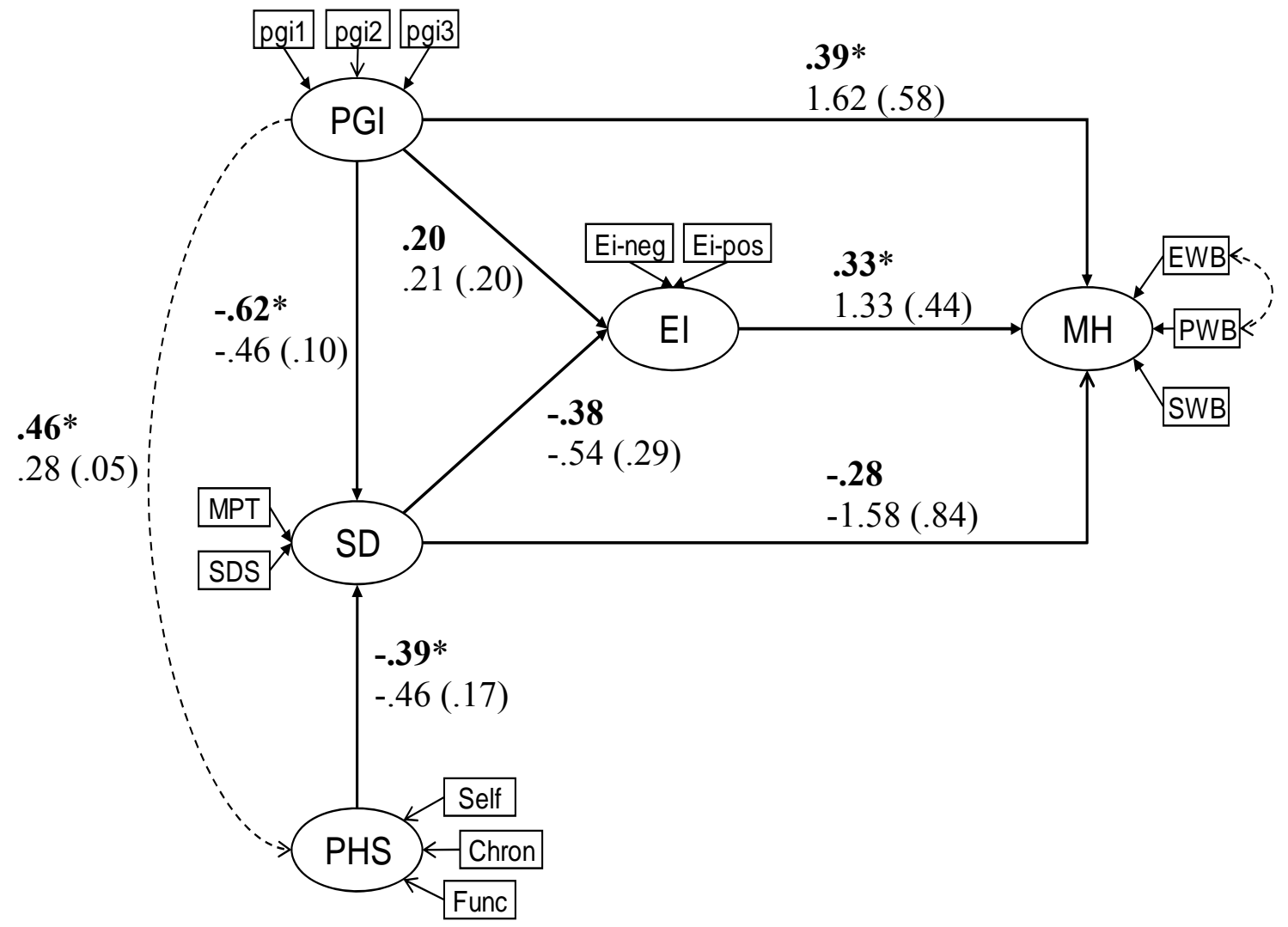

$* p<.05$

Note. Standardized (in bold font) and unstandardized path coefficients, and standardized errors (in parentheses) for each direct effect.

Figure 6. The final direct effects model with path loadings for the total sample. 


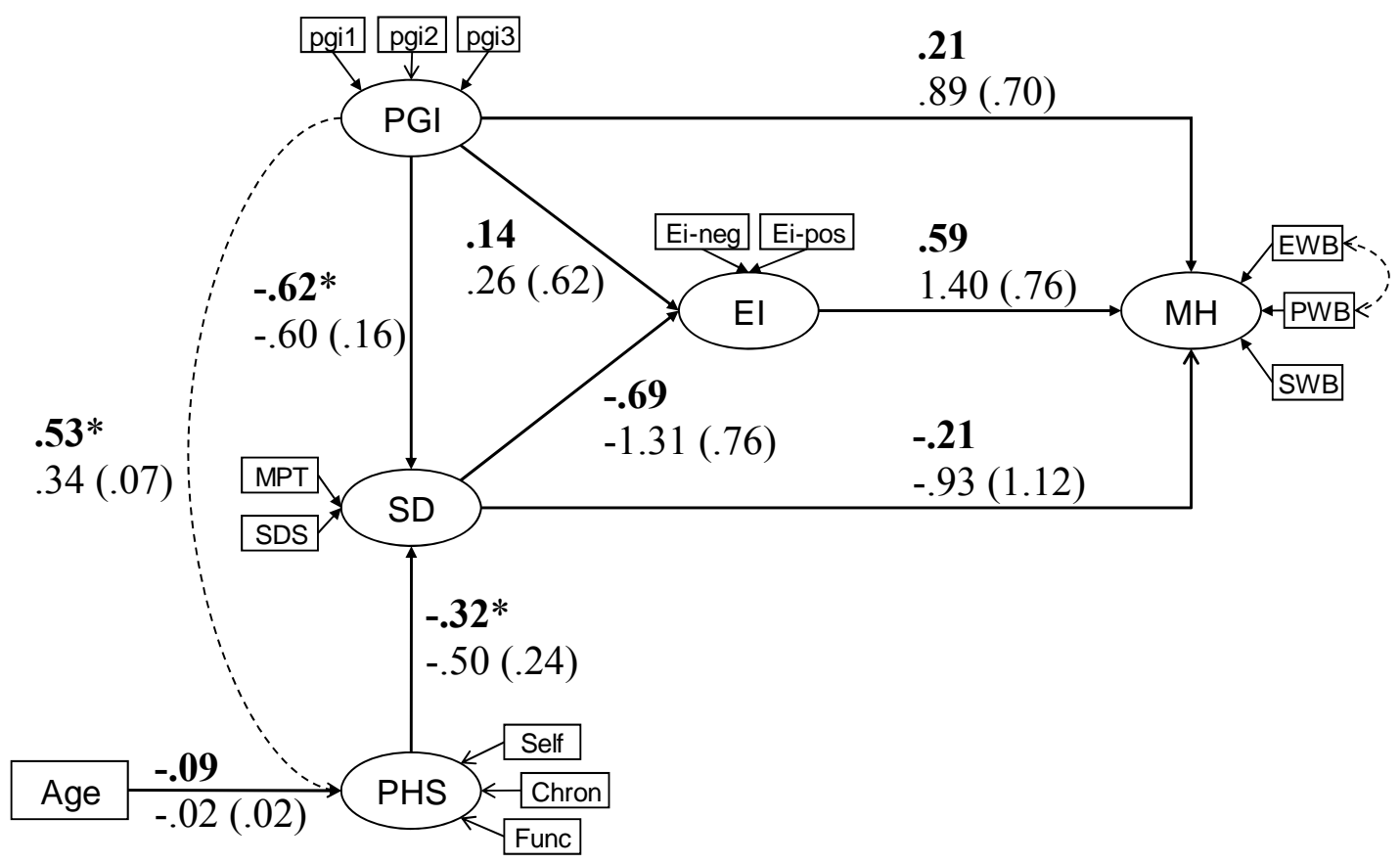

$* p<.05$

Note. Standardized (in bold font) and unstandardized path coefficients, and standardized errors (in parentheses) for each direct effect.

Figure 7. The final direct effects model with path loadings for women only. 


\section{CHAPTER IV}

\section{DISCUSSION}

Using the life-span perspective of ego-integrity (Erikson, 1959, 1980) and the Selective Optimization with Compensation (SOC) model (Baltes \& Baltes, 1990), the current study sought to explore the relations of PGI, self-discrepancy, and ego-integrity with mental health. According to Erikson $(1959,1980)$, an integrated sense of self is crucial to the experience of ego-integrity and an important criterion predictive of mental health. Also according to the SOC model (Baltes \& Baltes, 1990), despite the decline of physical health and losses of interpersonal relationships, older adults can still have optimal functioning by selectively pursuing goals that are important and making the best of their current circumstances. Selectively concentrating on the pursuit of goals that are personally most important and meaningful reflects the basic principle of PGI (Robitschek, 1998, 1999); accepting the self, situations, and/or experiences that cannot be changed reflect characteristics of ego-integrity. Further, when older adults are able to selectively focus, readjust, and substitute goals that reflect their actual self-representation, their levels of self-discrepancy may decrease (Heidrich, 1999; Heidrich \& Ward, 1992; Higgins, 1987). Analyses were done on both the total sample and the women only group since there was insufficient sample of men to test for gender differences. Because previous research has found that (1) the average longevity of older women is longer compared to older men (Cavanaugh \& Blanchard-Fields, 2006) and (2) PGI is related to other constructs such as assertiveness and expressiveness for the women only and not for the men (Robitschek \& Cook, 1999; Spering, 2008), analyzing the data for the women only addresses a feature of the gender differences in the literature and the extent to which 
research findings for the women may be different or the same from the total sample; therefore, the current study examined both the total sample and the women only group.

The current study hypothesized that self-discrepancy and PGI directly and indirectly predict mental health. However, the results indicated that the relation of selfdiscrepancy to mental health was not straightforward in either the total or women only samples. Neither the direct nor indirect effect of self-discrepancy on mental health was significant on its own; rather, self-discrepancy predicted mental health through the combined direct effect and indirect effect of ego-integrity. In other words, the mediated effect of ego-integrity was not present in the traditional sense described in SEM literature; however, the effect of self-discrepancy on mental health is there when the direct and indirect effects are combined. More specifically, when there is a consistent and congruent self-representation between the actual and ideal selves (i.e., a low level of selfdiscrepancy), aging adults are more likely to experience higher mental health, in part because they accept both the negative and positive aspects of themselves and their life experiences.

There are several important points to highlight from these results regarding the relation of self-discrepancies, ego-integrity, and mental health. First, these findings validate previous findings that demonstrated a positive link between ego-integrity and mental health, although for the total sample only and not for the women only group (Boylin, Gordon, \& Nehrke, 1976; Hogstel \& Curry, 1995; James \& Zarrett, 2005; Ranzijn \& Luszcz, 1999; Rylands \& Rickwood, 2001; Santor \& Zuroff, 1994; Torges, Stewart, \& Miner-Rubino, 2005). Second, these findings provide partial support for Erikson's $(1959,1980)$ theory of ego-integrity that a high level of ego-integrity is 
associated with successful aging and greater mental health, although for the total sample and not for the women only group. These findings, however, do not provide evidence that an integrated self is critical to the experiences of ego-integrity and an antecedent of mental health as hypothesized in the study. Third, these findings suggest that mental health in old age could be maintained or enhanced through striving to achieve an integrated self-concept and accepting features of the self, the past and present life experiences. These results, however, are based on correlational data rather than experimental data. Therefore, additional research using experimental research design or longitudinal research is needed to support these causal interpretations.

Partial support was found for the hypothesis that PGI directly and indirectly predicts mental health. For the total sample only, as predicted, PGI directly and indirectly predicted mental health. Although partial mediation did occur between PGI and mental health, it did so through the indirect effects of physical health status and self-discrepancy rather than through ego-integrity as the study had predicted. In other words, in addition to a high level of PGI predicting mental health directly, a high level of PGI also predicts a high level of physical health status, which is linked to a low level of self-discrepancy that is associated with greater mental health.

Although PGI did have a positive total effect on mental health, contrary to the study hypotheses, PGI did not bear either a direct effect or indirect effect on mental health individually for the women only group. Rather, the effect of PGI on mental health happened through the combined direct effect and indirect effect of self-discrepancy. In other words, similar to the total sample, for the women only group, a high level of PGI is linked to higher mental health, in part, because of lower self-discrepancy. Unlike the total 
sample, however, PGI did not have a significant direct effect on mental health, nor did PGI have an indirect effect on mental health or self-discrepancies through physical health status.

Even though none of the direct paths to mental health for the women only group was significant, more variance in mental health was accounted for in this group compared to the total sample. Specifically, for the women only group, $87 \%$ of the variance in mental health was accounted for by PGI, self-discrepancy, and ego-integrity, whereas $75.1 \%$ of the variance in mental health was accounted for by PGI, self-discrepancy, physical health status, and ego-integrity for the total sample. A difference of $11.9 \%$ of the variance in mental health between the total sample and the women only group is likely due to gender differences that the current model did not have sufficient power to assess. If there was a sufficient sample of men the current could analyze, it is predicted that (1) model invariance would occur between men and women and (2) there would be a smaller amount of variance in mental health accounted for in the men relative to the women. Model invariance between older men and women is likely to be present since gender differences in well-being, personality traits, and report of psychological distress and depression were found in previous research (Borden \& Berlin, 1990; Whisman, Uebelacker, Tolejko, Chatav, \& McKelvie, 2006).

Partial mediation also occurred between PGI and self-discrepancy for the total sample. In other words, PGI exerted a direct and indirect influence on self-discrepancy in that a high level of PGI is linked directly to (a) low levels of self-discrepancy and (b) high physical health status that is in turn predictive of lesser self-discrepancy. Although partial mediation did not occur between PGI and self-discrepancy for the women only 
group, a higher level of PGI still is associated with low levels of self-discrepancy directly, a finding that is similar to the total sample result.

For both the total sample and the women only group, several important points can be made about PGI as a predictor in the current study. First, a high level of PGI is a desirable personality trait that is likely to enhance mental health. This significant relation between PGI and mental health further strengthens previous findings that higher levels of PGI were associated with greater mental health (Hardin et al., 2007; Robitschek, 1998, 1999; 2003; Robitschek \& Keyes, 2006). Second, a high level of PGI is likely to protect older adults from inconsistent views of self. As suggested by Hardin and colleagues (2007), this may be because individuals with high levels of PGI recognize distress more quickly and continuously engage in growth opportunities, and thus they are likely to have lower levels of self-discrepancy. Finally, a high level of PGI is likely to promote high levels of physical health status in old age. This finding provides further support that PGI is an important predictor of physical health in college students (Spering, Robitschek, \& Hoang, 2008) as well as in older adults. Above all, these findings regarding PGI provide support for the SOC model's emphasis on the active engagement with life as an important component to successful aging (Baltes \& Baltes, 1990; Baltes et al., 1998; Rowe \& Kahn, 1997).

\section{Limitations of the Current Study and Future Research Recommendations}

There are several limitations in the current study. First, the final model for both the total sample and women only resulted from post-hoc modifications; hence, it needs to be cross-validated on new data. Further, the majority of the participants in the present study were middle class, Caucasian females with excellent mental status performance. 
Therefore, results may only be applicable to this particular group and may have limited generalizability to other populations (e.g., ethnic minority elders, elders suffering from a mental illness, elders with terminal illness or on palliative care). Future studies may want to replicate the final model in a more diverse population with equal representation of males and females and test for group invariance. Testing for multigroup invariance between men and women in the models in future studies would address one of the limitations of the current study and also explain the extent to which the current final models fit specifically for the women or the men only.

Second, quantitative self-report rating measures were the primary means of data collection. Quantitative self-report rating measures mask rich qualitative information such as how older adults interpret the meanings of an item on a measure, which in turn may have a potential influence on the extent to which they endorse an item. Understanding how older adults make sense of an item on a measure may give researchers insight on the cognitive and emotional processes that influence the variables being measured. Future studies may want to employ an open-ended interview format in order to understand how older adults interpret personal growth, for example.

Third, tests of mediation in the present study utilized the one-shot strategy in which all the measures were given at once. When all the predictors, mediators, and outcome variables are administered at one point in time in a cross-sectional design, as used in the current study, temporal order of the association based on significant correlations makes it difficult to interpret which variable predicts the other (Hoyle \& Robinson, 2004). The results could not be taken as evidence that certain variables (e.g., PGI and self-discrepancy) precedingly have an effect on other variables (e.g., ego- 
integrity and mental health). Future studies may want to use more stringent methodological designs such as either the replicative strategy or the longitudinal sequential strategy to test for mediation in the current model (Hoyle \& Robinson, 2004). In the replicative method, all the measures are administered at once at two or more points in time. Oppositely, testing for mediation using the sequential method requires that measures of interest are measured at different points in time to reflect their causal nature as depicted in the model. For example, the PGI predictor is measured at time 1; physical health status is measured at time 2 , self-discrepancy is measured at time 3 , ego-integrity is measured at time 4, and mental health indicators are measured at time 5 . In the sequential order, alternate hypotheses of causal inferences are controlled and/or ruled out.

Finally, there are other alternate models that may be a good fit to the data that the current study did not examine. First, other intrapersonal variables that were not tested in the current study, such as perceived stress and coping styles or strategies, may predict mental health. Future studies may want to examine how and where perceived stress and coping styles / strategies fit in the current SEM model. One possible prediction is that perceived stress and coping styles / strategies may mediate the relation between PGI and mental health. More specifically, a high level of PGI may link to lower levels of perceived stress and greater or more diverse coping styles and strategies, which in turn predict greater mental health. There are two reasons for these predictions. One, high PGI individuals are likely to perceive stress as growth opportunities, that is, as a positive event rather than a negative event. This positive appraisal of perceived stress is likely then be associated with greater well-being. Two, because of the constant engagement in improving aspects of the self, high PGI individuals are more likely to possess a wide 
range of functional coping styles and strategies that help them deal with their current situation, which in turn maintain their high levels of mental health.

Second, interpersonal variables may also predict mental health and should be examined in future studies. Specifically, social support should be included in the model since past literature demonstrated that social support is associated with mental health in older adults (e.g., Krause, 1997). Third, variables that serve as mediators may also function as moderators, which the current study did not test. This might include, for instance, self-discrepancy interacting with physical health status to predict mental health. More specifically, poor physical health may have a weaker detrimental effect on mental health for those with low self-discrepancies. This moderated effect of self-discrepancy and physical health status was partially supported in a study by Heidrich and Powwattana (2004), in which they found self-discrepancy interacting with physical health to predict happiness. In particular, they found that older women who are in poor physical health and are low in self-discrepancy reported higher levels of happiness compared to those who are in poor physical health and are high in self-discrepancy. In this sense, having a low level of self-discrepancy is a protective factor that prevents physically vulnerable older women from experiencing negative affects.

Finally, evidence of non-recursive models may also occur that the current study did not examine. For example, there might be a feedback loop between mental health and physical health status, in that high levels of mental health predict high levels of physical health status and vice versa. Since the current study was an exploratory test of the mediation model, by no means is this study intended to provide a conclusive answer to the research questions. 


\section{Implications for Practice}

The results of the current study have several possible clinical implications. First, given that personal growth is a desirable personality trait that is likely to promote physical as well as mental health in old age, interventions should be aimed at ways to help older adults flourish the remainder of their life (Keyes, 1998, 2002, 2003; Keyes \& Ryff, 1999; Ryff, 1989; Ryff \& Keyes, 1995) by maintaining this self-actualizing tendency (Rogers, 1961). Since personal growth initiative occurs by possessing the knowledge involved in the growth process and behaviors required to carry out the steps in the process (Robitschek, 1998, 1999), individualized intervention programs may need to target these two areas.

A few examples of how to improve PGI by targeting the cognitive and behavioral components of PGI are as follows. The first example is that if older adults have a misconception that old age is a time of disengagement from the pursuit of goals, as some of the participants in the current study indicated with the researcher, then therapy or other interventions could focus on reexamining and challenging this assumption. In this case, perhaps educating older adults about the Selective Optimization with Compensation (SOC) model (Baltes \& Baltes, 1990) may give them perspective on being flexible and adaptive in pursuing their goals rather than giving up on the goals completely. The second example is that if older adults are ambivalent about the advantages and disadvantages of personal growth, then interventions may need to match the client's stage of change (Prochaska \& DiClemente, 1982), perhaps using the spirit of motivational interviewing (Miller \& Rollnick, 2002). Motivational interviewing techniques allow the therapist to work with the client's resistance and work within the client's self-defined 
personal goals and values. When therapy is conducted from the client's goals, values, and readiness to change, clients are more likely to value change and carry out activities associated with personal development or improvement. The third example is that if older adults do not feel confident about personal growth, then therapy may need to focus on enhancing their self-efficacy for the change process. In contrast, if older adults do not find personal growth to be important, perhaps letting them know the benefits associated with personal growth in old age may raise their awareness and allow them to reconsider their perspective. The final example is that if older adults value the process of personal growth but do not possess the knowledge or behaviors needed to pursue personally relevant goals, then the treatment focus might concentrate on educating and role playing with them the steps and skills necessary to execute the plan. Keep in mind that although the continuous and intentional process of personal growth is vital to optimal functioning in late adulthood, knowing when and how to pursue these goals as well as when to substitute the goals is equally important as proposed by the SOC model (Baltes \& Baltes, 1990; Baltes et al., 1998).

The second clinical implication for the current findings is that given selfdiscrepancy had a total effect on mental health directly and through the influence of egointegrity for both the total sample and the women only group, interventions that focus on life review, reminiscence, and narrative therapy (Birren \& Cochran, 2001; Butler, 1963; Haber, 2006; Kivnick, 1993; Taft \& Nehrke, 1990) could be implemented to help older adults integrate various views of their self-concept to enhance their mental health. Engaging in meaning-making activities or reviewing their life may help older adults increase their mental health and age successfully by allowing them to examine 
unresolved past and present conflicting self-representation and life experiences. The strategy of engaging in self-reflection undoubtedly may yield greater insights and raise a deeper awareness of older adults' worldview of humanity and their concept of self that are characteristics of ego-integrity experiences Erikson $(1959,1980)$ described in his writing.

The findings of the present study also have broader social implications. These results debunk negative stereotypes about old age such as older adults are rigid in their way of thinking and are stuck in their way of living. These beliefs reflect the proverb that "you can't teach an old dog new tricks" when in fact, older adults can change and grow like other age groups. Compared to the means and standard deviations of PGI scores in older adults to college students, there were no significant differences (Robitschek, 1998, 1999, 2003). This finding suggests (1) PGI is not a age-restricted construct and (2) selfimprovement or growth continues to occur in old age. Despite age-related losses in their life, older adults who continue to be active and intentionally involved in selfimprovement and development are more likely to experience healthy aging than those who are not active and intentionally involved in this process. The idea of allowing older adults to continue engaging in the pursuit of goals sheds light on how important it is to allow older adults to be their own agents of change and to be in charge of their life decisions.

Based on the results from correlational data of the current study, personal growth initiative appears to be an important psychological marker that predicts physical health, self-discrepancy, and overall mental health. Without personal growth or this selfactualizing tendency, mental health may be compromised. Further, self-reflection also 
may be important in facilitating the integration of conflicting self-concepts and the acceptance of unresolved past experiences. In light of these findings, educational series such as community outreach and psychosocial workshops to inform older adults of these psychological components involved in optimal functioning may be necessary. Key findings could also be disseminated in a brochure format highlighting the benefits personal growth, physical health, and an integrated self-concept have on the state of flourishing in late adulthood.

As expected, there is no set of steps or secrets to guarantee optimal functioning or successful aging in late adulthood. There are, however, a few steps older adults could take possibly to ensure a flourishing life that are suggested from the findings of the current study. Because the results of the current study were based on correlational data, definitive response to the steps involved in the promotion of mental in old age cannot be for certain; rather, the response is more suggestive. As suggested from the results, the key steps involved in promoting mental health in the everyday life of older adults entail (1) the continuous active engagement in daily life activities and/or growth opportunities and (2) the practice of self-reflection to integrate discrepant self-concepts and to resolve past experiences and conflicts. With these two vital strategies, mental health promotion and mental illness prevention in late adulthood may be possible to accomplish. Finally, selfimprovement or personal striving through the constant engagement in personal growth is a journey and not a destination that discontinues in old age. A life well lived is a life of constant growth and change that allows one to flourish despite situational or biological factors. 


\section{REFERENCES}

Administration on Aging. (2006). Older population by age: 1900-2050. Online document available at http://www.aoa.gov/prof/Statistics/online_stat_data/AgePop2050.asp. Accessed on August 24, 2006.

Alexander, M. J., \& Higgins, E. T. (1993). Emotional trade-offs of becoming a parent: How social roles influence self-discrepancy effects. Journal of Personality and Social Psychology, 65, 1259-1269.

Baltes, P. B., \& Baltes, M. M. (1990). Psychological perspectives on successful aging: A model of selective optimization with compensation. In P. B. Baltes \& M. M. Baltes (Eds.), Successful aging: Perspectives from the behavioral sciences (pp. 134). Cambridge, England: Cambridge University Press.

Baltes, P. B., Lindenberger, U., \& Staudinger, U. M. (1998). Life-span theory in developmental psychology, In R. M. Lerner (Ed.), Handbook of child psychology: Vol. 1. Theoretical models of human development $\left(5^{\text {th }}\right.$ ed., Editor-in-Chief W. Damon, pp. 1029-11143). New York: Wiley.

Bandalos, D. L. (2002). The effects of item parceling on goodness-of-fit and parameter estimate bias in Structural Equation Modeling. Structural Equation Modeling, 9, 78-102.

Baron, R. M., \& Kenny, D. A. (1986). The moderator-mediator variable distinction in social psychological research: Conceptual, strategic, and statistical considerations. Journal of Personality and Social Psychology, 51, 1173-1182.

Bentler, P. M. (2005). EQS for Windows (Version 6.1) [Computer software]. Encino, CA: Multivariate Software.

Birren, J., \& Cochran, K. (2001). Telling the stories of life through guided autobiography groups. Baltimore: The Johns Hopkins University Press.

Birren, J. E., \& Renner, J. (1980). Concepts and issues of mental health and aging. In J. E. Birren \& R. B. Sloane (Eds.), Handbook of mental health and aging (pp. 3-33). Englewood Cliffs, NJ: Prentice-Hall.

Boldero, J., \& Francis, J. (2000). The relation between self-discrepancies and emotion: The moderating roles of self-guide importance, location relevance, and social selfdomain centrality. Journal of Personality and Social Psychology, 78, 38-52.

Bollen, K. A. (1987). Total, direct, and indirect effects in structural equation models. In C. C. Clogg (Ed.), Sociological methodology (pp. 37-69). Washington, DC: American Sociological Association. 
Borden, W., \& Berlin, S. (1990). Gender, coping, and psychological well-being in spouses of older adults with chronic dementia. American Journal of Orthopsychiatric, 60, 603-610.

Boylin, W., Gordon, S. K., Nehrke, M. F. (1976). Reminiscing and ego integrity in institutionalized elderly males. The Gerontologist, 16, 118-124.

Bruch, M. A., Rivet, K. M., \& Laurenti, H. J. (2000). Type of self-discrepancy and relationships to components of the tripartite model of emotional distress. Personality and Individual Differences, 29, 37-44.

Butler, R. N. (1963). The life review: An interpretation of reminiscence in the aged. Psychiatry, 26, 65-76.

Butler, R. N., Lewis, M. I., \& Sunderland, T. (1998). Aging and mental health: Positive psychosocial and biomedical approaches. Needham Heights, MA: Allyn and Bacon.

Byrne, B. M. (2006). Structural equation modeling with EQS: Basic concepts, applications, and programming. Mahwah, NJ: Lawrence Erlbaum Associates.

Cavanaugh, J. C., \& Blanchard-Fields, F. (2006). Adult development and aging. Belmont, CA: Thomson Wadsworth.

Centers for Medicare \& Medicaid Services (2004). Medicare Health Outcomes Survey. Online document available at http://www.hosonline.org/surveys/hos/download/HOS_2004_Survey.pdf. Accessed on May 1, 2007.

Dixon, R. A., \& Baltes, P. B. (1986). Toward life-span research on the functions and pragmatics of intelligence. In R. J. Sternberg \& R. K. Wagner (Eds.), Practical intelligence: Nature and origins of competence in the every world (pp. 202-235). Cambridge, England: Cambridge University Press.

Domino, G., \& Hanna, M. T. (1989). Measuring effective functioning in the elderly: An application of Erikson's theory. Journal of Personality Assessment, 53, 319-328.

Dudgeon, P. (2003). NIESEM: A computer program for calculating noncentral interval estimates (and power analysis) for structural equation modeling. Retrieved September 20, 2006, from http://rubens.its.unimelb.edu.au/ dydgeon/.

Erikson, E. H. (1959). The healthy personality. Psychological Issues, 1, 50-100.

Erikson, E. H. (1980). Identity and the life cycle (2 ${ }^{\text {nd }}$ Ed.). New York: Norton. 
Erikson, E. H., Erikson, J. M., \& Kivnick, H. Q. (1986). Vital involvement in old age. New York: Norton.

Federal Interagency Forum on Aging-Related Statistics. (2006). Older Americans update 2006: Key indicators of well-being. Hyattsville, MD: Author.

Francis, J. J., Boldero, J. M., \& Sambell, N. L. (2006). Self-lines: A new, psychometrically sound, 'user-friendly' idiographic technique for assessing selfdiscrepancies. Cognitive Therapy and Research, 30, 69-84.

Frazer, D. W., Leicht, M. L., Baker, M. D. (1996). Psychological manifestations of physical disease in the elderly. In Laura L. Carstensen, Barry B. Edelstein, \& Laurie Dornbrand (Eds.), The Practical Handbook of Clinical Gerontology (pp. 217-235). Thousand Oaks, CA: Sage Publications.

Freud, S. (1961). The id and the ego. In J. Strachey (Ed. and Trans.), The Standard Edition of the Complete Psychological Works of Sigmund Freud (Vol. 19, 12-66). London: Hogarth Press. (Original work published 1923).

Freund, A. M., \& Baltes, P. B. (1998). Selection, Optimization, and Compensation as Strategies of Life Management: Correlations with Subjective Indicators of Successful Aging. Psychology and Aging, 13, 31-543.

Freund, A. M., \& Baltes, P. B. (1999). Selection, Optimization, and Compensation as Strategies of Life Management: Correction to Freund and Baltes (1998). Psychology and Aging, 14, 700-702.

Gatz, M., \& Zarit, S. H. (1999). A good old age: Paradox or possibilitiy. In V. L. Bentson \& K. W. Schaie (Eds), Handbook of theories of aging (pp. 396-416). New York: Springer.

Gelso, C. J. (1979). Research in counseling: Methodological and professional issues. The Counseling Psychologist, 8, 7-35.

Gelso, C. J., \& Fretz, B. R. (1992). Counseling psychology. Fort Worth, TX: Harcourt Brace Javanovich.

Gerbing, D. W., \& Anderson, J. C. (1984). On the meaning of within-factor correlated measurement errors. Journal of Consumer Research, 11, 572-580.

Green S. B., \& Hershberger, S. L. (2000). Correlated errors in true score models and their effect on coefficient alpha. Structural Equation Modeling, 7, 251-270.

Haber, D. (2006). Life review: Implementation, theory, research, and therapy. International Journal of Aging and Human Development, 63, 153-171. 
Hamacheck, D. (1990). Evaluating self-concept and ego status in Erikson's last three psychosocial stages. Journal of Counseling Development, 68, 677-683.

Hardin, E. E. (2002). Depression and social anxiety among Asian and European Americans: The roles of self-discrepancy, optimism, and pessimism (Doctoral dissertation, The Ohio State University, 2002). Dissertation Abstracts International, 63, 2056.

Hardin, E. E., \& Lakin, J. L. (2007). The Integrated Self-Discrepancy Index: A reliable and valid measure of self-discrepancies. Unpublished manuscript.

Hardin, E. E., \& Leong, F. T. L. (2005). Optimism and pessimism as mediators of the relations between self-discrepancies and distress among Asian and European Americans. Journal of Counseling Psychology, 52, 25-35.

Hardin, E. E., Weigold, I. K., Robitschek, C., \& Nixon, A. E. (2007). Self-discrepancy and distress: The role of Personal Growth Initiative. Journal of Counseling Psychology, 54, 86-92.

Heidrich, S. M. (1999). Self-discrepancy across the life span. Journal of Adult Development, 6, 119-130.

Heidrich, S. M., \& D’Amico, D. (1993). Physical and mental health relationships in the very old. Journal of Community Health Nursing, 10, 11-22.

Heidrich, S. M., Forsthoff, C. A., \& Ward, S. E. (1994). Adjustment to cancer: The self as mediator. Health Psychology, 13, 346-353.

Heidrich, S. M., \& Powwattana, A. (2004). Self-discrepancy and mental health in older women with chronic illnesses. Journal of Adult Development, 11, 251-259.

Heidrich, S. M., \& Ryff, C. D. (1993a). Physical and mental health in later life: The selfsystem as mediator. Psychology and Aging, 8, 327-338.

Heidrich, S. M., \& Ryff, C. D. (1993b). The role of social comparison processes in the psychological adaptation of elderly adults. Journal of Gerontology: Psychological Sciences, 48, 127-136.

Heidrich, S. M., \& Ward, S. E. (1992). The role of self in adjustment to cancer in elderly women. Oncology Nursing Forum, 19, 1491-1496.

Heppen, J. B., \& Ogilvie, D. M. (2003). Predicting affect from global self-discrepancies: The dual role of the undesired self. Journal of Social and Clinical Psychology, 22, 347-368. 
Higgins, E. T. (1987). Self-discrepancy: A theory relating self and affect. Psychological Review, 94, 319-340.

Higgins, E. T. (1999). When do self-discrepancies have specific relations to emotions? The second generation question of Tangney, Niedenthal, Covert, and Barlow (1998). Journal of Personality and Social Psychology, 77, 1313-1317.

Higgins, E. T., Bond, R. N., Klein, R., \& Strauman, T. (1986). Self-discrepancies and emotional vulnerability: How magnitude, accessibility, and type of discrepancy influences affect. Journal of Personality and Social Psychology, 51, 5-15.

Higgins, E. T., Klein, R., \& Strauman, T. (1985). Self-concept discrepancy theory: A psychological model for distinguishing among different aspects of depression and anxiety. Social Cognition, 3, 51-76.

Hogstel, M. O., \& Curry, L. C. (1995). Ego integrity versus despair in the later year. Journal of Clinical Geropsychology, 1, 165-173.

Hoyle, R. H., \& Robinson, J. C. (2004). Mediated and moderated effects in social psychological research: Measurement, design, and analysis issues. In Carol Sansone, Carolyn C. Morf, \& A. T. Panter (Eds.), The Sage Handbook of Methods in Social Psychology (pp. 213-233). Thousand Oaks, CA: Sage Publications.

Hu, L. T., \& Bentler, P. M. (1999). Cutoff criteria for fit indexes in covariance structure analysis: Conventional criteria versus new alternatives. Structural Equation Modeling, 6, 1-55.

Jahoda, M. (1958). Current concepts of positive mental health. New York: Basic Books.

James, J. B., \& Zarrett, N. (2005). Ego integrity in the lives of older women: A follow-up of mothers from the Sears, Maccoby, and Levin (1951) patterns of child rearing study. Journal of Adult Development, 12, 155-167.

Jopp, D., \& Smith, J. (2006). Resources and life-management strategies as determinants of successful aging: On the protective effect of Selection, Optimization, and Compensation. Psychology and Aging, 21, 253-265.

Katz, S. (1983). Assessing self-maintenance: Activities of daily living, mobility, and instrumental activities of daily living. Journal of the American Geriatrics Society, 31, 721-726.

Keyes, C. L. M. (1998). Social well-being. Social Psychology Quarterly, 61, 121-140.

Keyes, C. L. M. (2002). The mental health continuum: From languishing to flourishing in life. Journal of Health and Social Behavior, 43, 207-222 
Keyes, C. L. M. (2003). Complete mental health: An agenda for the $21^{\text {st }}$ century. In Corey L. M. Keyes \& Jonathan Haidt (Eds.), Flourishing: Positive psychology and the life well-lived (pp. 3-12). Washington, DC: American Psychological Association.

Keyes, C. L. M. (2004). The nexus of cardiovascular disease and depression revisited: The complete mental health perspective and the moderating role of age and gender. Aging \& Mental Health, 8, 266-274.

Keyes, C. L. M. (2005a). Gender and subjective well-being in the United States: From subjective well-being to complete mental health. In K. V. Oxington (Ed.), Psychology of Stress (pp. 1-15). New York: Nova Biomedical Books.

Keyes, C. L. M. (2005b). Mental illness and/or mental health? Investigating axioms of the complete state model of health. Journal of Consulting and Clinical Psychology, 73, 539-548.

Keyes, C. L. M. (2005c). Chronic physical disease and aging: Is mental health a potential protective factor? Ageing International, 30, 88-104.

Keyes, C. L. M. (2007). Promoting and Protecting Mental Health as Flourishing: A Complementary Strategy for Improving National Mental Health. American Psychologist, 62, 95-108.

Keyes, C. L. M., \& Ryff, C. D. (1999). Psychological well-being in midlife. In S. L. Willis \& J. D. Reid (Eds.), Middle aging development in the third quarter of life (pp. 161-180). Orlando, FL: Academic Press.

Keyes, C. L. M., Shmotkin, D., \& Ryff, C. D. (2002). Optimizing well-being: The empirical encounter of two traditions. Journal of Personality and Social Psychology, 82, 1007-1022.

Keyes, C. L. M., \& Waterman, M. B. (2003). Dimensions of well-being and mental health in adulthood. In M. Bornstein, L. Davidson, C. L. M. Keyes, \& K. A. Moore (Eds.), Well-being: Positive development throughout the life course (pp. 481-501). Mahwah, NJ: Erlbaum.

Kivnick, H. Q. (1993). Everyday mental health: A guide to assessing life strengths. Generations, 17, 13-20.

Kline, R. B. (2005). Principles and practice of structural equation modeling ( $2^{\text {nd }}$ ed.). New York: Guilford Press.

Krause, N. (1997). Anticipated support, received support, and economic stress among older adults. Journal of Gerontology: Psychological Sciences, 52B, P284-P293. 
Labouvie-Vief, G. (2003). Dynamic integration: Affect, cognition, and the self in adulthood. Current Directions in Psychological Science, 12, 201-206.

Labouvie-Vief, G. (2004). Self-with-other representations and the organization of the self. Journal of Research in Personality, 39, 185-205.

Labouvie-Vief, G., Chiodo, L. M., \& Goguen, L. A. (1995). Representation of self across the life span. Psychology and Aging, 10, 404-415.

Lawton, M. P., \& Brody, E. M. (1969). Assessment of older people: Self-maintaining and instrumental activities of daily living. Gerontologist, 9, 179-186.

Levinson, D. J., Darrow, C. N., \& Klein, E. B. (1978). Seasons of a man's life. New York: Random House.

Liang, J., Bennett, J., Whitlaw, N., Maeda, D. (1991). The structure of self-reported physical health among the aged in the United States and Japan. Medical Care, 29, 1161-1180.

Liang, J., Shaw, B. A., Krause, N. M., Bennett, J. M., Blaum, C., Kobayashi, E., Fukaya, Ta., Sugihara, Y., \& Sugisawa, H. (2003). Changes in functional status among older adults in Japan: Successful and usual aging. Psychology and Aging, 18, 684695.

Loevinger, J. (1997). Stages of personality development. In R. Hogan \& J. A. Johnson (Eds.), Handbook of personality psychology. St. Louis: Washington University, Department of Psychology.

Logan, R. D. (1986). A reconceptualization of Erikson's theory: The repetition of existential and instrumental themes. Human Development, 29, 125-136.

Lowis, M. J. (1989). Ego integrity or despair: A study of elderly men. Unpublished Master's thesis, Rand Afrikaans University, Johannesburg.

MacKinnon, D. P. (2000). Contrasts in multiple mediator models. In J. Rose, L. Chassin,, C. C. Presson, \& S. J. Sherman (Eds.), Multivariate applications in substance use research: New methods for new questions (pp. 141-160). Mahwah, NJ: Erlbaum.

MacKinnon, D. P., Lockwood, C. M., Hoffman, J. M., West, S. G., \& Sheets, V. (2002). A comparison of methods to test mediation and other intervening variable effects. Psychological Methods, 7, 83-104.

Maslow, A. H. (1943). A theory of human motivation. Psychological Review, 50, 370396. 
McDonald, R. P., \& Ho, M. R. (2002). Principles and practice in reporting structural equation analyses. Psychological Methods, 7, 64-82.

McGregor, I., \& Little, B. R. (1998). Personal projects, happiness, and meaning: On doing well and being yourself. Journal of Personality and Social Psychology, 74, 494-512.

Miller, W. R., \& Rollnick, S. (2002). Motivational interviewing: Preparing people for change. New York: The Guilford Press.

Mossey, J. M., \& Shapiro, E. (1982). Self-rated health: A predictor of mortality among the elderly. American Journal of Public Health, 72, 800-808.

National Institute of Mental Health. (2006). Mental health for a lifetime: Research for the mental health needs of older Americans. Retrieved on September 20, 2006, from http://www.nimh.nih.gov/council/agingreport.cfm

Nehrke, M. F., Bellucci, G., Gabriel, S. J. (1978). Death anxiety, locus of control and life satisfaction in the elderly: Toward a definition of ego-integrity. Omega, 8, 19771978.

Nehrke, M. F., Hulicka, I. M., Morganti, J. B. (1980). Age differences in life satisfaction, locus of control, and self-concept. International Journal of Aging and Human Development, 11, 25-33.

Ogilvie, D. M., \& Clark, M. D. (1992). The best and worst of it: Age and sex differences in self-discrepancy research. In R. P. Lipka \& T. M. Brinthaupt (Eds.), Selfperspectives across the life span (pp. 186-222). Albany, NY: State University of New York Press.

Petrocelli, J. V., \& Smith, E. R. (2005). Who I am, who we are, and why: Links between emotions and casual attributions for self- and group discrepancies. Personality and Social Psychological Bulletin, 31, 1628-1642.

Phillips, A. G., \& Silvia, P. J. (2005). Self-awareness and the emotional consequences of self-discrepancies. Personality and Social Psychology Bulletin, 31, 703-713.

Prochaska, J. O., \& DiClemente, C. C. (1982). Transtheoretical therapy: Toward a more integrative model of change. Psychotherapy: Theory, Research, and Practice, 19, 276-288.

Ranzijn, R., \& Luszcz, M. (1999). Acceptance: A key to well-being in older adults? Australian Psychologist, 34, 94-98. 
Reddy, S. K. (1992). Effects of ignoring correlated measurement error in structural equation models. Educational and Psychological Measurement, 52, 549-570.

Robitschek, C. (1998). Personal growth initiative: The construct and its measure. Measurement and Evaluation in Counseling and Development, 30, 183-198.

Robitschek, C. (1999). Further validation of the Personal Growth Initiative Scale. Measurement and Evaluation in Counseling and Development, 31, 197-210.

Robitschek, C. (2003). Validity of Personal Growth Initiative Scale scores with a Mexican American college student population. Journal of Counseling Psychology, 50, 496-502.

Robitschek, C., \& Cook, S. W. (1999). The influence of personal growth initiative and coping styles on career exploration and vocational identity. Journal of Vocational Behavior, 54, 127-141.

Robitschek, C., \& Kashubeck, S. (1999). A structural model of parental alcoholism, family functioning, and psychological health: The mediating effects of hardiness and personal growth orientation. Journal of Counseling Psychology, 46, 159-172.

Robitschek, C., \& Keyes, C. L. M. (2006). Towards understanding mental health: The role of personal growth initiative, social support, and valuing mental health. Unpublished manuscript.

Rogers, C. R. (1961). On becoming a person. Boston: Houghton Mifflin.

Rowe, J. W., \& Kahn, R. L. (1997). Successful aging. Gerontologist, 37, 433-440.

Ryan, R. M., \& Deci, E. L. (2001). On happiness and human potentials: A review of research on hedonic and eudaimonic well-being. Annual Review of Psychology, $52,141-166$.

Ryff, C. D. (1989). Happiness is everything, or is it? Explorations on the meaning of psychological well-being. Journal of Personality and Social Psychology, 57, 1069-1081.

Ryff, C. D. (1991). Possible selves in adulthood and old age: A tale of shifting horizons. Psychology and Aging, 6, 286-295.

Ryff, C. D., \& Heincke, S. G. (1983). Subjective organization of personality in adulthood and aging. Journal of Personality and Social Psychology, 57, 1069-1081.

Ryff, C. D., \& Keyes, C. L. M. (1995). The structure of psychological well-being revisited. Journal of Personality and Social Psychology, 69, 719-727. 
Ryff, C. D., \& Singer, B. (1998). The contours of positive human health. Psychological Inquiry, 9, 1-28.

Rylands, K. J., \& Rickwood, D. J. (2001). Ego-integrity versus ego-despair: The effect of "accepting the past" on depression in older women. International Journal of Aging and Human Development, 53, 75-86.

Sambamoorthi, U., Olfson, M.., Wei, W., Crystal, S. (2006). Diabetes and depression care among Medicaid beneficiaries. Journal of Health Care for the Poor and Underserved, 17, 141-161.

Santor, D. A., \& Zuroff, D. C. (1994). Depressive symptoms: Effects of negative affectivity and failing to accept the past. Journal of Personality Assessment, 63, 294-312.

Satorra, A., \& Bentler, P. M. (2001). A scaled difference chi-square test statistic for moment structure analysis. Psychometrika, 66, 507-514.

Saxena, S., van Ommeren, M., Tang, K. C., \& Armstrong, T. P. (2005). Mental health benefits of physical activity. Journal of Mental Health, 14, 445-451.

Siegel, M., Bradley, E. H., \& Kasl, S. V. (2003). Self-rated life expectancy as a predictor of mortality: Evidence from the HRS and AHEAD Surveys. Genrontology, 49, 265-271.

Smith, M. B. (1959). Research strategies toward a conception of positive mental health. American Psychologist, 14, 673-681.

Spering, C. (2008). Validity of Personal Growth Initiative Scores in Older Adults. Unpublished manuscript.

Spering, C., Robitschek, C., \& Hoang, U. (2008, August). Predicting healthy behaviors in college students: Which constructs are most important? Poster to be presented at the American Psychological Association's Annual Conference. Boston, MA.

Strauman, T. J. (1997). Stability within the self: A longitudinal study of the structural implications of self-discrepancy theory. Journal of Personality and Social Psychology, 71, 1142-1153.

Tabachnick, B. G., \& Fidell, L. S. (2007). Using multivariate statistics $\left(5^{\text {th }}\right.$ ed.). Boston: Allyn and Bacon.

Taft, L. B., \& Nehrke, M. F. (1990). Reminiscence, life review, and ego integrity in nursing home residents. International Journal of Aging and Human Development, 30, 189-196. 
Tangney, J. P., Niedenthal, P. M., Covert, M. V., \& Barlow, D. H. (1998). Are shame and guilt related to distinct self-discrepancies? A test of Higgins's (1987) hypotheses. Journal of Personality and Social Psychology, 75, 256-268.

Tengland, P. A. (2001). Mental health: A philosophical analysis. London: Kluwer Academic Publishers.

Torges, C. M., Stewart, A. J., Miner-Rubino, K. (2005). Personality after the prime of life: Men and women coming to terms with regrets. Journal of Research in Personality, 39, 148-165.

U. S. Department of Health and Human Services. (1999). Mental health: A report of the Surgeon General. Rockville, MD: Author.

Valliant, G. E. (2002). Aging well: Surprising guideposts to a happier life. Boston: Little, Brown.

Van der Kooy, K. G., Van Hout, H. P. J., Van Marwijk, H. W. J., De Haan, M., Stehouwer, C. D. A., Beekman, A. T. F. (2006). Differences in heart rate variability between depressed and non-depressed elderly. International Journal of Geriatric Psychiatry, 21, 147-150.

Vandervoort, D. J., \& Skorikov, V. B. (2002). Physical health and social network characteristics as determinants of mental health across cultures. Current Psychology, 21, 50-68.

Waterman, A. S. (1993). Two conceptions of happiness: Contrasts of personal expressiveness (eudaimonia) and hedonic enjoyment. Journal of Personality and Social Psychology, 64, 678-691.

Whisman, M. A., Uebelacker, L. A., Tolejko, N., Chatav, Y., \& McKelvie, M. (2006). Marital discord and well-being in older adults: Is the association confounded by personality. Psychology and Aging, 21, 626-631.

Whitbourne, S. K., Zuschlag, M. K., Elliot, L. B., \& Waterman, A. S. (1992). Psychosocial development in adulthood: A 22-year sequential study. Journal of Personality and Social Psychology, 63, 260-271.

World Health Organization. (1948). World Health Organization constitution. In Basic Documents. Geneva: Author.

World Health Organization. (2001a). Basic documents. 43rd Edition. Geneva, World Health Organization: 1. 
Texas Tech University, Chloe Uyen Hoang, August, 2009

World Health Organization. (2001b). Strengthening mental health promotion. Geneva, World Health Organization (Fact sheet, No. 220). 


\section{APPENDIX A}

\section{EXTENDED LITERATURE REVIEW}

Aging, a universal biological phenomenon, is an imminent part of life. For the first few decades of this century, many countries will witness a dramatic increase in the older adult population (Administration on Aging, 2006). In 2004, older Americans over age 65 were the fastest growing segment of society, comprising over $12 \%$ of the U.S. population, which is about one in every eight Americans (Federal Interagency Forum on Aging-Related Statistics, 2006). Currently, 36.3 million Americans are now over age sixty-five, and by 2030 that number will reach 71.5 million, representing nearly $20 \%$ of the total U.S. population and more than twice their number in 2004. These trends will continue to be magnified into the next century. By 2050 , the projected growth rate of the older population is estimated to reach nearly 85 million as more people are predicted to live past their 80s (Federal Interagency Forum on Aging-Related Statistics, 2006).

Two major forces were speculated to contribute to this trend (Butler, Lewis, Sunderland, 1998). First, the post-World War II Baby Boomers generation (those born between 1946 and 1964) is growing older. They will start turning 65 in 2011, and during the period 1990 to 2020 , the population of adults 65 to 74 is expected to increase by $74 \%$. Second, life expectancy has extended. People are living longer due to the advances in medicine (such as the discovery of antibiotics) and improvement in medical technology and treatment options for life threatening diseases. The meteoric rise in lifespan has led to an unprecedented increase in the number of older adults that presents opportunities for research along with new challenges to health care and social service systems. 
Despite the dramatic increase in the number of older adults in the coming years, there is a shortage of research, training centers, and mental health services to meet the needs and demands of the aging population. Specifically in recent years, the National Institute of Mental Health (NIMH) released a briefing addressing the low number of geriatric grant applications the organization received each year compared to other social science areas (NIMH, 2006). If the number of aging adults continues to rise and knowledge regarding their aging needs and concerns is lacking, then effective and efficient ways of improving older adults' quality of life will be compromised. Given the pressing needs to advance mental health research of older citizens, it is the overall objective of the present study to explore factors that contribute to mental health of optimal aging in later life.

\section{Benefits of Optimal Mental Health in Old Age}

Promoting optimal mental health in old age has several practical, economic, and aspirational benefits. From a practical perspective, mentally healthy aging adults are less likely to suffer from cognitive decline or to be physically sick, have higher levels of physical functioning, and recover quicker from physical ailments compared to mentally unhealthy older adults (Frazer, Leicht, \& Baker, 1996; Heidrich \& D’Amico, 1993; Saxena, van Ommeren, Tang, \& Armstrong, 2005; Vandervoort \& Skorikov, 2002). If having mental health is a protective factor buffering the effects of physiological and cognitive degeneration in older adults, then older adults are less likely to use federal health care systems (such as Medicare and long-term care programs), which in turn could protect the viability of Social Security and other federal pension systems (e.g., Prescription Drugs, Food Stamps) in the future from an economic viewpoint (Keyes, 
2004; Sambamoorthi, Olfson, Wei, \& Crystal, 2006; Van der Kooy, Van Hout, Van Marwijk, De Haan, Stehouwer, \& Beekman, 2006). Finally from an aspirational perspective, if older adults are physically and mentally healthy, they are more likely to engage in various social and recreational roles that enable them to continue flourish and enjoy their lives (Keyes, 2002, 2003). Given the overall general benefits of achieving mental health in old age, the current study attempts to understand how older adults manage to maintain positive emotions and psychological functioning (i.e., mental health) despite changes or declines in physical and cognitive health and functioning, losses of interpersonal relationships, and restriction in social roles and responsibilities (Baltes \& Baltes, 1990; Birren \& Renner, 1980).

\section{Historical and Evolving Theoretical Conceptions of Mental Health}

For the past century, much has been learned about the relation of mental health to overall health and well-being. As a construct, mental health is theoretically difficult to define due to its subjective and evaluative nature (Smith, 1959). In other words, it is subjected to many different interpretations that are based on various expectations and standards across cultures over time. Because of its conceptual complexity, there are various theoretical frameworks that have been used in the past to explain mental health. The most familiar perspective - that mental health is simply the absence of disease, illness, or abnormality - not surprisingly, derives from the psychiatric tradition (Tengland, 2001). As expected, psychiatry is dedicated to the understanding of mental illnesses/disorders, as evidenced in the series of DSM textbooks. Similar to psychiatry, psychoanalytic literature has made equivocal attempts to operationalize mental health. However, it seems that the psychoanalytic characterization of mental health is purely 
theoretical rather than empirical, which poses a challenge to researchers (Tengland, 2001). In order to exemplify this point, take Freud's (1961) claims as an example, which summarize mental health as the inner balance between the id, ego, and superego. Clearly, this definition is problematic in operationalizing mental health because it is based purely on theoretical grounds that are intrinsically obscure and difficult to grasp and is not based on either observable or measurable criteria. Without explicit, observable, and measurable characteristics defining mental health, the psychoanalytic framework falls short in guiding scientific research.

In comparison to the psychoanalytic perspective, humanistic theory is not only based on theory, but it also provides practical and more observable criteria for defining mental health. Several major themes that appear in Rogers' thinking about mental health are terms like growth or change, adaptation, autonomy, and self-esteem or worth (Rogers, 1961). Because of Rogers' practical view on mental health, several of his criteria were used as guidelines in developing research instruments to facilitate the assessment of outcomes in therapy. In concert with Rogers' criteria of defining mental health, Marie Jahoda's classic study Current Concepts of Positive Mental Health (1958) also identified themes or categories of mental health criteria. She proposed that there are six criteria of positive mental health: autonomy, environmental mastery, attitude toward self, perception of reality, personal growth and self-actualization, and integration of personality. Some of Jahoda's (1958) list of mental health criteria later appeared in contemporary literature on mental health, suggesting some degree of convergence in the operational definition of mental health (Ryff, 1989; Keyes 2002, 2003). 
As seen, there are many definitions of mental health. Despite the various conceptualization of mental health, there is one popular theoretical view of mental health that the World Health Organization mentioned, and that is "...it is not merely the absence of disease or infirmity,... [but] a state of well-being in which the individual realizes his or her own abilities, can cope with the normal stresses of life, can work productively and fruitfully, and is able to make a contribution to his or her community" (WHO 2001a, $2001 b$, p. 1). This popular definition of mental health implies that (a) mental health is multidimensional, and (b) mental health is based on the absence of mental illness/disease as well as the presence of positive emotions and psychosocial functioning.

\section{Keyes's Structure of Mental Health}

Although the definition of mental health is multidimensional and encompasses many indicators as many theoretical viewpoints suggested, mental health is often measured using a single indicator, such as a measure of life satisfaction (Heidrich \& Powwattana, 2004), positive and negative affects (Petrocelli \& Smith, 2005; Phillips \& Silvia, 2005), general level of happiness in life (Heidrich \& Powwattana, 2004), and anxiety and/or depression (Bruch, Rivet, \& Laurenti, 2000; Heidrich, Forsthoff, \& Ward, 1994; Heidrich \& Ryff, 1993a, 1993b). Rarely, mental health indicators are assessed multidimensionally or integratively. However, in recent year, using the most popular definition of mental health, Keyes (1998, 2002, 2003, 2005a; Keyes \& Waterman, 2003) provided clearly defined criteria and procedures for measuring what constitute wellbeing. He has compiled a list of $14^{\mathrm{a}}$ important indicators or diagnostic symptoms that enable researchers to consistently define and quantify individuals' level of mental health. 
Domains of Mental Health. Based on Keyes's (1998, 2002, 2003, 2005a) formulation of mental health, there are three important domains that represent mental health and each of the domains consists of specifically distinct indicators (i.e., diagnostic symptoms). The three important domains of mental health that Keyes proposed are emotional, psychological, and social well-being (see Figure 1), which resonate with the historical and current premises that mental health is an absence of mental illness in addition to the presence of positive feelings and positive psychosocial functioning (Baltes \& Baltes, 1990; Baltes et al., 1998; Erikson, 1959, 1980; Jahoda, 1958; Keyes, 2002; Ryff \& Singer, 1998; Smith, 1959; U.S. Department of Health and Human Services, 1999; World Health Organization, 1948, 2001a, 2001b).

Emotional well-being is defined as experiencing the presence of positive feelings of contentment and pleasure in one's life. The symptoms that characterize emotional well-being consist of: (1) happiness (i.e., the extent to which individuals generally feel content or happy about life); (2) life satisfaction (i.e., the extent to which individuals are satisfied with life overall or in specific areas); and (3) the balance of positive and negative affects (i.e., the extent to which individuals experience more positive feelings and fewer negative feelings; Keyes, 2003; Keyes \& Waterman, 2003).

Psychological well-being is described as how well one is functioning, adjusting, and adapting to personal life. The indicators that characterize the psychological wellbeing domain include: (1) autonomy (i.e., the degree to which individuals have the ability to be self-determined and make autonomous decisions in life free from the pressure or influence of others); (2) self-acceptance (i.e., the extent to which individuals have a positive evaluation of self); (3) environmental mastery (i.e., the extent to which 
individuals can handle their daily life demands and handle their unpredictable complex environments); (4) purpose in life (i.e., the extent to which individuals have meaning, direction, and goals in life); (5) personal growth (i.e., the extent to which individuals are feeling and sensing that they are developing and growing as a person); and (6) positive relations with others (i.e., the extent to which individuals have intimate, trusting, and satisfying relationships with others; Keyes \& Ryff, 1999; Ryff, 1989; Ryff \& Keyes, 1995).

Social well-being is explained as the degree to which one is functioning, adjusting, and adapting to the social aspects of life. It consists of five diagnostic symptoms: (1) social actualization (i.e., the extent to which individuals find society has a potential to evolve in a positive direction); (2) social acceptance (i.e., the extent to which individuals have a positive appraisal of or positive attitude toward others); (3) social coherence (i.e., the extent to which individuals find society has meaning or is predictable); (4) social integration (i.e., the extent to which individuals sense that they are a part of society or their community); and (5) social contribution (i.e., the extent to which individuals feel they have something important or of value to contribute to society; Keyes, 1998).

The Hedonic and Eudaimonic Perspectives. Keyes's (1998, 2002, 2003) conception of three principle domains of well-being derives from two philosophical perspectives, the hedonic and eudaimonic views (see Figure 1). These two philosophical views characterize two distinct components of mental health, which are individuals' perception and evaluation of their level of affective state (i.e., emotional well-being) and their level of psychosocial functioning (i.e., psychological and social well-being; Keyes, 
Shmotkin, \& Ryff, 2002; Keyes \& Waterman, 2003; Ryan \& Deci, 2001; Waterman, 1993). The hedonic viewpoint to defining mental health reflects the idea that well-being consists of experiencing happiness and pleasure, which resonates with the domain of emotional well-being (Waterman, 1993). In contrast, the eudaimonic viewpoint to defining mental health reflects the idea that well-being consists of realizing and fulfilling potentials individuals have set for themselves, which resonates with the domain of functional well-being (i.e., the psychological and social domain; Waterman, 1993). Consistent with historical and current views of mental health, Keyes claims that optimal well-being in the emotional, psychological, and social domains entails that individuals experience their life as satisfying and happy in the fulfillment of their potentials (i.e., the hedonic view) as well as finding the pursuit of their personal goals meaningful and consistent with their self-concept (i.e., the eudaimonic view; Baltes \& Baltes, 1990; Erikson, 1959, 1980; Keyes, Shmotkin, \& Ryff, 2002; Keyes \& Waterman, 2003; McGregor \& Little, 1998; Ryan \& Deci, 2001; Waterman, 1993).

Levels of Mental Health. Based on the hedonic and eudaimonic philosophical views of mental health (Waterman, 1993), Keyes (1998, 2002, 2003) has provided theoretical criteria as well as specific indicators that allow researchers to empirically and systematically define and measure mental health on three levels ranging from languishing to moderately mentally healthy to flourishing in life (Keyes, 2003, 2005b). Languishing in life is defined as a state in which individuals feel jaded with life in general, and there are feelings of ennui, emptiness, loss, and a lack of purpose or meaning. Individuals who are languishing in life can be viewed as lacking the feeling of positive emotions and not functioning well in personal and social life. In contrast, flourishing in life is defined as a 
state in which individuals have a drive or an enthusiasm for life in general, and there is the presence of determination, motivation, energy, and ambition to live life to the fullest. The life of flourishing individuals is filled with positive emotions and they function psychologically and socially well.

Overall, there are two approaches to assess these three levels of mental health: the categorical and continuous approach (Keyes, 2003, 2005b). The categorical method of diagnosing individuals' level of mental health can be summarized as assessing whether individuals score high or low on more than seven symptoms of the $14^{\mathrm{a}}$ total emotional, psychological, and social symptoms scales. If individuals score low on at least 1 out of 3 symptoms of emotional well-being and 6 out of 11 functional well-being symptoms, then individuals can be diagnosed as languishing in life. On the other hand, if individuals score high on at least 1 out of 3 symptoms of emotional well-being and 6 out of 11 functional well-being symptoms, then individuals can be diagnosed as flourishing in life. Individuals for whom scores are in the middle range, not too extreme to be diagnosed as either languishing or flourishing, can be considered to be moderately mentally healthy.

Individuals' level of mental health can also be assessed using the continuous approach, which can be computed by summing all scores of the emotional, psychological, and social well-being scales together (Keyes, 2003, 2005a). Compared to the categorical approach, the continuous approach of forming a composite index of mental health based on the languishing-flourishing continuum is not only simpler to perform, but the continuous scores are more useful in structural equation modeling since the statistical analysis requires scores on at least an interval measurement scale. Further, this method fits with the study's objective, which is to understand the extent to which factors 
contribute to the overall level rather than the specific indicators of mental health.

Therefore, the continuous approach was used in the present study to fit with the statistical criteria of structural equation modeling. Despite the different approaches in obtaining the levels of mental health, both the categorical and continuous approaches found that languishing individuals have poor psychosocial functioning, are at higher risk for mental illness, miss more days at work, and have lots of physical limitations in addition to chronic physical health problems such as cardiovascular disease compared to moderately mentally healthy and flourishing individuals (Keyes, 2002, 2004, 2005a, 2005b, 2005c).

Keyes' (2002, 2003, 2005a, 2005b) multidimensional description of mental health not only describes the domains of well-being that advance the understanding of optimal human experience and functioning, it has provided an operational definition that explains how the construct can be measured as well. Since Keyes' theoretical and operational formulation of mental health is newly constructed, there is very little known about whether or how mental health is related to successful aging; specifically, whether or how successful aging is related to the mental state of flourishing and languishing in the life of older adults.

\section{Mental Health in Older Adults in the Context of Successful Aging}

In the aging literature, mental health in older adults is often conceptualized from the life-span perspective as being the same as or an outcome of successful or optimal aging (Baltes \& Baltes, 1990; Erikson, 1959, 1980; Rowe \& Kahn, 1997). According to the life-span perspective, successful aging contains three components: the absence of disease, the presence of high psychosocial functioning, and active engagement with life (Baltes \& Baltes, 1990; Rowe \& Kahn, 1997). The first two of the basic components of 
successful aging are consistent with the theoretical and operational definition of mental health as previously mentioned (Jahoda, 1958; Keyes, 2002; Rowe \& Kahn, 1997; Ryff \& Singer, 1998; Smith, 1959; U.S. Department of Health and Human Services, 1999; WHO, 2001a, 2001b). Further, the final component of successful aging, which is active engagement with life, alludes to one of the indicators / components that other theorists (e.g., Jahoda, 1958; Rogers, 1961) have used to define mental health. As seen, the three components of successful aging share a high degree of convergent validity with the multidimensional definition and characteristics of mental health described above. Given the high degree of convergent validity between successful aging and mental health, two assumptions can be made: (1) the presence of mental health in old age reflects the sign of successful aging and (2) successful aging indicates the presence of mental health.

There are two well-accepted theoretical perspectives on life-span development that clearly articulate the importance of the absence of disease, the presence of high psychosocial functioning, and active engagement with life as keys to successful aging. These two theoretical perspectives are the Selection, Optimization, and Compensation (SOC) model (Baltes \& Baltes, 1990; Baltes, Lindenberger, \& Staudinger, 1998) and Erikson's $(1959,1980)$ concept of ego-integrity versus despair.

\section{The Selection, Optimization, and Compensation (SOC) Model}

According to Baltes and Baltes (1990; Baltes et al., 1998), because age-related losses and declines are imminent as older adults age, older adults must continue to engage in the pursuit of personally fulfilling goals and be flexible and adaptable when pursuing these goals in order to maintain or enhance mental health in late adulthood. This component of mental health and a core foundation of successful aging is the definition for 
the Selection, Optimization, and Compensation (SOC) model (Baltes \& Baltes, 1990; Baltes et al., 1998). The basic premises of successful aging or positive mental health stated in the SOC model are: (1) older adults' ability to limit and selectively choose personally relevant goals they want to perform as they age in the face of physiological constrains (i.e., Selection), (2) older adults' engagement in the pursuit of goals that allow them to maximize or optimize their current areas of potential growth (i.e., Optimization), and (3) older adults' ability to be adaptive and flexible in letting go of goals that are no longer obtainable and substitute them with goals that are (i.e., Compensation). From this perspective, mental health in old age suggests the interaction between inner psychological and outer social influences of knowing when and how to engage in personal growth. Further, the SOC model reinforces the view that the likelihood of successful aging depends on older adults' ability to engage and be flexible in growth opportunities in order to maintain a healthy emotional, psychological, and social lifestyle (Baltes \& Baltes, 1990; Baltes et al., 1998). As discussed, this idea of successful aging appears to (1) reflect the assertion that mental health is multidimensional and is consisted of emotional, psychological, and social well-being domains that exists in the literature (Keyes, 2002; Ryff \& Singer, 1998; U.S. Department of Health and Human Services, 1999; World Health Organization, 2001a, 2001b) and (2) resonate with the one of the three important components of successful aging, which is the active engagement with life (Baltes \& Baltes, 1990; Rowe \& Kahn, 1997).

Research Findings Regarding the SOC Model. In gerontology literature, the SOC model is often described as a life-management strategy older adults use to cope with losses and enhance development. In other words, individual or combined processes of the 
SOC strategies are conceptualized from the loss-gain proposition. From the perspective of loss regulation, previous research found that in the face of limited personal, cognitive, health, and social resources, older adults who utilized the individual or combined SOC strategies experienced more positive features of growing older than those who did not use the SOC strategies (Jopp \& Smith, 2006). Further, for those who are high in resources, using or not using the SOC strategies had no effect on their well-being and satisfaction with aging. Findings from this study regarding loss regulation appear to suggest that the SOC strategies are a protective mechanism that is beneficial and important for older adults who have restricted resources, but has no effect on those who have unlimited resources. From the perspective of gain regulation, previous research also found that the SOC strategies are important at enhancing personal growth for older adults who are restricted in resources, but not for those who are plentiful in resources (Jopp \& Smith, 2006). Specifically, those with limited resources who utilized the Optimization strategy reported higher well-being and greater satisfaction with aging than those with limited resources who did not utilize the Optimization strategy. Research findings in support of the loss-gain regulatory system of the SOC strategies appear to imply that older adults who continue to engage in growth opportunities in the face of losses by utilizing the SOC strategies are more likely to have higher well-being and greater satisfaction with aging than those who do not use or are low in using the SOC strategies.

Research also found the SOC strategies to be predictive of subjective indicators of successful aging across all age groups (i.e., young, middle, and older adults). Specifically, a high engagement in the SOC strategies, in general, was linked to high levels of satisfaction with aging, emotional well-being, and psychosocial functioning 
(Freund \& Baltes, 1998, 1999). Further, these findings remain the same after controlling for age, subjective physical and mental health, intelligence, the Big Five personality variables, control beliefs, and personal life investment (Freund \& Baltes, 1998, 1999). Although there were no age-related differences in the positive correlations between the engagement in the SOC strategies and global subjective well-being, agerelated differences were observed in the extent of the engagement in the SOC strategies. Specifically, research found that as individuals age, the tendency to engage in the SOC strategies declines, even after controlling for physical health (Freund \& Baltes, 1998, 1999). Freund and Baltes explained that engaging in the SOC strategies require effortful behaviors and internal resources. However, because age-related decline in cognitive and sensorimotor functioning increases with age, engaging in the SOC strategies becomes difficult and limited. This explanation seems to suggest that it is age-associated mental decline (e.g., the impairment in executive functioning, sensorimotor abilities, and memory) and not the decline in physical health that interferes with the engagement in the SOC strategies and the pursuit of goals.

\section{Erikson's Ego-Integrity versus Despair Concept}

In addition to Baltes and Baltes's (1990; Baltes et al., 1998) Selection, Optimization, and Compensation (SOC) model of successful aging, Erikson (1959, 1980) also defined successful aging from the life-span perspective in the last stage called egointegrity versus despair. As a life-span theorist, Erikson $(1959,1980)$ stated that successful aging is a developmental process that consists of the interplay between the individual and society. Erikson $(1959,1980)$ viewed that individuals proceed through a series of eight different stages of the life cycle from childhood to old age and must 
overcome a crisis or a conflict of each stage in their social environment in order to experience the psychosocial strength of that stage. The psychosocial strength of a particular stage Erikson $(1959,1980)$ mentioned suggests the presence of mental health or well-being if individuals are able to successfully resolve the struggles of that particular stage.

Erikson's Stages of Psychosocial Development. Erikson's eight stages of psychosocial development can be categorized in three life periods -- infancy and childhood, adolescence, and adulthood (Erikson, 1959, 1980). Stages one to four occur in infancy and childhood during the first year of life through elementary school children up to age 12. Stage five occurs in adolescence between ages 13 and 19. Finally, stages six to eight occur in young adulthood between ages 20 to 40 through late adulthood in ages above 65 .

In infancy (estimated to occur during the first year of life), infants pass through the first stage called trust versus mistrust. Trust is established when an infant's biological needs are met by responsive, sensitive, and caring parents. Mistrust results when an infant's needs are not met and satisfied.

In early childhood (estimated to occur from ages 1 to 3 ), toddlers pass through the second stage called autonomy versus shame and doubt. Autonomy is achieved when parents encourage and foster toddlers' curiosity, exploration, and expression. Shame and doubt develop when parents restrain the toddlers' natural curiosity, exploration, and expression and exercise harsh punishment when disciplining them.

In play age (estimated to occur from ages 3 to 5), preschool children pass through the third stage called initiative versus guilt. During this age, children begin to imitate 
adults' roles and can assume responsibility through play and games. When parents cultivate the children's inventiveness and resourcefulness, they develop a sense of initiative. However, if parents discourage and criticize their children for using their imagination and take away their freedom to play and use their initiative, then children develop guilt feelings.

In school age (estimated to occur from ages 6 to 12), elementary school children pass through the fourth stage called industry versus inferiority. A sense of industriousness develops when children experience success from using the skills learned, and a sense of inferiority develops when children experience failure in learning and using the skills valued by society.

In adolescence (estimated to occur from ages 13 to 19), individuals go through the fifth stage called identity versus role confusion. When adolescents are able to establish an integrated image of their self-concept, their beliefs, and their personal potentials, a sense of their identity is developed; whereas failure to form an identity or self-concept results in role confusion.

In young adulthood (estimated to occur from ages 20 to 40), individuals navigate through the sixth stage called intimacy versus isolation. During this stage, intimacy is formed when young adults are able to create deep, intimate, and meaningful relationships with others and a sense of isolation results when young adults fail to form intimacy in relationships.

In middle adulthood (estimated to occur from ages 40 to 65), adults undergo the seventh stage called generativity versus stagnation. To achieve generativity, middle-aged adults seek to guide and contribute to the welfare of the next generation. A sense of 
stagnation results when middle-aged adults feel that they have nothing valuable or worthwhile to contribute to the next generation.

In late adulthood (estimated to occur after age 65), older adults proceed through the eighth stage called ego integrity versus despair, in which individuals are confronted with end of life issues and they begin to evaluate and reflect on their past life experiences (Erikson, 1959, 1980). Individuals who favorably resolve their past and current conflicts/crises at this eighth stage experience ego-integrity and wisdom is achieved; whereas, those who unsuccessfully resolved their past and present conflicts/crises or have negative responses to old age experience despair and wisdom is less likely to be achieved. Successful aging is inferred when older adults experience these behavioral, emotional, and cognitive core characteristics of ego integrity: having self-acceptance, lacking death anxiety, accepting the past without regrets, having an integrated selfconcept, feeling content about the past, and developing positive relations with others, and feeling satisfied with current life (Erikson, 1959, 1980; Hamachek, 1990; Hogstel \& Curry, 1995; Santor \& Zuroff, 1994). In contrast, less successful aging is inferred when older adults experience these features of despair: experiencing death anxiety, feeling regrets about the past, not having an integrated self-concept, finding life dissatisfied, and not having positive relationships with others (Erikson, 1959, 1980; Hamachek, 1990; Hogstel \& Curry, 1995; Santor \& Zuroff, 1994).

In Erikson's former writing (1959), he believed that adverse outcomes of former stages of psychosocial development would result in an adverse prognosis for the latter stages. In other words, Erikson's (1959) early theory asserted that later crises cannot be successfully resolved unless earlier stages have been resolved successfully first. For 
instance, Erikson (1959) mentioned that failure to develop basic trust in stage one (trust versus mistrust) would result in the development of paranoid fear and various psychopathological symptoms such as a lasting sense of shame and doubt in stage two (autonomy versus shame). When Erikson's early theoretical standpoint was tested empirically, findings did confirm the view that lasting harm would be done in the later stages if conflicts in the earlier stages are not resolved successfully. Take stage eight of ego integrity versus despair of development as an example. Research results demonstrate that ego integrity cannot be experienced or formulated if individuals have not already succeeded with the earlier stages of intimacy and generativity (Neugarten, 1968; Renshon, 1980; Whitbourne \& Weinstock, 1979 as cited in Lowis, 1989).

Even though there is general support for this view, in Erikson's later writings (1980), he clarified this proposition that the outcome of later stages, in particular stage eight of ego integrity versus despair, “... is not predetermined or foreclosed by the way life has been lived up to this point" (Erikson, Erikson, \& Kivnick, 1986, p. 40). Rather, as long as individuals are able to remember, reflect, and accept earlier crises, conflicts, experiences, and memories as inevitably meaningful and without feelings of regret, dissatisfaction, and guilt, older adults still have the potential to experience ego integrity (Erikson, 1980). In other words, through the practice of "life review and reminiscence" and/or narrative therapy (Birren \& Cochran, 2001; Butler, 1963; Haber, 2006; Kivnick, 1993; Taft \& Nehrke, 1990), ego-integrity can be experienced. This clarification of his later perspective conveys the notion that ego integrity is a process of living in late adulthood (i.e., individuals' philosophy of life) rather than a goal, an achievement, or an outcome older adults seek to achieve in later life. Further, the idea of accepting the self, 
forming positive relationships with others, feeling satisfied with life in general (i.e., experiencing ego-integrity) articulates to the hedonic viewpoint of emotional well-being and the eudaimonic viewpoint of psychosocial well-being (Waterman, 1993) that are used to define multidimensional mental health (Keyes, 2002, 2003, 2005a, 2005b).

Other Life-Span Theories in Relation to Erikson's Theory of Psychosocial Development. In addition to Erikson's theory of psychosocial development, there are other life-span developmental theories that clarify the process of successful aging such as Logan (1986), Loevinger (1997), and Levinson (Levinson, Darrow, \& Klein, 1986).

Logan (1986) pointed out that the process of aging progresses through a sequential cycle in which individuals first develop trust, then achievement, and finally wholeness. Each stage reflects a process rather than a resolution that individuals face during the entire life cycle. Logan's first stage of trust resonates with Erikson's stages one, two, and six where individuals learn to trust self and others; Logan's second stage of achievement resonates with Erikson's stages three, four, and seven where individuals value the need to achieve and be recognized; and Logan's final stage of wholeness resonates with Erikson's stages five and eight where individuals reconcile their identity and accept who they are. Logan's analysis of wholeness echoes the idea of embracing the good, the bad, and the ugly sides of the self and accepting life experiences the way they are without regret, which are the main themes in Erikson's eighth stage of integrity versus despair. Logan's explanation of wholeness is also similar to Loevinger's (1997) final Integrated stage, where individuals reconcile their inner conflicts and renounce their disappointments and failures. Parallel to Logan (1986) and Loevinger (1997), Levinson (Levinson, Darrow, \& Klein, 1978) also clarified that late adulthood is similar to the winter season in which individuals reminisce 
about the past and reconcile their view of self and with others. Logan's (1986) concept of wholeness, Loevinger's (1997) concept of integration, and Levinson's (Levinson, Darrow, \& Klein, 1986) concept of late adulthood are similar to Maslow's (1943) selfactualization concept, in which individuals accept the reality of life as well as of who they are and appreciate the life they have thus far.

Research Findings and Hypotheses Regarding Ego-Integrity. Critical to the experience of ego-integrity and an antecedent of mental health, according to Erikson $(1959,1980)$, is the integration of conflicting self-concept. This idea of the integrated self-concept as a component of mental health was also articulated in Rogers's (1961) and Jahoda's (1958) writings as previously discussed. Based on Erikson's (1959, 1980) writings, the presence of ego-integrity is a sign of successful aging and a sign of mental health in late adulthood. Specifically, he defined successful aging / mental health in old age as the absence of mental illness (e.g., despair, death anxiety) and the presence of positive affects (e.g., contentment, satisfaction) and psychosocial functioning (e.g., selfacceptance, positive relations with others). Note that Erikson's definition of mental health / successful aging reflects the theoretical consensus of what mental health is (Jahoda, 1958; Keyes, 2002; Rogers, 1961; Ryff \& Singer, 1998; Smith, 1959; U.S. Department of Health and Human Services, 1999; World Health Organization, 1948, 2001a, 2001b).

From a theoretical rationale, Erikson's $(1959,1980)$ idea of ego-integrity should predict mental health, a sign of successful aging, as formerly discussed. When empirical evidence was examined, previous research demonstrated that ego integrity and despair are predictive of general concepts of subjective and psychological well-being. Generally, evidence from ego-integrity literature indicates that experiencing ego-integrity in old age 
was associated positively with higher psychological well-being, higher positive emotions, and lower levels of depression and negative affectivity (Boylin, Gordon, \& Nehrke, 1976; Hogstel \& Curry, 1995; James \& Zarrett, 2005; Ranzijn \& Luszcz, 1999; Rylands \& Rickwood, 2001; Santor \& Zuroff, 1994; Torges, Stewart, \& Miner-Rubino, 2005). However, in past literature, measures of death anxiety, life satisfaction, self-acceptance, reminiscence, locus of control, and acceptance of the past are usually employed to define and measure subsets of ego-integrity features (see Boylin, Gordon, \& Nehrke, 1976; Domino \& Hanna, 1989; Nehrke, Bellucci, \& Gabriel, 1978; Nehrke, Hulicka, \& Morganti, 1980; Ranzijn \& Luszcz, 1999; Ryff \& Heincke, 1983; Torges, Stewart, \& Miner-Rubino, 2005; Taft \& Nehrke, 1990; Whitbourne, Zuschlag, Elliot, \& Waterman, 1992). Therefore, ego integrity was defined and measured in a limited way, possessing only certain core features of ego-integrity, as measured by the instruments the researchers selected. If ego integrity is defined as encompassing a broad array of behavioral, emotional, and cognitive characteristics, using only certain measures to define and measure a subset of ego integrity features may insufficiently capture, perhaps even obscure, Erikson's conception of ego-integrity, which in turn may lead to the problem of construct under-representation. Because previous literature has not examined egointegrity broadly and the extent to which ego-integrity influences the multidimensional definition of mental health, the current study attempted to fill in this gap by employing a psychometrically established measure of ego integrity (Ryff \& Heincke, 1983) that globally assesses all salient behavioral, emotional, and cognitive features of ego integrity to predict multidimensional mental health in older adults. 


\section{Predictors of Ego-Integrity and Mental Health}

Ego-integrity undoubtedly predicts mental health as suggested by its theoretical propositions and previous research (Boylin, Gordon, \& Nehrke, 1976; Erikson, 1959, 1980; Hogstel \& Curry, 1995; James \& Zarrett, 2005; Ranzijn \& Luszcz, 1999; Rylands \& Rickwood, 2001; Santor \& Zuroff, 1994; Torges, Stewart, \& Miner-Rubino, 2005). If experiencing ego-integrity is conducive to or synonymous with mental health or successful aging in late adulthood, what influences ego-integrity then? Note that because ego-integrity is a personality construct and mental health is inherently an evaluative concept influenced by individuals' perceptions and intrapersonal characteristics (Smith, 1959), intrapersonal rather than interpersonal factors may have the explanatory and predictive power explaining this inquiry. In particular, the internal processes of selfdiscrepancy (Higgins, 1987) and personal growth initiative (Robitschek, 1998, 1999, 2003) are of particular interest since they may be consistent with the meaning of successful aging and the presence of mental health from the life-span perspectives of Erikson's $(1959,1980)$ ego integrity and the SOC model (Baltes \& Baltes, 1990; Baltes et al., 1998) as discussed next.

In Erikson's ego-integrity as a mechanism that influences successful adaptation in old age, he highlighted an integrated sense of self as important to the experience of egointegrity and an indicator of mental health. This integrated self-concept consisted of bridging the gap among the different aspects of the self and of accepting experiences that cannot be changed in the past. As conceptualized, consistent self-concept is important in maintaining or enhancing mental health in old age and a crucial prerequisite for egointegrity. From this rationale, representation of the self-concept, specifically self- 
discrepancy (Higgins, 1987), appears to predict ego-integrity, which in turn predicts mental health in old age.

The second mechanism that explains successful aging and mental health in old age is the SOC model (Baltes and Baltes, 1990; Baltes et al., 1998). The main premise in the SOC model is that successful aging requires intentional and active engagement in the pursuit of personally meaningful goals as older adults age. This idea of continued personal growth suggests that personal growth initiative (PGI; Robitschek, 1998) may be an intrapersonal variable that explains the experiences of ego-integrity and mental health in old age. Specifically, as older adults intentionally seek out growth opportunities to improve the self and understand their life, they are more likely to experience egointegrity, which in turn would likely predict mental health. From this rationale, PGI appears to predict ego-integrity, which in turn predicts mental health in old age. Based on Erikson's (1959, 1980) ego-integrity concept and Baltes and Baltes'(1990, Baltes et al., 1998) SOC model, self-discrepancy and personal growth initiative may function as predictors of ego-integrity and mental health in late adulthood; hence, these intrapersonal factors were examined in the study.

\section{Self-Discrepancy Predicting Ego-Integrity and Mental Health}

Historical and current literature pertaining to the self generally has illustrated that conflicting and unintegrated self views can lead to psychological conflicts and emotional distress (Freud, 1961; Higgins, 1987; Rogers, 1961); whereas an organized, coherent and integrated pattern of the self is related to emotional and psychological health (Freud, 1961; Higgins, 1987; Rogers, 1961). In Freud's (1961) writing, he theorized that psychological health occurs when there is a differentiated ego from the id and the 
superego. A differentiated ego is an indication of a healthy and mature self since it is able to resolve conflicts between internal instinctual urges (i.e., the id) and external societal demands (i.e., the superego). Freud (1961) explained that individuals with a differentiated ego have a flexible range of healthy, adaptive defense mechanisms that allow them to cope effectively in stressful situations as well as allow them to transform repressed, undesired wishes into activities that promote successful adjustment to life. As for Rogers (1961), he believed that incongruent self-concept between the actual and ideal selves is the explanation for psychopathology. To Rogers (1961), characteristics of a mentally healthy person are someone who has a congruent actual and ideal self-concept and is capable of self-acceptance.

Self-Discrepancy from the Life-Span Perspective. In recent years, the study of self-representation was also examined from the life-span perspective. Specifically, Labouvie-Vief (2003, 2004; Labouvie-Vief, Chiodo, \& Goguen, 1995) demonstrated in her theory and research that self-representation regulates the affective and cognitive processes in her body of work called the dynamic-integration principle of optimization and differentiation / complexity. The dynamic-integration principle of optimization and differentiation / complexity emphasizes the integration of (1) the maximizing of positive affects and the minimizing of negative affects when interpreting life circumstances (defined as affect optimization) and (2) the ability to tolerate negative affects and objectively evaluate negative-valenced information (defined as affect differentiation / complexity). According to Labouvie-Vief, individuals with a differentiated and integrated self-representation are likely to have a high level of affect optimization and complexity. In other words, individuals with a differentiated and integrated self-representation are 
high in their ability to (a) focus on positive rather than negative affects, (b) tolerate negative affects, and (c) assess negative situations objectively. Further, these individuals are high in personal growth, positive affects, environmental mastery, relationship security, self-rated health and are low in negative affects. Note that these characteristics of an organized, coherent, and integrated sense of self that Labouvie-Vief described are similar to Keyes's (1998, 2002, 2003, 2005a) operational definitions of mental health that were discussed previously.

\section{Types and Consequences of Self-Discrepancy}

The concept of discrepant self-representation has a long history in the area of personality development. As discussed above, incompatible self-beliefs, known by many different terms in the literature, generally predict negative to psychological outcomes. Thus far, only self-discrepancy theory (Higgins, 1987) specifically explains the specific relationship between the different types of inconsistent self-representation as they relate to the specific negative psychological and affective outcomes. Because of the unique explanatory and predictive nature of self-discrepancy theory, it was used to guide the current research inquiry.

Higgins (1987) explained that individuals can experience different types of self discrepancy based on the combination of two factors: standpoints on the self and domains of the self. The standpoints on the self describe the viewpoint from which the self is to be evaluated: from one's own standpoint or from the standpoint of some other. On the other hand, the domains of the self describe three different types of self: (1) the actual self (described as the type of person one is currently, in the present time), (2) the ideal self 
(described as the type of person one hopes to be one day), and (3) the ought self (described as the type of person one is morally obligated to be).

Six types of self representation result from combining the two standpoints on and three domains of the self: actual/own (Who I am now), actual/other (Who someone else thinks that I am), ideal/own (Who I ideally want to be), ideal/other (Who someone else ideally wants me to be), ought/own (Who I should be), and ought/other (Who someone else thinks I should be) (Higgins, 1987). These six types of self-representation can further be divided into two categories: self-concept and self-guide. Self-concept is made up of the actual/own and actual/other self-representations, with the remaining four selfrepresentations (ideal/own, ideal/other, ought/own, and ought/other) making up an individual's self-guides (Higgins, 1987).

Higgins (1987) posited that discrepancies between self-concept (i.e., actual/own and actual/other) and self-guides (i.e., ideal/own, ideal/other, ought/own, and ought/other) lead to different types of negative affective states. He summarized his postulates as possessing the following characteristics: (1) the actual-ideal selfdiscrepancy is associated with the absence of positive outcomes, resulting in dejectionrelated emotions such as depression, disappointment, and loneliness; and (2) the actualought self-discrepancy is linked to the presence of negative outcomes, resulting in agitation-related emotions such as anxiety, worry, and fear.

Higgins (1987) proposed that the links between specific types of selfdiscrepancies and negative emotional outcomes are not equally active in every person; rather, the relations depend on four factors that constitute the self-regulatory significance of self-discrepancy: magnitude, accessibility, applicability, and importance (Higgins, 
1987, 1999). The magnitude of self-discrepancy is described as the degree of inconsistency between one's self-concept and self-guide. Accessibility of self-discrepancy is described as the likelihood a particular self-discrepancy is available to the individual. Applicability of self-discrepancy is described as how pertinent a particular type of selfdiscrepancy is to the current context. Importance of self-discrepancy is described as the extent to which possessing a domain of self is valuable to the individual. Overall, research (Higgins, 1987, 1999) has found that the greater the magnitude, accessibility, applicability, and importance of the self-discrepancy, the stronger the relation between self-discrepancies and negative emotional consequences.

Levels of Self-Discrepancy

In general, self-discrepancy exists on two levels - overall and in specific domains. Overall or global self-discrepancy measures the extent to which self-discrepancy is present in the individuals; whereas domain specific self-discrepancy measures the discrepant beliefs individuals have about the self in the different life domains such as career, relationship, and health. In Higgins's self-discrepancy theory (1987), incompatible beliefs about the self are often described and measured globally. In recent years, Heidrich (1999) proposed and found that when self-discrepancy is measured in specific life domains, inconsistent self-beliefs produce a general psychological discomfort similar to when self-discrepancy was measured globally. Approaches to Measuring Self-Discrepancy

The Verbal Method. There are overall three approaches to assessing global selfdiscrepancy: the idiographic trait-listing approach, the nomothetic trait-rating approach, and the spatial approach. The idiographic method of assessing global self-discrepancy 
involves using the original Selves Questionnaire (Higgins, Klein, \& Strauman, 1985). It entails having participants freely generate lists of attributes that describe their different domains of the self from the own and/or other's standpoint. After listing the attributes from the different self-representations, participants then rate the extent to which they or some important others believe they actually, ideally, or ought to possess each attribute listed using a 4-point rating scale ranging from 1 (slightly) to 4 (extremely). Selfdiscrepancy scores are computed by following two steps. The first step requires comparing attributes that describe one's self-concept to the attributes that describe one's self-guide to determine the degree of match and mismatch. Attributes are considered to be matched when both self-concept and self-guide listed the same or synonymous terms. Attributes are considered to be mismatched when both self-concept and self-guide listed the opposite or antonymous terms. For example, if the attribute "smart" was used to describe the actual self, then it would be considered a match to the attribute "intelligent" listed to describe the ideal self. Further, if the attribute "average" was used to describe one's actual self and the attribute "smart" was used to describe one's ideal self, then the attributes are considered to be a mismatch, indicating some degree of self-discrepancy. The second step requires comparing the extent ratings of the actual self to the ratings for the ideal or ought self. Attributes are considered to be a match if the point difference between the ratings for the actual self and the different self-guides differ by equal or less than 1. Attributes are considered to be a mismatch if the point difference in the rating differs by 2 or more. Extent ratings also allow the experimenter to make the distinction between "true" matches and "synonymous" mismatches (Higgins, 1987). A "true" match occurs when attributes are synonymous (e.g., smart and intelligent), and the difference in 
their ratings is equal to or less than 1 (e.g., smart is rated 4 and intelligent is rated 3). A "synonymous" mismatch occurs when attributes are synonymous, but the difference in their ratings is equal to or greater than 2 (e.g., smart is rated 4 and intelligent is rated 1). After attribute and extent ratings of matches and mismatches are determined, the self discrepancy score is calculated using a formula Higgins created (see Higgins 1987). In this process, the number of mismatches is added up, with true mismatches weighting more in magnitude than synonymous mismatches. Afterward, the difference between the total number of matches from the total number of mismatches for the two self-states is computed to yield a composite self-discrepancy score (i.e., the difference in the total number of matches and mismatches from the actual and ideal self or from the actual and ought self.

The second approach of assessing self-discrepancy is using the nomothetic method. The nomothetic method, developed by Tangney, Niedenthal, Covert, and Barlow (1998), involves providing participants with a list of experimenter-generated attributes for each self-state from two different standpoints on the self. Given the attribute list, participants are asked to rate the extent to which the attributes described a particular domain of the self. For example, participants are asked to rate the extent to which the attribute "intelligent" describes their actual, ideal, or ought self from their own standpoint and from the standpoint of some important other. Then, self-discrepancy scores are obtained by subtracting the sum of self-guides (i.e., the ideal or the ought self) from the sum of the self-concept (i.e., the actual self) for both the own and other's standpoint.

Both the idiographic and nomothetic methods have strengths and limitations inherent in their methodology. The idiographic method was regarded as having high 
construct validity and predictive power because it assesses discrepancies based on attributes that are personally important or accessible to participants (Higgins, 1987). Although the qualitative idiographic method of the Selves Questionnaire may have reasonable theoretical appeal, there are limitations as part of its methodological assessment from the participants' and researchers' viewpoints (Tangney et al., 1998). First, the idiographic method requires participants to generate new, distinct, and different attributes for each self-representation. This can become overtaxing and difficult to participants with limited working vocabulary or with memory retrieval problems, such as the elderly, which may result in participants providing identical lists of attributes of the self. Second, the idiographic method is very time-consuming for the researchers as it requires training raters to formulate rules about when attributes can be considered a match or mismatch. This is evidenced in the coding of the Selves Questionnaire.

The quantitative nomothetic measure of self-discrepancy addresses these limitations of the idiographic method; however, it too has limitations. First, beyond the economical advantage from the researcher's perspective of obtaining self-discrepancy scores, the nomothetic method may contain attributes not important or accessible to participants. Therefore, it may seriously miss attributes centrally salient to participants, which may underestimate the predictive power of discrepancy scores (Higgins, 1999). Second, past research using the nomothetic approach has failed to replicate the unique relationships between actual-ideal discrepancy and dejection-related emotions and between actual-ought discrepancy and agitation-related emotions as proposed by Higgins (1987; Higgins et al., 1985) using the idiographic approach. Often, the failure to replicate 
the results has been attributed to the problem rooted in employing the different methodological measurement (Higgins, 1999).

To address the criticisms of both idiographic and nomothetic methods, Hardin (2002; Hardin \& Leong, 2005) developed a self-discrepancy measure that combines the strengths of both methods. In Hardin's self-discrepancy measure, participants first generate attributes most important and accessible to them (as suggested by Higgins, 1987). Next, to provide assistance to participants for whom this task is difficult, participants are provided with an attribute list that they can use to complete or alter their self states. After participants complete their list of self-descriptors, they rate the extent to which they perceive a discrepancy between the actual self-concept and their different self-representations. Evidence for the validity of Hardin's method was supported in Hardin and Lakin (2007) in which the actual-ideal self-discrepancies predicted dejectionrelated emotions and actual-ought self-discrepancies predicted agitation-related emotions.

The Spatial Method. One unique characteristic of both the idiographic and nomothetic methods is that self-discrepancy is measured using a verbal task. Recently, there is another way to measure self-discrepancy that departs from the traditional verbal trait-based characterization of the self and it is called the spatial distance approach. To date, there are two measures that utilize this approach - the Marker Placement Task (MPT; Heppen \& Ogilvie, 2003) and the Self-Lines measure (Francis, Boldero, \& Sambell, 2006). In the MPT, instead of having participants describe or endorse their attributes, they simply make an explicit nonverbal spatial judgment of where their actual self-concept is in relation to the other self-guides. The task requires participants to place a circle sticker, representing their actual self, on a sheet of paper where a larger circle 
representing the ideal self, for example, is in the upper right corner of the page. The level of self-discrepancy is then assessed by measuring the physical distance between the actual self and the other self-guides such as the ideal self.

Followed the tradition of the spatial distance approach and combined with the idiographic method of the Selves Questionnaire, a new measure called the Self-Lines was constructed to measure self-discrepancy (Francis, Boldero, \& Sambell, 2006). Similar to the Selves Questionnaire, the Self-Lines measure asks participants to first list attributes of the ideal and ought self-guides that are cognitively important and accessible to them. This idiographic procedure is used in order to enhance the predictive validity of selfdiscrepancy on emotions. Next, on a separate sheet of paper that has a vertical bar for each attribute listed, participants copy one attribute to the upper end of each bar and then think of an opposite descriptor of this attribute and put it on the lower end of each bar. The justification for requiring participants to generate an antonym of each attribute listed for each self-standard is to have participant-determined attribute matches and mismatches rather than the raters using the thesaurus (Francis, Boldero, \& Sambell, 2006). This method is different from the Selves Questionnaire in that the Self-Lines measure eliminates the subjective aspect of determining synonyms and antonyms, a feature that was criticized as problematic and time consuming in the scoring of the Selves Questionnaire. Once the attribute and its opposite are listed at the ends of the vertical bar, participants are asked to designate a line on the bar to indicate the location of their actual, ideal, and ought selves. Scoring of the actual-ideal and actual-ought self-discrepancy are computed by first measuring the physical distance on the bar between the actual and ideal selves and between the actual and ought selves. Next, the length of actual-ideal self and 
actual-ought self measured for all attributes listed is averaged to yield a composite ideal and ought self-discrepancy score.

Approaches to Measuring Self-Discrepancy Used in the Current Study. In the current study, self-discrepancy was assessed globally and in specific domains that are important and accessible to the elderly. Global self-discrepancy was measured by the Marker Placement Task (MPT; Heppen \& Ogilvie, 2003, see Appendix H), which employs the spatial task, and domain-specific self-discrepancy was measured by the SelfDiscrepancy Scale (SDS; Heidrich, 1999; Heidrich, Forshoff, \& Ward, 1994, see Appendix I), which employs the nomothetic approach.

As a spatial task that measures self-discrepancy globally, there are advantages as well as less ideal features that are part of the MPT. One advantage of using the MPT is that it addresses the limitations of the idiographic approach as mentioned previously. The less ideal quality of using the MPT is that because of the state-dependent nature of the measure, Heppen and Ogilvie (2003) recommended a repeated measure strategy to "reduce recall biases of retrospective memory" (p. 354). They suggested that the MPT be assessed over a period of weeks and then be aggregated to yield an average selfdiscrepancy score. However, because the current study attempts to control for attrition rate in elderly participants, Heppen and Ogilvie's (2003) recommendation was not used.

There are several justifications for not using Heppen and Ogilvie's (2003) recommendation. One, given the evidence in Strauman's study (1997) that specific selfdescriptions of self-discrepancy vary over the life span (i.e., as individuals grow older), but the magnitude and type of self-discrepancy remain stable over a short period of time (e.g., such as two years), the magnitude of self-discrepancy as measured by the MPT is 
not expected to fluctuate dramatically day by day. Two, providing that the MPT is a spatial task measuring the magnitude of global self-discrepancy, slight changes in day-today mood should not drastically influence one's level of self-discrepancy.

To measure domain-specific self-discrepancy, the Self-Discrepancy Scale (SDS; Heidrich, 1999; Heidrich, Forshoff, \& Ward, 1994) was used. Although the SDS (Heidrich, 1999; Heidrich et al., 1994) employs the nomothetic method, it does not share the same limitations as the other nomothetic self-discrepancy measures. Unlike previous nomothetic methods of measuring self-discrepancy (Tangney et al., 1998), the SDS taps into dimensions, such as physical health, coping with growing older, and relationships with others, that are uniquely important and accessible to the concept of self in geriatric participants (Heidrich, 1999; Heidrich et al., 1994) rather than attributes that reflect a wide range of personality characteristics.

\section{Research Findings Regarding Self-Discrepancy}

In general, despite the different methodological measurements, empirical support for self-discrepancy theory's major postulates has been found using correlation and experimental designs with clinical and non-clinical samples. Overall, negative emotional outcomes resulting from discrepancies between the different self-states have been found (Alexander \& Higgins, 1993; Francis, Boldero, \& Sambell, 2006; Hardin \& Leong, 2005; Heppen \& Ogilvie, 2003; Higgins, 1987, 1999; Higgins, Bond, Klein, \& Strauman, 1986; Higgins, Klein, \& Strauman, 1985; Strauman, 1997; Tangney et al., 1998). Specifically, evidence supports that the presence of a high level of self-discrepancy is linked to symptoms of depression and anxiety. 
Because there is substantial evidence to suggest the ideal self is more important in the elderly than the ought self since the ideal self reflects a transcendental goal that older adults strive to attain whereas fulfilling the ought self may be dependent on physical demands or health status and is not as meaningful to this age group (Baltes \& Baltes, 1990; Dixon \& Baltes, 1986; Francis, Boldero, \& Sambell, 2006; Heidrich, 1999; Heidrich, Forsthoff, \& Ward, 1994; Heidrich \& Ward, 1992; Ogilvie \& Clark, 1992), only the actual-ideal self-discrepancy was examined. Finally, because empirical evidence indicates that physical health status is predictive of self-discrepancy, which in turn influences mental health (Heidrich \& Ward, 1992; Heidrich \& Powwattana, 2004) the current study also attempts to replicate this relationship.

Given that the presence of a high level of self-discrepancy predicts negative emotional outcomes, a number of studies have also examined and found that the absence or a low level of self-discrepancy predicts positive emotional states. For example, Higgins (1987) has found that the absence of actual-ideal discrepancy is related to feelings of happiness and satisfaction, whereas the absence of actual-ought discrepancy is related to feelings of calmness and security. Further, self-discrepancies were found to be negatively associated with optimism (Hardin \& Leong, 2005), associated with decreased positive affects of cheerfulness and tranquility (Hardin \& Lakin, 2007), and negatively related to general positive affects such as excited, enthusiastic, and proud (Hardin, Weigold, Robitschek, \& Nixon, 2007). Regardless of how self-discrepancy is measured, global self-discrepancy is associated with various indices of well-being and distress.

Research has also looked at the relationships among self-discrepancy, age, physical health status, and mental health from a developmental trajectory. In cross-sectional studies comparing younger, middle-aged, and older 
adults, actual-ideal self-discrepancy was found to decrease across age groups and not within an age group, and actual-ideal self-discrepancy was also found to be negatively related to psychological well-being in all three age groups (Heidrich, 1999; Heidrich, Forsthoff, \& Ward, 1994; Heidrich \& Ryff, 1993a, 1993b; Heidrich \& Ward, 1992; Ryff, 1991). One explanation for the decrease in actual-ideal self-discrepancy was because of the lowered ideal self assessments as individuals age; hence, the ideal self becomes more attainable. Perhaps another reason for the decrease in the ideal self toward late life is better explained by the SOC model (Baltes \& Baltes, 1990) of adjusting to old age. To compensate for physical and social losses, older adults selectively optimize areas or aspects of the self that are attainable; hence, the decrease in the ideal self that eventually led to the decrease in actual-ideal self-discrepancy.

Although actual-ideal self-discrepancy decreases with age; however, it increases as physical health problem increases. Specifically, findings reveal that for those with poorer physical health such as those with cancer, their level of actual-ideal selfdiscrepancy was greater than compared to those with better physical health (Heidrich \& Ward, 1992). In longitudinal studies, poorer physical health status was also found to be associated with greater actual-ideal self-discrepancy (Heidrich and Powwattana, 2004).

Several key points can be summarized and postulated from the aforementioned findings in self-discrepancy literature. One, ideal self-discrepancy is predictive of negative emotional distress as well as positive psychological outcomes. Two, ideal selfdiscrepancy decreases with age, but increases with poorer physical health status, which in turn is linked to lower well-being. Three, a low level of self-discrepancy indicates an 
integrated and consistent sense of self, and thus should predict the presence of egointegrity, which in turn is predictive of higher mental health.

\section{Hypotheses Regarding Self-Discrepancy in the Current Study}

Although these three key findings predicted (1) the antecedents of selfdiscrepancy and (2) the role of self-discrepancy in maintaining and enhancing mental health directly and indirectly, one major limitation existed in the studies' methodology and that is only certain aspect of mental health was measured. If mental health is defined as encompassing several symptoms of positive feelings and functioning (Keyes, 2002, 2003, 2005a), not measuring mental health multidimensionally may miss represent the theoretical definition of mental health in late adulthood. Hence, the current study sought to address this limitation by replicating the three previous key points using multidimensional assessments of mental health. More specifically, the current study tested these hypotheses: (1) the extent to which multidimensional mental health is influenced by the level of the ideal self-discrepancy, (2) whether the role of physical health status in maintaining or impairing mental health is largely due to the effects of self-discrepancy, and (3) whether having an integrated, consistent self-representation is linked to ego-integrity, which in turn is predictive of mental health.

\section{Personal Growth Initiative Predicting Ego-Integrity and Mental Health}

Central to the life-span developmental perspective of Erikson's $(1959,1980)$ theory of ego-integrity versus despair and Baltes and Baltes's (1990; Baltes et al., 1998) SOC model is the core assumption that development is a process that lasts a life time and growth / change does not stop when individuals reach late adulthood. Baltes and Baltes (1990; Baltes et al., 1998), in particular, stated in the SOC model that continued growth 
and development is essential to successful aging. Based on this argument, the inner strength of personal growth initiative (PGI; Robitschek, 1998) emerges as a potential personality variable that plays a role in older adults' ability to function, adjust, and adapt to emotional, psychological, and social demands. This idea of the continuous active engagement in growth opportunities also reflects one of the core components of successful aging mentioned in Rowe and Kahn's (1997) writing as well as in Roger's (1961) writing, in which he refers to as the concept of the general propensity for growing, changing, and optimizing some aspects of the self as the actualizing tendency. Further, the idea of being able to identify and utilize individuals' internal assets, resources, and strengths to pursue goals despite age-related losses in old age reiterates one of the important precepts of counseling, which is teaching individuals the skills needed for, or helping them employ their strengths in the pursuit of, a better, healthier, and more meaningful life (Gelso \& Fretz, 1992). The assumption is that once individuals are able to access and exercise their internal assets, resources, and strengths, they are more likely to live a flourishing life filled with high levels of mental health as evidenced in their ability to function, adjust, and adapt to emotional, psychological, and social demands. As individuals age, external resources such as physical and cognitive functional capacity decline (Federal Interagency Forum on Aging-Related Statistics, 2006). If external resources become scarce as individuals age and internal strengths of continued growth become especially viable to older adults' well-being (Baltes \& Baltes, 1990), then perhaps the inner strength of personal growth initiative (PGI; Robitschek, 1998) constitutes one core building block that is crucial to the promotion of mental health in late life. 
Definition of PGI. By definition, PGI describes the process of taking the initiative to actively and intentionally engage in growth opportunities to develop, change, and grow as a person (Robitschek, 1998, 1999). In order for PGI to be present, cognitive and behavioral components are required (Robitschek, 1998, 1999). The cognitive component refers to individuals' thought processes of valuing and having awareness and knowledge of the change process. The behavioral component describes the process of seizing growth opportunities and executing the actions necessary to implement self change and development.

Important to the definition of PGI is the concept that personal growth is a purposeful and intentional process rather than an outcome that results from unintentional behaviors (Robitschek, 1998, 1999), which makes Robitschek's (1998, 1999) conception of PGI theoretically distinct from Ryff's (1989; Ryff \& Keyes, 1995) conception of personal growth. In Ryff's (1989; Ryff \& Keyes, 1995) theory of personal growth, individuals are aware of the process of ongoing self growth and development; however, they are not necessarily intentionally engaging in the process. Even though both Robitschek's PGI (1998, 1999) and Ryff's personal growth (1989; Ryff \& Keyes, 1995) theories describe individuals' orientation toward personal growth (Robitschek \& Kashubeck, 1999), each theory portrays the process of personal growth dissimilarly, which in turn provides different implications for research and practice. Take growing older as an example. Individuals age no matter if they are intentionally engaging in the process or not (i.e., the process of Ryff's (1989; Ryff \& Keyes, 1995) personal growth). Hence, Ryff's (1989) personal growth cannot be taught in counseling because it is a natural part of human development. However, if older adults do not actively seize 
opportunities to grow and do not have the intrinsic motivation to intentionally engage in behaviors to change in order to become a better person or make life more meaningful (i.e., the process of Robitschek's $(1998,1999)$ PGI), their level of PGI could be improved in therapy.

Research Findings and Hypotheses Regarding PGI. To date, prior empirical research studies have found that PGI is a relatively stable construct and has no group differences based on ethnicity, age, or gender (Robitschek, 1998, 1999, 2003). In general, empirical data provide support that a higher level of PGI is related to greater positive affect or well-being (Hardin et al., 2007; Robitschek, 1998, 1999; 2003; Robitschek \& Keyes, 2006) and lower levels of distress or poor functioning (Hardin et al., 2007; Robitschek \& Kashubeck, 1999). Also, in the area of career development, having a high level of PGI was associated with more positive vocational outcomes (Robitschek \& Cook, 1999). In particular, college students with higher levels of PGI were more likely to engage in potential vocational environmental exploration and have a more crystallized vocational identity than students with lower levels of PGI (Robitschek \& Cook, 1999). The results suggest that individuals who are high in PGI have more positive vocational outcomes compared to those with low levels of PGI. The findings from these studies suggest that because individuals with high levels of PGI are more likely to actively seek out opportunities in areas in which they would like further development, they are more likely to experience positive vocational outcomes and an enhanced level of general wellbeing compared to those with low levels of PGI.

As stated previously, much of the literature on PGI has indicated that PGI is a strong correlate of psychological well-being and distress (Hardin et al., 2007; Robitschek, 
1998, 1999; 2003; Robitschek \& Kashubeck, 1999; Robitschek \& Keyes, 2006). For example, Robitschek and Kashubeck (1999) found that PGI is positively associated with Ryff's (1989) domains of psychological well-being such as satisfaction in life, selfacceptance, and positive relations with others. Similarly, PGI is found to have a positive relationship with general positive affects and a negative relationship with social anxiety and negative affects (Hardin et al., 2007). Although there is strong evidence to indicate that PGI is clearly related to distress and well-being, these findings exist predominantly in college student samples and is limited in the older adult population (Spering, 2008). Therefore, the present study seeks to empirically test the relationships between PGI and mental health in the aging population.

In addition to PGI being related to different aspects of well-being, PGI was also found to be related to self-discrepancy (Hardin et al., 2007). Specifically, Hardin and colleagues (2007) suggested that PGI was related to fewer negative affects, higher positive affects, and lower self-discrepancies. Further, individuals with higher levels of PGI were more likely to experience higher levels of positive affects because of their ability to recognize and resolve their self-discrepancies more quickly and successfully than individuals who are low in PGI. Given the evidence that PGI and self-discrepancy are related to mental health in that self-discrepancy partially mediates the relation between PGI and positive affects specifically (Hardin et al., 2007), the current study also sought to examine the specific influence of self-discrepancy in the mental health of older adults.

In addition to PGI relating to mental health and self-discrepancy as previously discussed, PGI may also relate to ego-integrity. The core principle of PGI is that 
continued growth is a desirable personality trait to possess since it allows individuals to capitalize on growth opportunities to constantly improve the self and to accomplish goals that are important and meaningful to the individuals (Robitschek, 1998, 1999, 2003). From this conceptualization, there seems to be a link between PGI and ego-integrity in that if older adults are high in PGI, then they are more likely to experience features of ego-integrity since the intentional and active engagement in growth opportunities allows them to resolve psychosocial struggles in late life successfully (Erikson, 1959, 1980). Although this theoretical argument appears valid, the relationship between PGI and egointegrity has not been empirically tested in the literature. Therefore, the current study sought to examine whether PGI is a significant predictor of ego-integrity in addition to being a significant predictor of self-discrepancy and mental health. The Proposed Model in the Current Study (see Figure 2)

The current study attempts to provide an integrated picture of mental health in older adults from the life-span perspective using structural equation modeling (SEM). The overarching goal of the study was to extend and confirm previous findings to test a model in which PGI and self-discrepancy directly and indirectly predict multidimensional mental health for both the total sample and the women only group. Since there are gender differences in the average longevity of older adults (Cavanaugh \& Blanchard-Fields, 2006) and previous research has found gender differences between PGI and other constructs such as assertiveness and expressiveness (see Robitschek \& Cook, 1999; Spering, 2008), the current study also attempted to examine gender differences in the proposed model. 


\section{Hypotheses Based on Erikson's Ego-Integrity versus Despair Concept. From the} life-span perspective of Erikson's $(1959,1980)$ and Baltes and Baltes (1990, Baltes et al., 1998), successful aging is a life-long process involving the continued engagement in growth opportunities and getting the inner life in order to experience a healthy emotional, psychological, and social life. More specifically, Erikson's $(1959,1980)$ concept of egointegrity outlined that an integrated sense of self (i.e., low levels of self-discrepancy) (a) is crucial to the development of a healthy emotional and psychosocial well-being (Boylin, Gordon, \& Nehrke, 1976; Hogstel \& Curry, 1995; James \& Zarrett, 2005; Ranzijn \& Luszcz, 1999; Rylands \& Rickwood, 2001; Santor \& Zuroff, 1994; Torges, Stewart, \& Miner-Rubino, 2005) and (b) may be a key requirement that is predictive of ego-integrity. In this sense, ego-integrity may serve as a mediator that explains how and why a relationship exists between self-discrepancy and mental health. For example, if older adults have inconsistent beliefs about their self-concept and have not been able to resolve these self-discrepancies (i.e., they have a high level of self-discrepancy), then they are less likely to accept themselves and the past, less likely to find life satisfying and meaningful, and less likely to adapt to dissatisfaction, regrets, and guilt; in other words, they are likely to have a low level of ego integrity. Having a low level of ego-integrity, in turn, would reduce their levels of emotional, psychological, and social well-being as well as make them more susceptible to live a languishing life (i.e., to have a low level of mental health). In contrast, if older adults do not have inconsistent beliefs about their selfconcept or if they do and have resolved these self-discrepancies successfully (i.e., they have a low level of self-discrepancy), then they are more likely to accept themselves and the past, more likely to find life satisfying and meaningful, and more likely to adapt to 
dissatisfaction and disappointment; in other words, they are more likely to have a high level of ego integrity. Having a high level of ego integrity, in turn, would enhance their levels of emotional, psychological, and social well-being in addition to making them more likely to live a flourishing life (i.e., to have a high level of mental health).

Hypotheses Based on the SOC Model. In addition to Erikson's $(1959,1980)$ theory of ego-integrity, Baltes and Baltes (1990, Baltes et al., 1998) argued in the selective optimization with compensation (SOC) model that the process of continued growth despite age-related losses is also essential to the likelihood of successful aging. This concept of intentional and active engagement in growth opportunities implies that PGI predicts mental health in old age (Hardin et al., 2007; Robitschek, 1998, 1999; 2003; Robitschek \& Kashubeck, 1999; Robitschek \& Keyes, 2006) as well as predicts the likelihood of ego-integrity since experiencing features of ego-integrity indicates the presence of mental health in the emotional, psychological, and social domains (Boylin, Gordon, \& Nehrke, 1976; Hogstel \& Curry, 1995; James \& Zarrett, 2005; Ranzijn \& Luszcz, 1999; Rylands \& Rickwood, 2001; Santor \& Zuroff, 1994; Torges, Stewart, \& Miner-Rubino, 2005). From this rationale, ego-integrity may also serve as a mediating variable between PGI and mental health. For example, if older adults do not continue to take the initiative in developing, growing, and changing as a person generally or in a specific domain that they find important (i.e., if older adults have a low level of PGI), then they are more likely to find life less meaningful, more likely to have a negative view of themselves because they are not striving to grow and change as a person, and more likely to look at life with regrets, disappointment, and guilt as they continue to age; in other words, they would have a low level of ego-integrity. Having these negative views 
of the past, present, and future and of the self and others (i.e., having a low level of ego integrity), in turn, would decrease their levels of emotional, psychological, and social well-being as well as make them more susceptible to live a languishing life (i.e., to have a low level of mental health). On the other hand, if older adults continue to actively and intentionally engage in growing and developing as a person despite physiological and mental limitations (i.e., continue to have a high level of PGI), then they are more likely find life satisfying and having meaning, more likely to have positive view of themselves because they see themselves improving and thriving, and more likely to look at life with contentment, appreciation, and satisfaction as they age; in other words, they are more likely to have a high level of ego-integrity. Having high level of ego-integrity, in turn, would increase their levels of emotional, psychological, and social well-being in addition to making them more likely to live a flourishing life (i.e., to have a high level of mental health).

The current study also attempted to replicate the following previous findings: that PGI negatively predicts self-discrepancy (Hardin et al., 2007), that physical health status negatively predicts self-discrepancy (Heidrich \& Powwattana, 2004; Heidrich \& Ward, 1992), and that age negatively predicts physical health status (Birren \& Renner, 1980; Federal Interagency Forum on Aging-Related Statistics, 2006; Frazer, Leicht, \& Baker, 1996; Heidrich \& D’Amico, 1993; Saxena, van Ommeren, Tang, \& Armstrong, 2005; Vandervoort \& Skorikov, 2002).

Importance of the Present Study

Consistent with the premises of the life-span perspective, if getting ones' inner life in order (i.e., having high levels of ego-integrity) through having an integrated sense 
of self (i.e., having low levels of self-discrepancy) and the continued engagement in growth opportunities (i.e., having high levels of PGI) are crucial to successful aging, then possessing these core features of ego-integrity ensures that older adults are more likely to live a flourishing life marked by the presence of a high level of mental health as characterized by having positive feelings and psychosocial functioning. This contention provides the rationale that ego-integrity may serve as a mediator that explains how and why a relationship exists between PGI and mental health and between self-discrepancy and mental health. Since previous empirical findings found that self-discrepancy is influenced by the level of PGI and physical health status (Hardin et al., 2007; Heidrich \& Powwattana, 2004; Heidrich \& Ward, 1992), and physical health status is influenced by age (Birren \& Renner, 1980; Federal Interagency Forum on Aging-Related Statistics, 2006; Frazer, Leicht, \& Baker, 1996; Heidrich, D’Amico, 1993; Saxena, van Ommeren, Tang, \& Armstrong, 2005; Vandervoort \& Skorikov, 2002), the current study also sought to replicate these findings. The overarching goal of the study was understanding how these complex relations among the predictors and mechanisms of age, physical health status, PGI, self-discrepancy, and ego-integrity influence the state of flourishing or languishing in late life from Erikson's $(1959,1980)$ theory of ego-integrity versus despair and Baltes and Baltes's (1990; Baltes et al., 1998) Selective, Optimization, and Selection (SOC) model in structural equation modeling (SEM). Such understanding of how these relations exist might provide mental health professionals with knowledge that may facilitate the promotion of successful and optimal aging in the geriatric population. 


\section{APPENDIX B}

Participant Recruitment Flyer

Are you a senior who is at least 65 years of age?

- If so, please consider participating in a TTU aging research study to help advance the understanding of healthy aging and the needs in older adults' lives.

- The survey takes between 15-30 minutes to complete and it is confidential.

- Participants get to win \$30 giftcard, a dinnercertificate, or memory workbooks.

- If you are interested, pleasepick up a survey from

-_fillin name of person in charge.

- If you have any questions, please contact chloe Hoang at 806-747-0606.

This study is being conducted by Mrs. chloe Hoang. and Dr. Erin Hardin in the Department. of Psychology at Texas Tech university. 


\section{APPENDIX C}

Prize Drawing Form

\section{Prize Diparying ITrim}

Name:

Phone Number:

Best time to call:

Can we leave you a message: $\square$ Yes $\square$ No

Email Address:

Preferred Method of Contact: $\square$ Phone $\quad \square$ Email

Please rank the prizes you would like to win

$$
(1=\text { want most to } 3=\text { want least }) \text { : }
$$

$\$ 30$ gift card a dinner certificate memory workbooks 


\section{APPENDIX D}

Demographic Questionnaire

\section{Please answer the following questions:}

1. Age:

2. Gender: __Female Male

3. Race/Ethnicity (select one): African American / Black Asian / Asian American / Pacific Islander Latino / Latina / Hispanic Native American / American Indian White / Caucasian / European American Biracial or Multicultural (please specify):

Other (please specify)

4. Highest level of education completed (select one):

Less than high school

High school diploma or equivalent

Some college

Associate's degree

Bachelor's degree (B.A., B.S.)

Some graduate school

Master's degree (M.A., M.S., MBA)

Doctoral degree (Ph.D., M.D., J.D.)

5. Relationship Status (select one):

Single

Separated

Divorced

Widow/Widower

Married or Partnered

Living with significant other, not married

Have a significant other, not living together

_ Other, please specify

6. How would you identify your socio-economic status (select one):

Working class

Lower middle class

Middle class

Upper middle class

Upper class 
7. Have you ever been prescribed or are you currently taking any of the following medications: Aricept, Clioquinoline, Cognex, Exelon, Namenda, Razadyne, or Reminyl? Y Yes _ No

8. Please list all the civic, church, and community organizations that are you involve in currently:

9. Living arrangements (check all that apply):

Alone

With spouse / partner

With children

With grandchildren

With other family members

With friends

In assisted living

Other, please specify

10. Current employment status (check as many as apply):

Working part-time

Working full-time

Homemaker/caregiver for other people

Volunteering (\# of hours per month)

Student

Retired

Other:

11. What is your religious affiliation?

Atheist

Agnostic

Jewish

Muslim

Hindu

Buddhist

Spiritual, not religious

Christian (please circle): Catholic Protestant

Other (specify):

Other Christian (please specify):

None

12. Where would you rate yourself in terms of how religious/spiritual you are?

$\begin{array}{llllll}\text { Very religious/spiritual.....1 } & \mathbf{2} & \mathbf{3} & \mathbf{4} & \mathbf{5} \ldots \ldots \text {... Not at all religious/spiritual }\end{array}$ 


\section{APPENDIX E}

Physical Health Status

1. In general, would you say your physical health is:

_ Poor _ Fair _ Good__ Very Good__ Excellent

2. In general, compared with other people your age, would you say that your physical health is:
Poo
Fair
Good
Very Good
Excellent

3. Has a doctor ever told you that you had (please check all that apply):

_ Hypertension or high blood pressure Angina pectoris or coronary artery disease

Congestive heart failure

A myocardial infarction or heart attack

Other heart conditions, such as problems with heart valves or the rhythm of your heartbeat

A stroke

Emphysema, or asthma, or COPD (chronic obstructive pulmonary disease)

Crohn's disease, ulcerative colitis, or inflammatory bowel disease

Arthritis of the hip or knee

Arthritis of the hand or wrist

Osteoporosis, sometimes called thin or brittle bones

Sciatica (pain or numbness that travels down your leg to below your knee)

Diabetes, high blood sugar, or sugar in the urine

Any cancer (other than skin cancer) 


\section{APPENDIX F}

Functional Limitation

Activities of Daily Living Index (ADL; Katz, 1983) \&

Instrumental Activities of Daily Living Index (IADL; Lawton \& Brody, 1969)

1. Please check the box that most applies for each activity:

\begin{tabular}{|l|l|l|l|}
\cline { 2 - 4 } \multicolumn{1}{l|}{} & \multicolumn{1}{c|}{$\begin{array}{c}\text { Need } \\
\text { No Help }\end{array}$} & $\begin{array}{c}\text { Need } \\
\text { Some Help }\end{array}$ & $\begin{array}{c}\text { Unable to } \\
\text { Do At All }\end{array}$ \\
\hline a. Bathing & & & \\
\hline b. Dressing & & & \\
\hline c. Eating & & & \\
\hline d. Getting in/out of bed/chairs & & & \\
\hline e. Walking & & & \\
\hline f. Using the toilet & & & \\
\hline g. Using the telephone & & & \\
\hline h. Getting to places beyond walking distance & & & \\
\hline i. Shopping for food/clothes & & & \\
\hline j. Preparing meals & & & \\
\hline k. Doing housework or handyman work & & & \\
\hline 1. Doing laundry & & & \\
\hline m. Taking medications & & & \\
\hline n. Managing money & & & \\
\hline
\end{tabular}




\section{APPENDIX G}

Personal Growth Initiative Scale

(PGIS; Robitschek, 1998, 1999)

Using the scale below, circle the number which best describes the extent to which you agree or disagree with each statement.

\begin{tabular}{|c|c|c|c|c|c|c|}
\hline & \multicolumn{3}{|c|}{ DISAGREE } & \multicolumn{3}{|c|}{ AGREE } \\
\hline & $\begin{array}{l}\stackrel{Q}{0} \\
\stackrel{\vec{B}}{E} \\
\stackrel{\overrightarrow{0}}{\varangle}\end{array}$ & 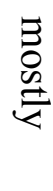 & 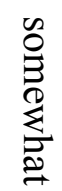 & 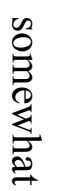 & 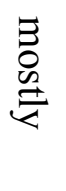 & 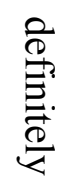 \\
\hline $\begin{array}{l}\text { 1. I know how to change specific things that I want to } \\
\text { change in my life. }\end{array}$ & 0 & 1 & 2 & 3 & 4 & 5 \\
\hline 2. I have a good sense of where I am headed in life. & 0 & 1 & 2 & 3 & 4 & 5 \\
\hline $\begin{array}{l}\text { 3. If I want to change something in my life, I initiate } \\
\text { the transition process. }\end{array}$ & 0 & 1 & 2 & 3 & 4 & 5 \\
\hline 4. I can choose the role that I want to have in a group. & 0 & 1 & 2 & 3 & 4 & 5 \\
\hline $\begin{array}{l}\text { 5. I know what I need to do to get started toward } \\
\text { reaching my goals. }\end{array}$ & 0 & 1 & 2 & 3 & 4 & 5 \\
\hline $\begin{array}{l}\text { 6. I have a specific action plan to help me reach my } \\
\text { goals. }\end{array}$ & 0 & 1 & 2 & 3 & 4 & 5 \\
\hline 7. I take charge of my life. & 0 & 1 & 2 & 3 & 4 & 5 \\
\hline $\begin{array}{l}\text { 8. I know what my unique contribution to the world } \\
\text { might be. }\end{array}$ & 0 & 1 & 2 & 3 & 4 & 5 \\
\hline 9. I have a plan for making my life more balanced. & 0 & 1 & 2 & 3 & 4 & 5 \\
\hline
\end{tabular}




\section{APPENDIX H}

Self-Discrepancy Scale

Based on the Marker Placement Task

(MPT; Heppen \& Ogilvie, 2003)

Instructions: On the back of this page is a circle that represents your Ideal self. The "Ideal" self is your beliefs concerning the attributes or characteristics you would ideally like to possess; the type of person you wish, desire or hope to be. On this page is a sticker that represents your Actual self. The "Actual" self is your beliefs concerning the attributes or characteristics you think you actually possess.

Using the sticker on this page, please place it anywhere on the back of the page that best represents the distance between your actual self and your ideal self. That is, how far or close are you from being the person you ideally like to be, the type of person you wish, desire, or hope to be?<smiles>C1CCCCC1</smiles> 
Texas Tech University, Chloe Uyen Hoang, August, 2008

Ideal 


\section{APPENDIX I}

Self-Discrepancy Scale

(SDS; Heidrich, 1999)

Please circle how much you agree or disagree with the following statements. If the statement is not applicable to you (for example, you do not have a spouse), circle zero.

\section{MY ACTUAL SELF AND MY IDEAL SELF ARE A VERY CLOSE MATCH WHEN I} THINK ABOUT:

\begin{tabular}{|c|c|c|c|c|c|c|c|}
\hline & & \multicolumn{3}{|c|}{ DISAGREE } & \multicolumn{3}{|c|}{ AGREE } \\
\hline & N/A & 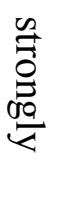 & 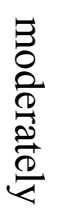 & 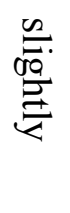 & $\frac{n}{\square}$ & 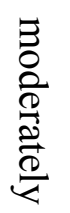 & 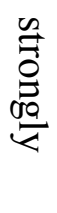 \\
\hline 1. how satisfied I am with my life & 0 & 1 & 2 & 3 & 4 & 5 & 6 \\
\hline 2. my physical health & 0 & 1 & 2 & 3 & 4 & 5 & 6 \\
\hline 3. how I solve problems of daily living & 0 & 1 & 2 & 3 & 4 & 5 & 6 \\
\hline 4. being able to socialize with friends & 0 & 1 & 2 & 3 & 4 & 5 & 6 \\
\hline 5. my relationship with my spouse or partner & 0 & 1 & 2 & 3 & 4 & 5 & 6 \\
\hline 6. how I am coping with growing older & 0 & 1 & 2 & 3 & 4 & 5 & 6 \\
\hline 7. my ability to learn new things & 0 & 1 & 2 & 3 & 4 & 5 & 6 \\
\hline 8. accepting life as it comes & 0 & 1 & 2 & 3 & 4 & 5 & 6 \\
\hline 9. dealing with my emotions and feelings & 0 & 1 & 2 & 3 & 4 & 5 & 6 \\
\hline 10. being as physically active as I want & 0 & 1 & 2 & 3 & 4 & 5 & 6 \\
\hline 11. coping with change in my life & 0 & 1 & 2 & 3 & 4 & 5 & 6 \\
\hline 12. pursuing my leisure interests and hobbies & 0 & 1 & 2 & 3 & 4 & 5 & 6 \\
\hline 13. my physical appearance & 0 & 1 & 2 & 3 & 4 & 5 & 6 \\
\hline $\begin{array}{l}\text { 14. taking care of home and household } \\
\text { responsibilities }\end{array}$ & 0 & 1 & 2 & 3 & 4 & 5 & 6 \\
\hline 15. myself as a parent & 0 & 1 & 2 & 3 & 4 & 5 & 6 \\
\hline 16. taking care of health & 0 & 1 & 2 & 3 & 4 & 5 & 6 \\
\hline 17. fulfilling job or career responsibilities & 0 & 1 & 2 & 3 & 4 & 5 & 6 \\
\hline 18. relationships with other family members & 0 & 1 & 2 & 3 & 4 & 5 & 6 \\
\hline 19. my relationship with others & 0 & 1 & 2 & 3 & 4 & 5 & 6 \\
\hline $\begin{array}{l}\text { 20. my involvement in community and/or } \\
\text { religious activities }\end{array}$ & 0 & 1 & 2 & 3 & 4 & 5 & 6 \\
\hline
\end{tabular}




\section{APPENDIX J}

Ego-Integrity Scale

(Ryff \& Heincke, 1983)

\begin{tabular}{|c|c|c|c|c|c|c|}
\hline \multirow[b]{2}{*}{$\begin{array}{l}\text { Below are items which are used by people to describe } \\
\text { themselves. Please circle the number that best describe } \\
\text { you. }\end{array}$} & \multicolumn{3}{|c|}{ DISAGREE } & \multicolumn{3}{|c|}{ AGREE } \\
\hline & 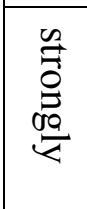 & 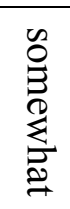 & 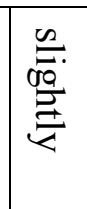 & 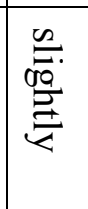 & 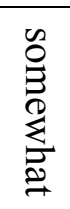 & 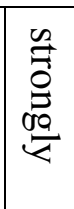 \\
\hline $\begin{array}{l}\text { 1. If I had to do it all over again, there are very few } \\
\text { things about my life that I would change. }\end{array}$ & 1 & 2 & 3 & 4 & 5 & 6 \\
\hline $\begin{array}{l}\text { 2. I feel generally contended with what I have } \\
\text { accomplished in my life. }\end{array}$ & 1 & 2 & 3 & 4 & 5 & 6 \\
\hline $\begin{array}{l}\text { 3. I wish my life were just beginning so I could avoid } \\
\text { many of the mistakes I made earlier in my life. }\end{array}$ & 1 & 2 & 3 & 4 & 5 & 6 \\
\hline $\begin{array}{l}\text { 4. In general I would say I have few regrets about my } \\
\text { past life. }\end{array}$ & 1 & 2 & 3 & 4 & 5 & 6 \\
\hline $\begin{array}{l}\text { 5. All in all, I am comfortable with the choices I made } \\
\text { regarding my life's work. }\end{array}$ & 1 & 2 & 3 & 4 & 5 & 6 \\
\hline $\begin{array}{l}\text { 6. I still feel angry about certain of my childhood } \\
\text { experiences. }\end{array}$ & 1 & 2 & 3 & 4 & 5 & 6 \\
\hline $\begin{array}{l}\text { 7. If I had had just a couple more lucky breaks, my life } \\
\text { would have turned out much differently. }\end{array}$ & 1 & 2 & 3 & 4 & 5 & 6 \\
\hline $\begin{array}{l}\text { 8. My life has been fulfilling, and I am not frightened } \\
\text { by the thought of death. }\end{array}$ & 1 & 2 & 3 & 4 & 5 & 6 \\
\hline $\begin{array}{l}\text { 9. If I could turn back the clock, there are many things I } \\
\text { would do differently. }\end{array}$ & 1 & 2 & 3 & 4 & 5 & 6 \\
\hline $\begin{array}{l}\text { 10. It doesn't bother me to think about goals I haven't } \\
\text { reached and probably never will. }\end{array}$ & 1 & 2 & 3 & 4 & 5 & 6 \\
\hline $\begin{array}{l}\text { 11. Reading old diaries and letters usually brings more } \\
\text { pain than pleasure. }\end{array}$ & 1 & 2 & 3 & 4 & 5 & 6 \\
\hline $\begin{array}{l}\text { 12. One of my greatest disappointments is that I have } \\
\text { not been able to do more traveling. }\end{array}$ & 1 & 2 & 3 & 4 & 5 & 6 \\
\hline $\begin{array}{l}\text { 13. I often wish I had been born during a different } \\
\text { period of history. }\end{array}$ & 1 & 2 & 3 & 4 & 5 & 6 \\
\hline $\begin{array}{l}\text { 14. There are many people whose life I would prefer to } \\
\text { my own. }\end{array}$ & 1 & 2 & 3 & 4 & 5 & 6 \\
\hline
\end{tabular}




\begin{tabular}{|c|c|c|c|c|c|c|}
\hline & \multicolumn{3}{|c|}{ DISAGREE } & \multicolumn{3}{|c|}{ AGREE } \\
\hline & 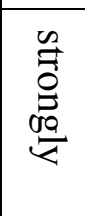 & 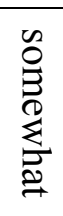 & 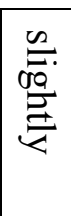 & 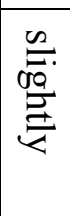 & 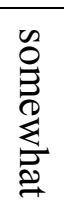 & 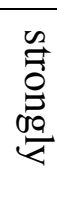 \\
\hline $\begin{array}{l}\text { 15. When I consider the ups and downs of my past life, } \\
\text { they somehow fit together in a meaningful way. }\end{array}$ & 1 & 2 & 3 & 4 & 5 & 6 \\
\hline $\begin{array}{l}\text { 16. There are some disappointments in life I will never } \\
\text { be able to accept. }\end{array}$ & 1 & 2 & 3 & 4 & 5 & 6 \\
\hline
\end{tabular}




\section{APPENDIX K}

Scales of Emotional Well-Being Cantril's (1965) Life Satisfaction and Happiness Scale, Bradburn's (1969) Symptoms of Positive Negative Affect

1. Overall these days, how satisfied are you with your life.
0
2
3
$4 \quad 5$
6
7
8
9
10
Terrible
Delighted

2. Overall these days, how happy are you with your life.

$\begin{array}{ccccccccccc}0 & 1 & 2 & 3 & 4 & 5 & 6 & 7 & 8 & 9 & 10 \\ \begin{array}{c}\text { Worst } \\ \text { possible }\end{array} & & & & & & & & & & \begin{array}{c}\text { Best } \\ \text { possible } \\ \text { situation }\end{array} \\ & & & & & & & & & & \\ \text { situation }\end{array}$

Please indicate how much of the time during the past 30 days have you felt the following symptoms:

\begin{tabular}{|lcc|c|c|c|}
\cline { 2 - 6 } \multicolumn{1}{c|}{} & $\begin{array}{c}\text { None } \\
\text { of the } \\
\text { time }\end{array}$ & $\begin{array}{c}\text { A Little } \\
\text { of the } \\
\text { time }\end{array}$ & $\begin{array}{c}\text { Some } \\
\text { of the } \\
\text { time }\end{array}$ & $\begin{array}{c}\text { Most } \\
\text { the } \\
\text { time }\end{array}$ & $\begin{array}{c}\text { All } \\
\text { the } \\
\text { time }\end{array}$ \\
\hline 1. So sad nothing could cheer you up & 0 & 1 & 2 & 3 & 4 \\
\hline 2. Nervous & 0 & 1 & 2 & 3 & 4 \\
\hline 3. Restless or fidgety & 0 & 1 & 2 & 3 & 4 \\
\hline 4. Hopeless & 0 & 1 & 2 & 3 & 4 \\
\hline 5. That everything was an effort & 0 & 1 & 2 & 3 & 4 \\
\hline 6. Worthless & 0 & 1 & 2 & 3 & 4 \\
\hline 7. Cheerful & 0 & 1 & 2 & 3 & 4 \\
\hline 8. In good spirits & 0 & 1 & 2 & 3 & 4 \\
\hline 9. Extremely happy & 0 & 1 & 2 & 3 & 4 \\
\hline 10. Calm and peaceful & 0 & 1 & 2 & 3 & 4 \\
\hline 11. Satisfied & 0 & 1 & 2 & 3 & 4 \\
\hline 12. Full of life & 0 & 1 & 2 & 3 & 4 \\
\hline
\end{tabular}




\section{APPENDIX L}

Scale of Psychological Well-Being

(SPWB; Ryff, 1989)

The following set of questions deals with how you feel about yourself and your life. Please remember that there are no right or wrong answers.

\begin{tabular}{|c|c|c|c|c|c|}
\hline \multicolumn{3}{|c|}{ DISAGREE } & \multicolumn{3}{|c|}{ AGREE } \\
\hline 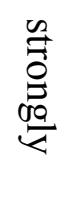 & 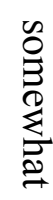 & 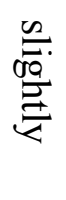 & 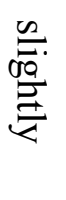 & 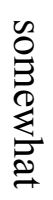 & 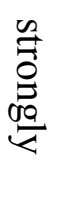 \\
\hline 1 & 2 & 3 & 4 & 5 & 6 \\
\hline 1 & 2 & 3 & 4 & 5 & 6 \\
\hline 1 & 2 & 3 & 4 & 5 & 6 \\
\hline 1 & 2 & 3 & 4 & 5 & 6 \\
\hline 1 & 2 & 3 & 4 & 5 & 6 \\
\hline 1 & 2 & 3 & 4 & 5 & 6 \\
\hline 1 & 2 & 3 & 4 & 5 & 6 \\
\hline 1 & 2 & 3 & 4 & 5 & 6 \\
\hline 1 & 2 & 3 & 4 & 5 & 6 \\
\hline 1 & 2 & 3 & 4 & 5 & 6 \\
\hline 1 & 2 & 3 & 4 & 5 & 6 \\
\hline 1 & 2 & 3 & 4 & 5 & 6 \\
\hline 1 & 2 & 3 & 4 & 5 & 6 \\
\hline 1 & 2 & 3 & 4 & 5 & 6 \\
\hline 1 & 2 & 3 & 4 & 5 & 6 \\
\hline 1 & 2 & 3 & 4 & 5 & 6 \\
\hline
\end{tabular}




\begin{tabular}{|c|c|c|c|c|c|c|}
\hline & \multicolumn{3}{|c|}{ DISAGREE } & \multicolumn{3}{|c|}{ AGREE } \\
\hline & 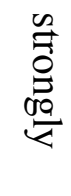 & 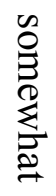 & 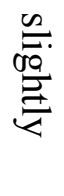 & 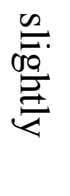 & 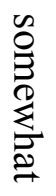 & 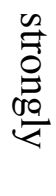 \\
\hline $\begin{array}{l}\text { 17. I gave up trying to make big improvements or } \\
\text { changes in my life a long time ago. }\end{array}$ & 1 & 2 & 3 & 4 & 5 & 6 \\
\hline $\begin{array}{l}\text { 19. I judge myself by what I think is important, not by } \\
\text { the values of what others think is important. }\end{array}$ & 1 & 2 & 3 & 4 & 5 & 6 \\
\hline
\end{tabular}




\section{APPENDIX M}

Scale of Social Well-Being

(SSWB; Keyes, 1998)

Circle the number that best describes your present agreement or disagreement with each statement.

\begin{tabular}{|c|c|c|c|c|c|c|}
\hline & \multicolumn{3}{|c|}{ DISAGREE } & \multicolumn{3}{|c|}{ AGREE } \\
\hline & 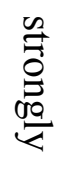 & 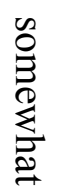 & 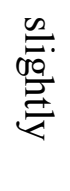 & 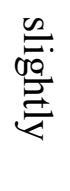 & 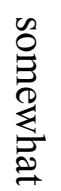 & 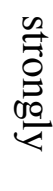 \\
\hline 1. The world is too complex for me. & 1 & 2 & 3 & 4 & 5 & 6 \\
\hline $\begin{array}{l}\text { 2. I don't feel I belong to anything I'd call a } \\
\text { community. }\end{array}$ & 1 & 2 & 3 & 4 & 5 & 6 \\
\hline 3. People who do a favor expect nothing in return. & 1 & 2 & 3 & 4 & 5 & 6 \\
\hline $\begin{array}{l}\text { 4. I have something valuable to give to give the } \\
\text { world. }\end{array}$ & 1 & 2 & 3 & 4 & 5 & 6 \\
\hline $\begin{array}{l}\text { 5. The world is becoming a better place for } \\
\text { everyone. }\end{array}$ & 1 & 2 & 3 & 4 & 5 & 6 \\
\hline 6. I feel close to other people in my community. & 1 & 2 & 3 & 4 & 5 & 6 \\
\hline $\begin{array}{l}\text { 7. My daily activities do not produce anything } \\
\text { worthwhile for my community. }\end{array}$ & 1 & 2 & 3 & 4 & 5 & 6 \\
\hline $\begin{array}{l}\text { 8. I cannot make sense of what's going on in the } \\
\text { world. }\end{array}$ & 1 & 2 & 3 & 4 & 5 & 6 \\
\hline 9. Society has stopped making progress. & 1 & 2 & 3 & 4 & 5 & 6 \\
\hline $\begin{array}{l}\text { 10. People do not care about other people's } \\
\text { problems. }\end{array}$ & 1 & 2 & 3 & 4 & 5 & 6 \\
\hline 11. My community is a source of comfort. & 1 & 2 & 3 & 4 & 5 & 6 \\
\hline $\begin{array}{l}\text { 12. I find it easy to predict what will happen next in } \\
\text { society. }\end{array}$ & 1 & 2 & 3 & 4 & 5 & 6 \\
\hline 13. Society isn't improving for people like me. & 1 & 2 & 3 & 4 & 5 & 6 \\
\hline 14. I believe that people are kind. & 1 & 2 & 3 & 4 & 5 & 6 \\
\hline $\begin{array}{l}\text { 15. I have nothing important to contribute to } \\
\text { society. }\end{array}$ & 1 & 2 & 3 & 4 & 5 & 6 \\
\hline
\end{tabular}




\title{
APPENDIX N
}

\author{
Information Form
}

\begin{abstract}
Study Title: Promoting Mental Health in Older Adults
Principal Investigators: Chloe Uyen Hoang, M.A., \& Erin Hardin, Ph.D. Department of Psychology / Texas Tech University

Contact Telephone Number: (806) 747-0606 or (806) 742-3711 x250
\end{abstract}

Purpose of the Research Study: This study asks about the different thoughts and Feelings you have about yourself and your behaviors and perceptions of health in several areas. Your participation will help us gain a better understanding of the needs of older adults.

Requirements of the Study: You must be at least 65 years of age to participate in this study and you can only do this survey one time. You will be asked to fill out several

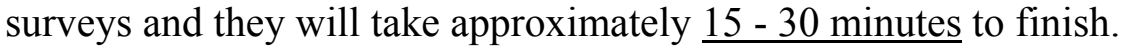

Doing the survey is completely up to you. No one can force you. You can quit at anytime you want and you won't lose anything. Although it is good for us if you answer every question, you may skip any questions that you do not feel comfortable answering.

We do not think there will be any harm to you from answering these questions. After you have completed filling out the survey, you will have the option to participate in the drawing for a chance to win one of several prizes, ranging from a $\$ 30$ gift card, a dinner gift certificate to a local restaurant, and various memory training workbooks by different authors. Winners will be drawn after all data have been collected for the study. If you win, we will contact you using information you have given us on the drawing ticket. You do not need to be present to win.

Confidentiality Issues: All of the information we collect will be kept behind a locked door at Texas Tech University, separate from your contact information. Therefore, your name will not be associated with your responses. Only Ms. Hoang, Dr. Hardin, and their assistants will see your answers and your answers will be stored in a computer database without your name. After we are done collecting information, we may make a public presentation and/or a publication. Only group information, not individual information, will be presented. No one from your family, work, or circle of friends will ever know what your answers were. Further, your contact information will not be sold or distributed in any other way.

Questions: Dr. Hardin or Ms. Hoang will answer any questions you have about the study. For questions about your rights as a subject or about injuries caused by this research, contact the Texas Tech University Institutional Review Board for the Protection of Human Subjects, Office of Research Services, Texas Tech University, Lubbock, Texas 79409. Or you can call (806) 742-3884. 


\section{APPENDIX O}

Contact Information Form

Name:

Phone Number:

Best time to call:

Can we leave you a message: $\square$ Yes $\square$ No

Email Address:

Preferred Method of Contact: $\square$ Phone $\square$ Email 


\section{APPENDIX P \\ Debriefing Letter}

\section{Research Title: Promoting Mental Health in Older Adults}

The questionnaires you have completed were designed to determine the possible roles of how you view yourself and how you grow and develop as a person influence the extent to which you accept your past, yourself, and others. The study also examines the level of your acceptance of the past, and feeling content with your current life and not worrying about the unknowable future would contribute to achieving mental health, which is beneficial to successful aging. Several studies in the past have answered each of these questions individually, but they have not looked at all these possible links together. Your participation was crucial in helping us gain a better understanding of your needs relating to aging issues.

We thank you for taking your time to complete the questionnaires. After all data for the study have been collected, Ms. Hoang will contact the winner using the phone number or email address you have provided on the drawing ticket. You do not need to be present to win. Please feel free to contact us, Ms. Hoang at (806) 747-0606 or uyen.hoang@tttu.edu, or Dr. Hardin at 742-3711 x250 or erin.hardin@ttu.edu, with any questions. Also, if you are interested in the results of the study, please let Ms. Hoang know and she will send you the information as soon as the data are analyzed. Thank you again! 